\title{
ATTITUDES AND BELIEFS ABOUT CORPORAL PUNISHMENT AMONG INNER CITY HOMELESS PARENTS: A QUALITATIVE NARRATIVE STUDY
}

\author{
A Dissertation \\ presented to \\ the Faculty of the Graduate School \\ at the University of Missouri-Columbia \\ In Partial Fulfillment \\ of the Requirements for the Degree \\ Doctor of Philosophy \\ by \\ ELLEN MARIE CHIOCCA
}

Dr. Tina L. Bloom, Dissertation Supervisor

DECEMBER 2018 
(C) Copyright by Ellen M. Chiocca 2018

All Rights Reserved 
The undersigned, appointed by the dean of the Graduate School, have examined the dissertation entitled

\section{ATTITUDES AND BELIEFS ABOUT CORPORAL PUNISHMENT AMONG INNER} CITY HOMELESS PARENTS: A QUALITATIVE NARRATIVE STUDY

presented by Ellen M. Chiocca,

a candidate for the degree of Doctor of Philosophy,

and hereby certify that, in their opinion, it is worthy of acceptance.

Professor Tina L. Bloom

Professor Lawrence Ganong

Professor Patricia J Kelly

Professor Linda F. C. Bullock 
COMMITTEE MEMBERS

Committee Chair: Tina L. Bloom, PhD, MPH, RN

Associate Professor of Nursing

Sinclair School of Nursing, University of Missouri

Committee Member: Lawrence Ganong, PhD

Professor of Nursing

Sinclair School of Nursing, University of Missouri

Committee Member: Linda F. C. Bullock, PhD, RN, FAAN

Professor of Nursing, Associate Dean of Research

University of Virginia

Committee Member: Patricia J Kelly, PhD, MPH, APRN 


\section{ACKNOWLEDGEMENTS}

I have several people to thank after this long journey. I would first like to thank my husband, Ralph Zarumba, for his incredible patience, love and support throughout this entire process. I would also like to thank my wonderful daughter, Isabella Chiocca for her love and understanding as well.

Many, many thanks to my patient, brilliant advisor, Dr. Tina Bloom who gives great advice, and without whom I would not be at the finish line. Thank you for all your time and hard work in helping me get to this point.

Thank you to my committee, Dr. Ganong and Dr. Bullock for your wisdom and indispensable feedback. An extra special thanks to Dr. Pat Kelly. It was your N5697B course that planted the seed for this research project.

An extra special, heartfelt thanks to Dr. Wipke-Tevis and the doctoral admissions committee for their faith in me.

To the faculty in the Sinclair School of Nursing - thank you.

And a very special thank you to the participants of my study for their selflessness in sharing their personal stories with me. I am in awe of their bravery and resilience.

E a mio padre. Eri quello che diceva sempre che la scuola era importante e ci ha fatto lavorare tutti sodo. Mi hai mostrato con l'esempio che il duro lavoro e la perseveranza significano successo. 


\section{TABLE OF CONTENTS}

ACKNOWLEDGMENTS ............................................................................... ii

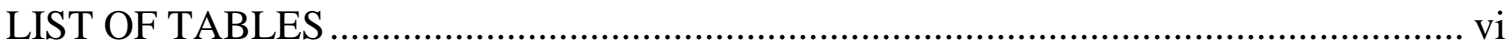

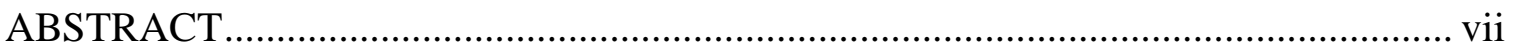

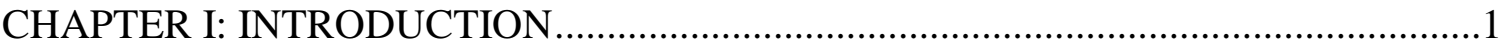

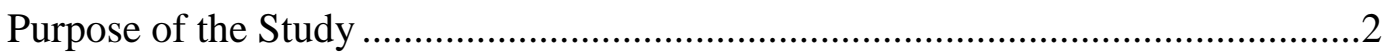

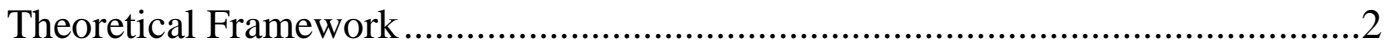

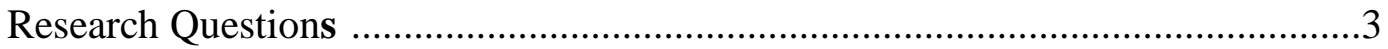

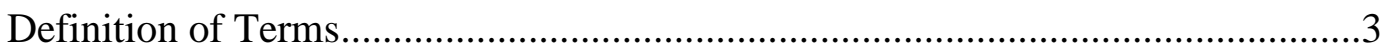

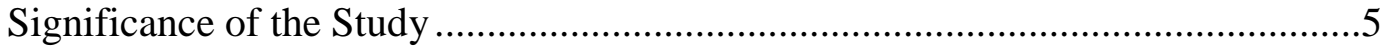

CHAPTER II: REVIEW OF THE LITERATURE ..............................................

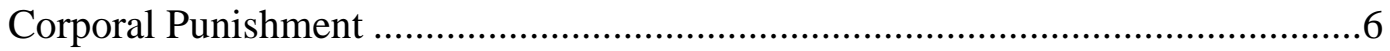

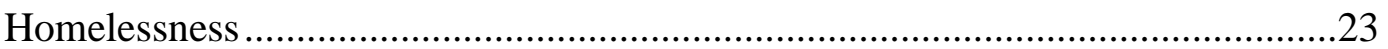

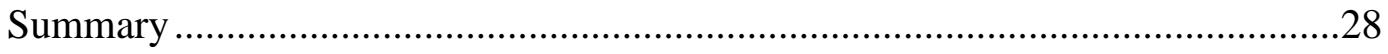

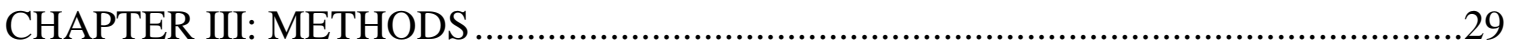

Study Objectives and Research Design Overview..........................................29

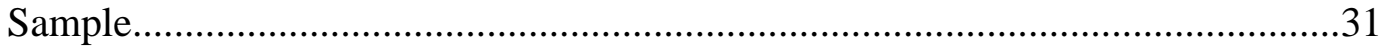

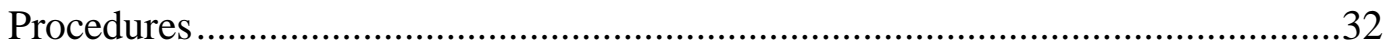

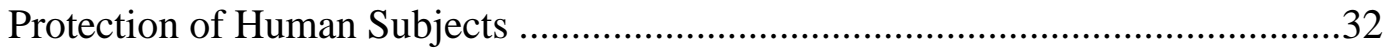

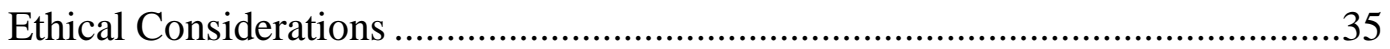

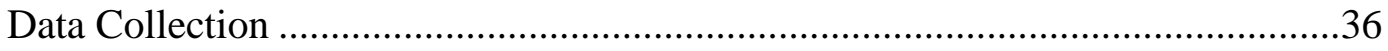




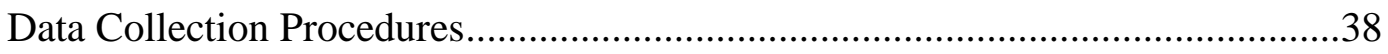

Data Analysis .........................................................................................4 40

Credibility and Trustworthiness.................................................................45

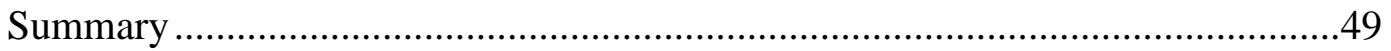

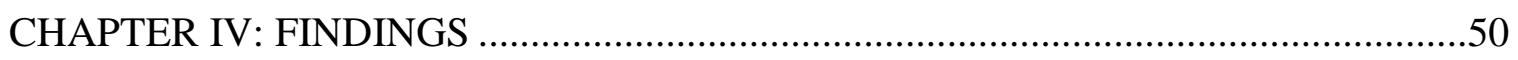

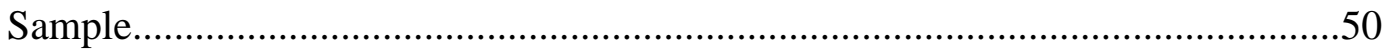

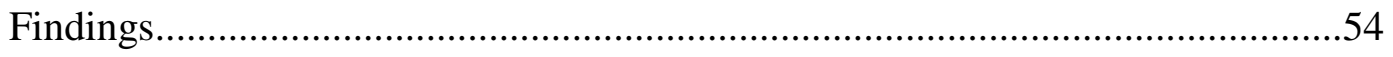

Attitudes and Beliefs about Corporal Punishment.............................................58

Participant Descriptions of Severe Childhood Physical Abuse ...........................59

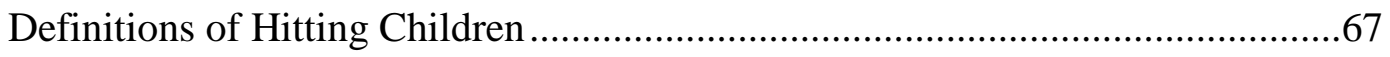

Influences on Participant Beliefs about Hitting Children ..................................81

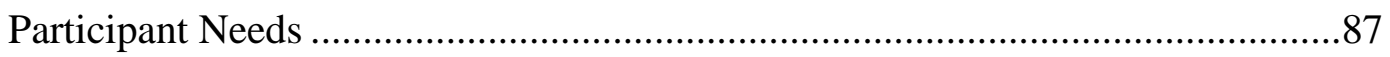

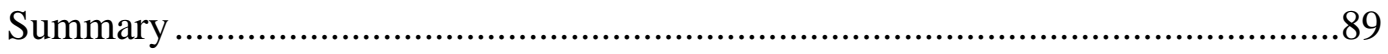

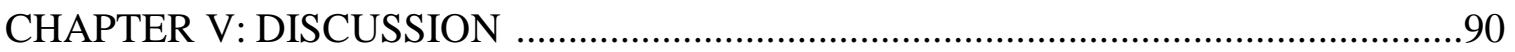

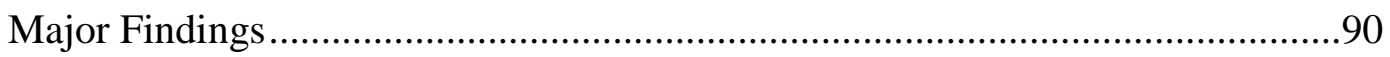

Theoretical Links: The Social-ecological Model of Prevention ..........................94

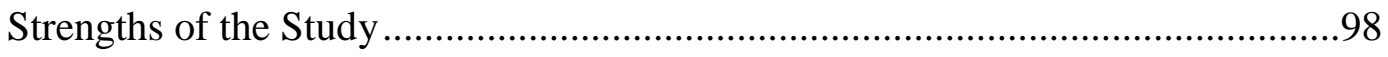

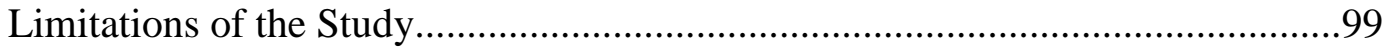

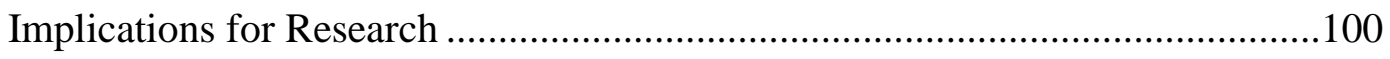

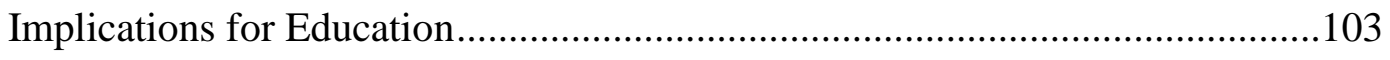

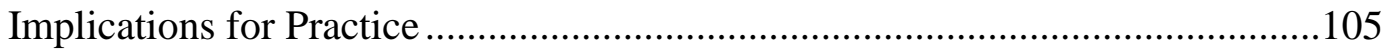

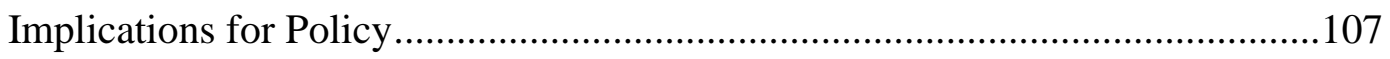

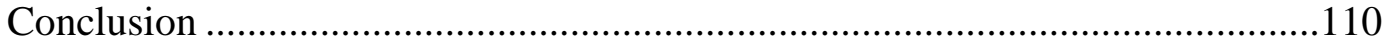


APPENDIX A: DEMOGRAPHIC QUESTIONNAIRE ........................................111

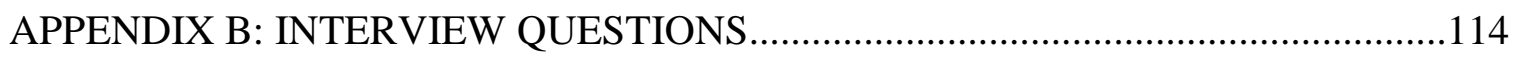

APPENDIX C: RECRUITMENT FLYER AND SCRIPT .......................................116

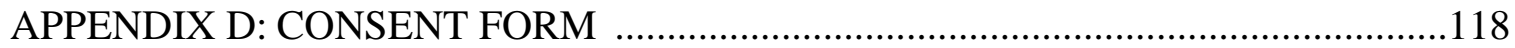

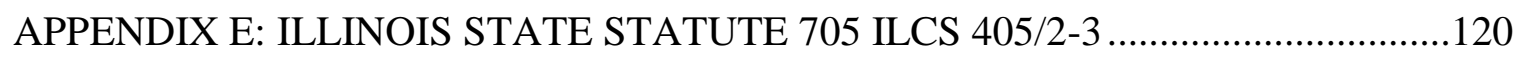

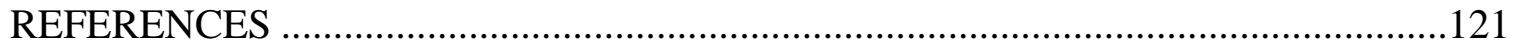

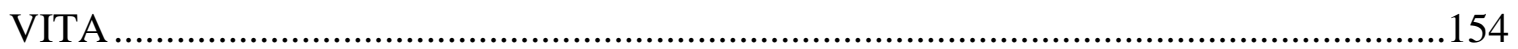




\section{LIST OF TABLES}

Table 4.1: Demographic Data ..................................................................53

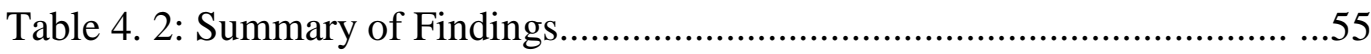




\begin{abstract}
Despite the large body of research on the harmful effects and ineffectiveness of corporal punishment $(\mathrm{CP})$, it is a common and socially acceptable method of child discipline in the United States. Parents are most likely to use CP when experiencing one or more stressors or lack social supports; one group of parents that suffers from multiple stressors and lacks social support is homeless parents. A qualitative, narrative study was conducted to explore the attitudes and beliefs of homeless parents regarding the use of $\mathrm{CP}$, their opinions about the No-Hit policy at the shelter where they live, and what types of help or support they believed the shelter could provide for them. Data were collected from 18 homeless parents ( $n=14$ mothers; $n=4$ fathers), age twenty to fifty-seven years, living in a shelter in a large Midwestern urban area. Results yielded five themes: (1) substantial participant experiences of childhood physical and emotional trauma; (2) clear conceptual definitions of and reasons for hitting children; (3) participant perspectives on interventions and policies related to corporal punishment; (4) strong family, community, religious and cultural influences on participant beliefs about hitting children; and (5) financial help from the shelter and help with housing is a main priority need expressed by participants. Findings present important implications for the development of more culturally sensitive and trauma-informed educational strategies, practices and policies for families and children impacted by poverty and violence.
\end{abstract}

Keywords: parental attitudes, corporal punishment, spanking, psychosocial risk factors, homelessness 


\section{CHAPTER I \\ INTRODUCTION}

Corporal punishment $(\mathrm{CP})$ is a common and socially acceptable method of child discipline in the United States. A nationally representative survey conducted in 2014 revealed that 76 percent of men and 65 percent of women, aged 18 to 65 years, agreed that a child sometimes needs a "good hard spanking" (Child Trends, 2015).

There is a significant amount of research on the harmful effects of CP (Afifi, Brownridge, Cox \& Sareen, 2006; Gershoff, 2013; Gershoff, 2010; Gershoff, 2002; Gershoff \& Grogan-Kaylor, 2016; Grogan-Kaylor, 2004), its inefficacy (Durrant \& Ensom, 2012; Gershoff, 2013; Gershoff \& Grogan-Kaylor, 2016), and potential lifelong negative socio-emotional consequences (Gershoff, 2002; Gershoff \& Grogan-Kaylor, 2016). In addition, $\mathrm{CP}$ is associated with increased risk for physical injury.

Parents are most likely to use $\mathrm{CP}$ when experiencing one or more stressors, or lack social supports (Kelch-Oliver \& Oyeshiku Smith, 2015; MacKenzie, Nicklas, Waldfogel \& Brooks-Gunn, 2012). One group of parents that suffers from multiple stressors and lacks social support is homeless parents (David, Gelberg \& Suchman, 2012). Parents' attitudes and beliefs about the use of CP have been studied, but none of the study participants has been homeless. Homeless parents face stressors that housed parents do not, which may lower a parent's threshold for anger. Further, many homeless parents have histories of trauma and abuse, post-traumatic stress disorder, live in high crime areas and thus may be at higher risk for witnessing or being the victim of community violence, which may also affect how they parent their child (Haber \& Toro, 2004). 
It is important to understand the attitudes and beliefs about the use of $\mathrm{CP}$ among this high-risk group of parents because of these stressors, and the numerous negative child outcomes associated with the use of CP. This study examined the attitudes and beliefs about the use of $\mathrm{CP}$ among a group of homeless parents, asked for their perspectives on a No-Hit policy in the shelter where they live, and finally, explored what types of support these parents most need.

\section{Purpose of the Study}

Using a qualitative narrative design, this dissertation research examined the attitudes and beliefs among a group homeless parents about the use of CP in general, and their opinions about the shelter's overall no violence policy in comparison to the No-Hit policy which applies to the hitting of both adults and children. Participants were also asked about what types of support and help from shelter staff they thought would be most helpful. Study findings will be used to provide data for interdisciplinary collaboration in developing relevant and culturally sensitive educational materials regarding effective child discipline that does not involve the use of $\mathrm{CP}$.

\section{Theoretical Framework}

The Social-ecological Model of Prevention (SEM), a human ecology framework, was used to frame this research study. This model uses four concepts to understand the complexity of interpersonal violence and ways it can be prevented (Centers for Disease Control and Prevention (CDC), 2018). These concepts include the individual, relationships, community, and society. The SEM of violence prevention demonstrates how the factors that precipitate and influence the hitting of children do not exist in isolation but are interrelated. Children and families exist as part of an ecological system. 
For example, parents' attitudes and beliefs (individual) about CP merge with what they learned from their family of origin (relationships), and social norms that are shaped by larger societal influences such as culture, religion (community), policy, and law (society). SEM is an ideal framework to allow the consideration of these inter-related factors, realizing that the parental decision to use $\mathrm{CP}$ does not occur in isolation.

\section{Research Questions}

Applying a socio-ecological perspective, the goal of this study was to generate a more complete understanding of homeless parents' beliefs about the use of CP as it relates to their own experiences with childhood violence, and their opinions regarding the No-Hit policy in the shelter where they live. The guiding research questions were: 1). What are participant attitudes and beliefs about $\mathrm{CP}$ in general? 2). What are participant attitudes and beliefs about the shelter's No-Hit policy which applies to all shelter residents, including children? 3). What types of support and help do homeless parents need from shelter staff?

\section{Definition of Terms}

Corporal punishment is "the use of physical force with the intention of causing the child to experience pain, but not injury, for the purpose of correction or control of the child's behavior" (Straus, 2001, p. 4).

Harsh corporal punishment is "a severe form of corporal punishment in which an object (e.g., belt, paddle and hair brush) [is] used on occasion for the purpose of disciplining a child, provided it [does] not extend beyond the buttocks, [is] not conducted out of anger, and [does] not result in injury" (Tomoda et al., 2009, p. 66). 
Flogging, also called whipping or caning, is a beating carried out with a whip or rod. The blows are mainly directed to the person's back. This type of physical discipline has been and is still used as a way to punish criminals, military personnel and children, both in homes at in schools (Caribbean Development Research Services, 2009).

Paddling is the term used to describe a child being hit on the bottom with a wooden board, often carried out by a teacher or school principal (Gershoff, 2010).

Pop (popping) corresponds to a light hit on the top of the hand, usually to convey to a young child that he/she is not supposed to touch something (Ipsa \& Halgunseth, 2004; LeCuyer, Christensen, Kearney, \& Kitzman, 2011; Taylor, Hamvas \& Paris, 2011). Viewed interchangeably with "tap" among African-American mothers (Ipsa \& Halgunseth, 2004).

Slap is "to strike sharply with or as if with the open hand" (Merriam-Webster, 2018).

Spank (spanking) involves hitting a child on the buttocks with an open hand (Gershoff, 2010).

Swat means "to hit with a sharp slapping blow usually with an instrument" (Merriam-Webster, 2018).

Tap (tapping) corresponds to a light hit on the top of the hand, usually to convey to a young child that he/she is not supposed to touch something (Ipsa \& Halgunseth, 2004; LeCuyer, Christensen, Kearney, \& Kitzman, 2011; Taylor, Hamvas \& Paris, 2011). Viewed interchangeably with "pop” among African-American mothers (Ipsa \& Halgunseth, 2004). 
Whip (whipping), Whup (whupping): indicates "striking a child more than once, usually on the buttocks, with an open hand, a brush, or a belt" (Ipsa \& Halgunseth, 2004, p. 471).

No Hit Zone describes "an environment in which no adult shall hit a child, no adult shall hit another adult, no child shall hit an adult, and no child shall hit another child” (Frazier, Liu \& Dauk, 2014). The No Hit Zone concept was originated in 2005 by Lolita McDavid, MD, professor of pediatrics at Rainbow Babies and Children's Hospital in Cleveland, Ohio (National Association of Children's Hospitals and Related Institutions (NACHRI), 2006).

\section{Significance of the Study}

The main significance of this study lies in the fact no studies exist that have explored what homeless parents in particular believe about the use of $\mathrm{CP}$, and how their childhood experiences with CP affect these beliefs. The qualitative methodology will result in rich data by exploring the participants' views more extensively through in-depth interviews. Knowledge and understanding of the factors affecting homeless parents' beliefs about the use of $\mathrm{CP}$, especially in the context of a No-Hit policy where they live, may also provide data to help design and test interventions to decrease the use of $\mathrm{CP}$ overall. Additionally, the knowledge gained from this study will aim to inform both practice and policy, by helping to understand the socio-ecological roots of the beliefs about $\mathrm{CP}$ in this vulnerable population. Research of this kind will also be significant to healthcare providers, teachers, school administrators, childcare providers, psychologists, and social workers. 


\section{CHAPTER II \\ REVIEW OF THE LITERATURE}

Corporal Punishment

The majority of American parents both approves of and uses some form of corporal punishment (CP) to correct or control their child's behavior. According to a 2014 report published by the Brookings Institute, $81 \%$ of American parents believe that spanking their children is sometimes necessary, and $61 \%$ of mothers surveyed reported that they hit, beat, spanked, or slapped their children (Cuddy \& Reeves, 2014). A study conducted that same year involved the audio recording of 33 mothers interacting with their 2-5-year-old children found that the median rate of $\mathrm{CP}$ use in the sample was 18 times per week. In $73 \%$ of cases, the children went on to repeat the behaviors for which they had been punished within 10 minutes of being hit (Holden, Williamson, \& Holland, 2014).

Some researchers argue that $\mathrm{CP}$ is effective in correcting a child's behavior, (Baumrind, 1996a, 1996b, 1997; Larzelere \& Kuhn, 2005) while others have demonstrated that $\mathrm{CP}$ is not just ineffective but harmful (Afifi, et al, 2006; Durrant \& Ensom, 2012; Gershoff, 2013; Gershoff, 2010; Gershoff, 2002; Gershoff \& GroganKaylor, 2016; Grogan-Kaylor, 2004; Hineline \& Rosales-Ruiz, 2012). As previously stated, one explanation for this variation in findings may be found in the Socialecological Model of Prevention (CDC, 2018), which helps to illustrate how the influence of culture, religion, family and society affect attitudes and beliefs about CP. 


\section{Defining Corporal Punishment}

Corporal punishment is defined as "the use of physical force with the intention of causing the child to experience pain, but not injury, for the purpose of correction or control of the child's behavior" (Straus, 2001, p. 4). This distinction between inflicting pain but not physical injury is what distinguishes CP from physical abuse. Tomoda et al. (2009) define harsh CP as "a severe form of corporal punishment in which an object (e.g., belt, paddle and hair brush) [is] used on occasion for the purpose of disciplining a child, provided it [does] not extend beyond the buttocks, [is] not conducted out of anger, and [does] not result in injury" (p. 66). It is important to note that the use of CP on the buttocks with an object, as described by Tomoda et al., is legal in every state in the United States, if no injury results (Gundersen Center for Effective Discipline, 2018). In the United States, many of these methods of CP are known euphemistically as “spanking," "slapping," “smacking," "swatting," "popping," "whacking," "paddling," "whipping," or "whupping" (Gershoff \& Bitensky, 2007; Straus, 2010). The use of these euphemisms aids in blurring the line between CP and physical abuse (Knox, 2010).

The Committee on the Rights of the Child (CRC), the monitoring body of the United Nations Convention on the Rights of the Child (UNCRC), defines CP as:

“some degree of pain or discomfort, however light. Most involves hitting ("smacking", "slapping", "spanking") children, with the hand or with an implement - whip, stick, belt, shoe, wooden spoon, etc. But it can also involve, for example, kicking, shaking or throwing children, scratching, pinching, biting, pulling hair or boxing ears, forcing children to stay in uncomfortable positions, burning, scalding or forced ingestion (for 
example washing children's mouths out with soap or forcing them to swallow hot spices). In the view of the committee, corporal punishment is invariably degrading. In addition, there are other non-physical forms of punishment which are also cruel and degrading and thus incompatible with the convention. These include, for example, punishment which belittles, humiliates, denigrates, scapegoats, threatens, scares or ridicules the child" (United Nations Committee on the Rights of the Child, 2006).

As a response to the provisions of the UNCRC, 53 countries across the world have banned CP entirely, both in the home and in schools (Global Initiative to End All Corporal Punishment of Children, 2018). The United States is the only United Nations member nation that has signed the Convention on the Rights of the Child but has not ratified it. This means that the United States is not legally bound to abide by the Convention (Global Initiative to End All Corporal Punishment of Children, 2018).

\section{Types of Corporal Punishment}

The degree of physical force applied when $\mathrm{CP}$ is used varies, depending on the age of the child, the infraction, and the level of anger of the adult applying the punishment (Holden, Williamson, \& Holland, 2014; Straus, 2010). Light physical force may include slapping on the child's hand or bottom. This type of CP is typically used on infants or young children for reasons such as putting objects in their mouths, doing something dangerous, "testing limits", "acting spoiled" (Burchinal, Skinner \& Reznick, 2010). Heavier physical force involves hitting the child with hard objects such as a wooden spoon, shoe, hairbrush, whip, stick, broom, board (paddle) or belt, and usually involves older children who have been previously disciplined for the same issue (Straus, 
2001). A teacher or principal most often use boards (i.e., paddles) on school-aged children to mete out CP, a practice that is legal in 19 states in the United States (Gershoff \& Font, 2016).

Hitting a child is not the only way that pain can be inflicted in order to control the child's behavior. Other painful forms of CP include washing a child's' mouth out with soap or putting hot sauce on a child's tongue or forcing a child to kneel on pointed or painful objects, such as jacks, stones, uncooked rice or hot sand (Fontes, 2002).

Scratching, pinching, biting a child; pulling a child's hair, or twisting a child's ear, are also forms of CP. More severe forms of CP may involve shaking or throwing a child; forcing a child to perform calisthenics, run laps, or to remain in uncomfortable or painful positions; locking a child in a confined space, or tying or restraining a child (Futterman, 2003; Hunter, Jain, Sadowski, \& Sanhueza, 2000; Nilsson, 2005; Straus, 2010).

\section{Predictors of Parental Endorsement and Use of Corporal Punishment}

As previously noted, beliefs about $\mathrm{CP}$, including decisions about when and how to use it, do not occur in isolation. Individual characteristics of the parent and child, the parent-child relationship, and parental expectations of the child's abilities and behavior can affect beliefs about and decisions to use CP (Grogan-Kaylor \& Otis, 2007). Additionally, family of origin beliefs about the appropriateness of $\mathrm{CP}$, social context, cultural norms, and religious beliefs influence beliefs and decisions about the use of $\mathrm{CP}$.

Combs-Orme and Cain (2008) found that mothers of infants, particularly younger mothers, and those who perceived their infant as being "difficult" were more likely to use CP. Low socioeconomic status (Dietz, 2000; Friedson, 2016) was found to be associated with support for $\mathrm{CP}$, as well as low level of education, being socialized into the use of 
violence to solve problems (Dietz, 2000) and support for authoritarian parenting values (Friedson, 2016). Taylor, Hamvas, Rice, Newman, \& DeJong (2011) studied a sample of urban parents $(\mathrm{n}=500)$ and found that having a positive attitude toward $\mathrm{CP}$ is a strong predictor of its use. Specifically, perceived social norms were the strongest predictors of having positive attitudes toward $\mathrm{CP}$, particularly when study participants believed that $\mathrm{CP}$ was endorsed by professionals, family, and friends. These social norms derive from cultural and religious beliefs.

\section{Cultural Influences Regarding the Corporal Punishment of Children}

Culture is a variable that influences the acceptability and pervasiveness of the use of $\mathrm{CP}$ as a method of child discipline. The type, degree, and intensity of socially acceptable CP vary between and among cultures all over the world. (Bradley, 1998; Denby \& Alford, 1996; Grogan-Kaylor \& Otis, 2007; Taylor, Hamvas, Rice, Newman \& DeJong, 2011). Specific child-rearing practices to which parents adhere reflect cultural and religious beliefs about parental authority, as well as the nature of children and their role in society. A child's role aligns with behavioral expectations of the child based on age and gender, as well as social role expectations related to filial piety, obedience, autonomy, and independence (Rao, McHale \& Pearson, 2003).

For example, in Western societies, children are expected to be independent, and autonomous, yet when young children explore, they may encounter threats to their safety which elicit physical discipline from the parent (Burchinal, Skinner, \& Reznick, 2010). Various Eastern societies derive their beliefs about child development from ancient philosophers. For instance, in Confucian thought, the environment is considered paramount in child development, and parents strive to provide the best possible 
environment for the child to achieve his or her goals (Wang \& Chang, 2015). Conversely, in the Hindu idea of child development, emphasis is placed on the belief that a child is born with innate predispositions, or Samsakaras, that may lead to certain predetermined tendencies (Kakar, 2012). In both China and India, two child socialization goals are valued and important: filial piety and academic achievement (Rao, McHale \& Pearson, 2003). Because of the high value placed on filial piety in China, Chinese mothers do not see authoritarian parenting practices, including the use of $\mathrm{CP}$, as authoritarian control, but as training.

Lansford et al., (2010) surveyed the use of CP on children ages 7-10 years, in nine countries: China, Colombia, Italy, Jordan, Kenya, the Philippines, Sweden, Thailand, and the United States. At the time of the study, CP had been banned in the home in just Sweden. Results of this study ( $n=1398$ mothers; $n=1146$ fathers; $n=1417$ children) revealed that across the entire sample, $54 \%$ of girls and $58 \%$ of boys had experienced mild CP, as defined as "spanking, hitting or slapping on the hand, arm or leg; shaking; or hitting with an object." Thirteen per cent of girls and $14 \%$ of boys experienced severe CP within the last month of the study. Severe $\mathrm{CP}$ was defined as "hitting or slapping the child on the face, head or ears; beating the child repeatedly with an implement". Seventeen per cent of parents in this study believed that $\mathrm{CP}$ was a necessary method of child discipline. In this sample, mothers used CP more frequently than did fathers, with the incidence of CP the lowest in Sweden and highest in Kenya. There were also differences found in degree of CP used. Kenya, Jordan, the Philippines, Italy, and Colombia showed the highest incidence and frequency of mild CP. 
Frias-Armenta and McCloskey (1998) found that harsh discipline practices ranging from $\mathrm{CP}$ to violent physical abuse were common practices in Mexico; this was due to cultural beliefs that demand respect for parent and elders, and the view that these discipline methods produce obedient children. Other Latinos are also more likely to use physical discipline such as a tapaboca (slap on the mouth) when a child uses foul language, or a cocotazo (knuckle rap to the head) when a child says something that is perceived as stupid. Other practices involve immersing an out of control child in a tub of cold water or forcing the child to kneel on uncooked rice as a punishment for being disrespectful (Fontes, 2002).

Hunter and colleagues (2000) studied the use of CP in rural India. Five hundred mothers, ages 18-50 years participated in face-to-face surveys regarding typical child discipline practices. In this cohort, mothers were the primary disciplinarians of children. The most common forms of child discipline used were scolding, slapping, and beating with a broom, shoe, or stick. Other forms of discipline that were commonly used included tying the child's hands and feet, forcing chili peppers into the child's mouth, threatening to burn or beat the child; pulling hair, kicking, withholding food, forced calisthenics, and forced kneeling for an extended period of time, sometimes on hot sand or with a brick in each hand. Forty-two per cent of the mothers interviewed reported using severe physical discipline techniques such as kicking, throwing or knocking the child down, hanging the child by the hands or feet, grabbing the child by the neck and choking the child; burning, scalding, or branding the child or threatening the child with a knife or gun (Hunter, et al., 2000). Some of the mothers who participated in this study did express remorse regarding several of the more severe discipline techniques that they used. These forms of discipline 
included threats to send their child away, invocations of ghost or evil spirits to hurt their child, holding burning sticks to their male child's penis to control masturbation, branding the skin, hanging the child by the hands or feet, and threatening their child with death (Hunter et al., 2000).

In St. Croix, U. S. Virgin Islands, and much of the Caribbean and West Indies, child-rearing patterns are authoritarian have cultural roots in British colonial and penal policies (Antoine, 2008), the history of slavery in the region, as well as traditional West African childrearing practices (Arnold \& Phil, 1982). These cultural patterns arose to ensure obedience and control during the period of slavery, and CP is used freely (Arnold \& Phil, 1982). Another cultural belief in the West Indies that supports the use of CP is belief in the biblical axiom, "spare the rod, and spoil the child". West Indian parents often believe that $\mathrm{CP}$ is a way of expressing "tough love" and strict adherence to religious teachings and as such, is a good thing, a way of showing a child love, and that the parent has the child's best interest at heart (Bailey, Robinson \& Coore-Desai, 2014). Often, parents in the West Indies use $\mathrm{CP}$, believing that the harder they hit the child, the more they demonstrate love and religious devotion. Likewise, children accept harsh $\mathrm{CP}$ as a normal part of their childhood (Anderson \& Payne, 1994). In Barbados, 54\% of adults approve of hitting children with a belt, cane, or strap ("flogging"), but $74 \%$ of Barbadian children oppose flogging or caning at school (Caribbean Development Research Services, 2009).

In Jamaica, discipline is severe, consisting of beatings and floggings, and parents use their hands, sticks, belts, shoes and switches to carry out this physical punishment (Burke \& Sutherland, 2014). These discipline techniques are not reserved for what 
would be considered severe infractions; children are punished this way for lying, stealing, being disobedient or impolite; not completing their chores, "playing in the house" "crying too much", and "not eating" the food that was given to them (Smith \& Mosby, 2003). This level of CP is culturally sanctioned in Jamaica, however, when Jamaican and other Caribbean families immigrate to the United States, they tend to be overrepresented among those parents and children engaged with Child Protective Services and law enforcement agencies for what is perceived to be child abuse by American standards (Baptiste, Hardy \& Lewis, 1997).

In all 50 states in the United States, CP is legal in the home, and legal in schools in nineteen states (Gundersen Center for Effective Discipline, 2018; 2018a). In the United States, parents state that they are most likely to use CP when they are angry (Holden, Williamson \& Holland, 2014), their child has done something that is potentially unsafe (Burchinal et al., 2010), or hurt or hit someone else (Gershoff, 2013). Parents use CP intending to extinguish their child's aggressive behaviors, yet the use of CP is likely to increase aggressive behavior in the child (Gershoff, 2002; Gershoff \& Grogan-Kaylor, 2016). One explanation for this behavioral outcome is social learning theory (Bandura, 1977) which posits that children learn from observing the behavior of others, imitation, and role modeling. When an adult models the use of physical force to achieve desired behaviors, the child learns that physical aggression is an effective means in attaining the goal of the aggressor, and the child is more likely to imitate this behavior (Bandura, 1977). Nelson, Hart, Yang, Olsen, and Jin (2006) used Social Learning Theory to predict aggression in preschool-aged children in China $(n=215)$. They found that $\mathrm{CP}$ was predictive of physical aggression in boys, and relational aggression in girls. Chang, 
Schwartz, Dodge, and Chang (2003) found very similar results ( $\mathrm{n}=325)$, in

kindergarteners in China, but the aggression was more marked for boys if the parent meting out the $\mathrm{CP}$ was the father; no gender differences were found when the mother used harsh CP; both boys and girls demonstrated equal amounts of increased aggression in the school setting.

African-American parents are more likely to favor the use of CP than EuropeanAmerican parents (Friedson, 2016; Ipsa \& Halgunseth, 2004) and use it more frequently (Deater-Deckard, Lansford, Dodge, Petit \& Bates, 2003; Mc Loyd \& Smith, 2002; Straus, 2001; Xu, Tung \& Dunaway, 2000). For example, in 2014, a nationally representative survey found that $81 \%$ of African American women, compared with $62 \%$, of both Hispanic and white women, agreed that a child sometimes needs a "good hard spanking." There were no significant differences by race or ethnicity among males. Approximately $56 \%$ of Asian women approved of the use of CP (Child Trends, 2015).

\section{Religious Influences Regarding the Corporal Punishment of Children}

Another important influence on a parent's decision to use CP as a method of discipline is the parent's religious beliefs (Dobson, 2014; Ellison, Bartkowski \& Segal, 1996a; Ellison, Bartkowski \& Segal, 1996b; Ellison \& Bradshaw, 2009; Greven, 1991). Fundamentalist or conservative Protestant parents are more likely than mainstream Protestant, Catholic, or parents with no religious affiliation to endorse and use CP (Ellison, Musick, \& Holden, 2011; Grogan-Kaylor \& Otis, 2007; Vieth, 2014 Gershoff, 2002; Gershoff, Miller \& Holden, 1999; Giles-Sims et al., 1995; Greven, 1991; Mahoney, Pargament, Tarakeshwar, \& Swank, 2000; Owen \& Wagner, 2006; Xu, Tung \& Dunaway, 2000). These beliefs stem from literal interpretations of biblical passages, 
primarily in the Old Testament (e.g., "he who spares the rod, spoils the child"), beliefs about Biblical inerrancy, the existence of Hell, authoritarian images of God and use of the Bible as a guide for childrearing (Dobson, 2014; Ellison \& Bradshaw, 2009; Ellison \& Sherkat, 1993; Greven, 1991). Fundamentalist or conservative Protestants also believe that the use CP is a way of fulfilling the biblical mandate of physically disciplining children who are seen as being born as willful and sinful (Abelow, 2011; Ellison \& Sherkat, 1993; Vieth, 2014). For these parents, the use of CP ensures that children submit to absolute parental authority and, by extension, the will of God (Dobson, 1992; Ellison \& Sherkat, 1993; Grasmick, Bursik \& Kimpel, 1991; Wiehe, 1990). Dobson (2014) refers to the use of CP as the "Biblical method" of child discipline, in which he advises no more than two applications of CP on the buttocks ("two smacks max"). Dobson advocates inflicting the maximum painful physical punishment without causing injury, so parents can "shape the will" of the child and help the child to be fully prepared for spiritual salvation and entrance into heaven.

More recent research has shown that attitudes and beliefs about $\mathrm{CP}$ among conservative Protestants are amenable to change through education and updated interpretations of biblical text. Miller-Perrin and Perrin (2017) examined the attitudes and beliefs about $\mathrm{CP}$ among students at a private, Christian university $(\mathrm{n}=129)$. Participants were given education about the effects of CP, progressive biblical interpretations, or both. The researchers found that support for CP decreased most significantly for participants with conservative religious beliefs who received education on the negative effects of $\mathrm{CP}$ and were provided with progressive biblical interpretations of scripture. 
The relationship between fundamentalist and evangelical Protestantism and use of $\mathrm{CP}$ applies in schools as well. School CP is heavily concentrated in Southern states, where fundamentalist and evangelical Protestantism is widely practiced (Owen \& Wagner, 2006). Grasmick, Morgan, and Kennedy (1992) found that both socioeconomic status (SES) and religion influenced whether their study participants supported the use of $\mathrm{CP}$ in schools. Specifically, SES related to the endorsement of $\mathrm{CP}$ in terms of attitudes and beliefs about $\mathrm{CP}$ that are associated with ones' level of education, not specific occupation. A participant's religion predicted the endorsement of CP not in degree of religiosity, but in the form of denominational affiliation of Christianity. When the researchers controlled for age, gender, and religion, fundamentalist and evangelical Protestants were far more likely than other Protestants, Catholics, or those claiming no religious affiliation to support CP in schools (Grasmick, Morgan, \& Kennedy, 1992).

\section{Other Influences}

Another explanation parental approval and use of $\mathrm{CP}$ can be found in the Cultural Spillover Theory (Straus, 1991). This theoretical framework suggests that a society that approves and supports physical force in one area of life (e.g., crime control, sports, entertainment), will have higher levels of violence in other areas of life (e.g., domestic violence, $\mathrm{CP}$ in the home and in schools). In other words, societies with high levels of legitimate violence will also have higher levels of criminal violence. Lansford and Dodge (2008) examined the Standard Cross-Cultural Sample of anthropological records assembled by Murdock and White (1969) which identifies 186 cultural groups, representing 200 provinces distributed relatively equally across the world. Lansford \& 
Dodge (2008) concluded that the use of CP is related to a higher prevalence of violence and crime at both an individual and societal level.

\section{Misinterpreting Cultural or Religious Practices as Corporal Punishment}

Certain cultural or religious practices are carried out that cause pain to a child but are considered socially acceptable. For example, ear piercing and male circumcision are physically painful to the child and permanently alter the child's appearance, yet these cultural or religious practices are not considered abusive (Lansford, 2010). Likewise, certain traditional healing practices such as coining (cao gio) or cupping leave patterned bruising; the practice of moxibustion leaves small burns (Vitale \& Prashad, 2017). These practices are not meant to hurt the child, rather, to relieve the child of illness. Outside the context of the culture in which these practices are carried out, they may be considered abusive. Examining painful healing practices within the context of culture is useful to a certain extent, namely, in the interest of cultural relativism and cultural sensitivity; however, these constructs have been used unjustifiably in the name of tolerance (Renteln, 2010); e.g. the cultural and religious practice of female genital mutilation (FGM).

\section{Effects of Corporal Punishment on Children}

A significant body of research has shown that CP is both ineffective (Durrant \& Ensom, 2012; Gershoff, 2013; Gershoff \& Grogan-Kaylor, 2016; Hineline \& RosalesRuiz, 2012) and harmful (Afifi, et al, 2006, Gershoff, 2013; Gershoff, 2010; Gershoff, 2002; Gershoff \& Grogan-Kaylor, 2016; Grogan-Kaylor, 2004). Gershoff (2002) conducted a meta-analysis of the research literature on CP spanning sixty years $(n=88$ research studies). The results of this meta-analysis demonstrated a link between $\mathrm{CP}$ and 
increased child aggression, decreased moral internalization, increased delinquent, criminal and anti-social behavior; decreased quality of the parent-child relationship, increased internalizing and externalizing behaviors in children, poor mental health in adulthood, increased risk of abusing one's own child or spouse, and being the victim of physical violence. Subsequent research studies have reinforced the findings that $\mathrm{CP}$ is associated with negative outcomes including antisocial behavior (Grogan-Kaylor, 2004), increased child aggression (Taylor, Manganello, Lee, \& Rice, 2010; Thompson, Kaczor, Lorenz, Bennett, Meyers, \& Pierce, 2017); increased risk of major depression, alcohol abuse or dependence and externalizing problems in adulthood (Afifi et al, 2006). A more recent meta-analysis (Gershoff \& Grogan-Kaylor, 2016) of 75 studies largely confirmed Gershoff's (2002) previous meta-analytic findings, identifying 17 separate detrimental child outcomes associated with the use of $\mathrm{CP}$. These findings include immediate defiance, low moral internalization, aggression and antisocial behavior, increased internalizing and externalizing behaviors, mental health problems including alcohol and substance abuse and low self-esteem. Other negative outcomes include altered cognitive abilities, decreased self-regulation, and negative parent-child relationships. The negative effects continue beyond childhood, including an increased risk of becoming a victim of physical abuse, and experiencing mental health issues in adulthood including antisocial behaviors, alcohol, or substance abuse. This research also demonstrated that children who have been hit are more likely to support the use of CP as adults (Gershoff \& GroganKaylor, 2016).

A recent integrative literature review (Chiocca, 2017) of 25 studies published between 1990 and 2014 revealed that for many of the study participants, external factors, 
such as cultural norms and religious beliefs, played large roles in whether parents approved of using CP. Further, parental stress, poverty, lack of knowledge of child development characteristics, and beliefs that children must be controlled were factors associated with approval of CP. While the studies included in this review were published over an approximately 34-year period, the results were consistent over time. CP has also been linked to the intergenerational transmission of intimate partner violence (DeaterDeckard, Lansford, Dodge, Petit \& Bates, 2003; Schwartz, Hage, Bush, \& Burns, 2006) and is correlated with being a victim of physical abuse, as well as increased risk of abusing one's child partner or spouse (Gershoff, 2002).

Parents' use of CP has also been associated with both internalizing and externalizing behavior problems in populations of children all over the world. The degree of CP correlates with the type and severity of these effects. An international group of researchers examined the prevalence of $\mathrm{CP}$ in six different countries (China, Italy, India, Kenya, the Philippines, and Thailand) among 8 to 12-year-old children ( $\mathrm{n}=292$ mothers surveyed). Both internalizing (increased anxiety) and externalizing (increased aggression) behaviors were identified in children who experienced CP (Gershoff, Lansford, Zelli, Grogan-Kaylor, Chang, Deater-Deckard, \& Dodge, 2010). Mathurin, Gielen \& Lancaster (2006) studied a group of 155 youths (ages 11-17 years) in St. Croix, U. S. Virgin Islands. They found that adolescent males who experienced CP scored lower on scales that measure self-esteem, self-adequacy, emotional stability, emotional responsiveness (e.g., "I have trouble showing people how I feel") and overall worldview ("I see life as full of dangers"). The greater the intensity of CP, the more intense the internalizing behaviors were for males; no relationship was found for girls. 
Increased hostile and aggressive behaviors were found in adolescent boys and girls in St. Croix, U. S. Virgin Islands who had been victims of CP. These behaviors also became more pronounced as the intensity of the physical punishment increased, particularly in males (Mathurin, Gielen \& Lancaster, 2006). These findings have been replicated in children and adolescents living in countries all over the world, namely Canada (Pagani, Tremblay, Nagin, Zoccolillo, Vitaro, \& McDuff, 2004); China (Nelson et al, 2006); China, India, Italy, Kenya, the Philippines, and Thailand; (Gershoff, Lansford, Zelli, Grogan-Kaylor, Chang, Deater-Deckard, \& Dodge, 2010); Jamaica, Jordan, and Singapore (Sim \& Ong, 2005). CP was associated with antisocial behavior and other behavior problems in the United States (Grogan-Taylor, 2004, 2005), Brazil, Hong Kong, Jordan, Mongolia, Norway (Javo, Ronning, Heyerdahl, \& Rudmin, 2004), and the United Kingdom (Gardner Meeks, Powell, \& Grantham-McGregor, 2007; Jaffee, Caspi, Moffitt, Polo-Thomas, Price, \& Taylor, 2004; Lau, Kim, Tsui, Cheung, Lau, \& Yu, 2004; Messer, Goodman, Rowe, Meltzer, \& Maughan, 2006; Abu Taleb, 2001; Vitolo, Fleitlich-Bilyk, Goodman, \& Bordin, 2005).

Harsh CP has been associated with even more severe sequelae. Tomoda et al. (2009) screened 1,455 young adults, ages 18-25 years to identify 22 controls, and 23 subjects who had been exposed to harsh CP consistently, i.e., for a minimum of three years' duration, 12 episodes per year, and frequently involving objects. Their most prominent finding in the subject group was a significant reduction in gray matter volume in the right medial frontal gyrus and equivocal changes in the left medial frontal gyrus and right anterior cingulated gyrus shown by magnetic resonance imaging. These brain abnormalities are associated with addiction (Crockford, Goodyear, Edwards, Quickfall \& 
el-Guebaly, 2005; Drexler, Schweitzer, Quinn, Gross, Ely, Muhammad, \& Kilts, 2000), depression and suicidal behavior, (Bar, Wagner, Koschke, Boettger, Schlosser, \& Sauer, 2007; Fitzgerald, Laird, Maller, \& Daskalakis, 2008; Raust, et al, 2007), post-traumatic stress disorder, (Geuze, Westenberg, Jochims, de Kloet, Bohs, Vermetten, \& Schmal, 2007; Hou et al, 2007), and dissociative disorders (Veltman et al, 2005). Tomoda et al (2009) note that these findings do not generalize to those who experienced milder, less frequent and less persistent $\mathrm{CP}$ before age 6 years.

Some researchers have argued that $\mathrm{CP}$, when used for "minor transgressions" or after a verbal warning, is appropriate and effective, and may even benefit children, especially when moderated by parental warmth (Deater-Deckard, Dodge, Bates \& Petit, 1996; Erkman \& Rohner, 2006; Gunnoe \& Mariner, 1997; Larzelere, 1996; Larzelere, 2000; Larzelere \& Kuhn, 2005). Other authors have hypothesized that the use of CP, particularly harsh $\mathrm{CP}$, when administered by a usually loving parent, sends conflicting messages to the child, resulting in psychological trauma and an arrest in important aspects of social cognition (Tomoda et al., 2009).

A parent or caregiver's decision to use CP is related to a complex interaction of factors involving the parent, child, and environment. Parents who experienced $\mathrm{CP}$ as a child are more likely to use physical methods to discipline their children (Bell \& Roman, 2012; Simons-Wurtele, 2010). Parental fatigue or frustration, substance abuse, depression, or other mental health concerns; intimate partner violence, lack of knowledge of a child's developmental capabilities; a fussy or hyperactive young child, and cultural or societal approval of the hitting of children all interact to create conditions in which a parent is more likely to use CP (Dubowitz, 2014; Holden, Williamson \& Holland, 2014). 
Poverty, large family size (Afifi et al, 2006), decreased access to affordable health care and social services, lack of social supports also place stress on families, thus increasing risk for the use of CP (Mackenzie, Nicklas, Waldfogal, \& Brooks-Gunn, 2012).

\section{Homelessness}

As previously noted, poverty is a predictor for the use of CP. Homelessness and poverty are inter-related. A lack of affordable housing or childcare, scarce employment opportunities, dwindling public assistance programs, and rising health care costs create social conditions that increase risk for homelessness. When these conditions are paired with other risk factors such as addiction, mental illness, domestic violence and other forms of abuse, the possibility of homelessness increases (Grant, Gracy, Goldsmith, Shapiro, \& Redlener, 2013; National Coalition for the Homeless, 2014). Homelessness can be viewed on a continuum, as situational, episodic, or chronic (Nooe \& Patterson, 2010). That is, homeless individuals may experience changes in housing status that include living on the street, or one's vehicle or abandoned building; being "doubled up" (i.e. staying with a series of friends or family but having no home of one's own); living in emergency shelter, transitional housing, or incarceration in correctional facilities (Nooe \& Patterson, 2010)

The United States Department of Housing and Urban Development (HUD) defines homelessness as "a person who lacks a fixed, regular, and adequate nighttime residence” (United States Department of Housing and Urban Development, 2016). Homeless individuals include veterans, unaccompanied youth, and the unsheltered homeless. Homeless families are categorized into two groups: those with parents or legal guardians under the age of 25 who have one or more child under age 18, and homeless 
individuals who are part of households that have at least one adult age 18 and older, and one child under the age of 18 (United States Department of Housing and Urban Development, 2016).

As of January 2016, 355,212 people were homeless in the United States, with 4,113 representing families with children under the age of 18 (United States Department of Housing and Urban Development, 2016). In 2016, 56\% of all homeless individuals lived in some type of shelter; less than half were staying in unsheltered locations (United States Department of Housing and Urban Development, 2016). Eighty-nine percent of homeless persons were over age 24 , ten percent were between age 18 and 24 years, and one percent was children younger than 18 years. Thirty five percent of the homeless population was families with children. The majority (46.3\%) of families experiencing homelessness in 2016 were African American, 39\% were White; 68.8\% were nonHispanic, and 31.2\% were Hispanic (United States Department of Housing and Urban Development, 2016). Homeless families are typically headed by a young, single woman with limited education and job skills, and who has young children (National Alliance to End Homelessness, 2016).

\section{Pathways to Homelessness}

Chamberlain \& Johnson (2011) have identified several pathways to homelessness: 'housing crises', 'family breakdown', 'substance abuse', 'mental health,' and 'youth to adult'. According to these authors, persons experiencing a housing crisis or family breakdown are homeless for a shorter time. Conversely, those on the mental health, substance abuse, and youth to adult pathways are more likely to be chronically homeless (Chamberlain \& Johnson, 2011; Shelton, Taylor, Bonner \& van den Bree, 2009; Stein, 
Burden Leslie \& Nyamathi, 2002). Families can be either homeless for the short or long term, depending on the circumstances. Family homelessness is most prevalent among poor and low-income families, mainly due to wage stagnation and inflated housing prices. In fact, since the Great Recession of 2009, the number of homeless families and children has increased to a record high (Grant, Gracy, Goldsmith, Shapiro, \& Redlener, 2013).

\section{Trauma as Both Cause and Effect of Homelessness}

For many homeless people, the pathway to homelessness has very often included their own experiences with trauma, violence, and abuse. Being homeless is also both a traumatic experience and increases the risk of further victimization and trauma (Hopper, Bassuk \& Olivet, 2009). Violence is also omnipresent in the lives of homeless families with young children. This violence may come in the form of domestic violence, street violence, being the victim of violence in one's childhood, witnessing violence, and community violence (Swick \& Williams, 2006). Family violence of all types is particularly disruptive as this interferes with the normal bonding and attachment between parent and child, creating anxiety, distrust, and chaos within the family (Anooshian 2005; Swick, 2008). Homelessness itself is also a form of psychological trauma for individuals and families due to the loss of one's home, the conditions of shelter life, and particularly for women who are homeless due to abuse (Hopper, Bassuk \& Olivet, 2009).

Homelessness has also been found to be associated with Adverse Childhood Experiences (ACEs). Roos, Mota, Afifi, Katz, Distasio, \& Sareen (2013) studied the links between homelessness and ACEs in nationally representative sample and found that ACEs were very prevalent among homeless individuals and associated with poor mental health 
outcomes. A history of childhood physical abuse was also associated with homeless women having fewer and higher risk social networks (Green, Tucker, Wenzel, Golinelli, Kennedy, Ryan, \& Zhou, 2012), and in homeless individuals overall, it predicted later physical abuse, chronic homelessness, depression, and indirectly predicted drug and alcohol problems (Stein, Burden Leslie \& Nyamathi, 2002).

\section{Impact of Homelessness and Shelter Life on Family Dynamic and Parenting}

The experience of homelessness has measurable negative effects on the mental health of parents and children, affecting the family dynamic, and how homeless individuals' parent their children. Homeless mothers have high rates of major depression that are exacerbated by their experiences of extreme poverty and limited social supports (Bassuk \& Beardslee, 2014). A lack of privacy and crowded living conditions can make shelter life very stressful for both parent(s) and children (Bassuk \& Beardslee, 2014; Friedman, 2000). Further, many homeless families live in high crime areas and thus may be at higher risk for witnessing or being the victim of community violence, which may also affect how they parent their child (Haber \& Toro, 2004).

Some homeless parents find stress in feelings of being judged by others, and difficulty in adhering to shelter rules. Lindsay (1998) studied homeless women in North Carolina and Georgia. These study participants reported alterations in their roles as disciplinarians and caretakers, and stated that shelter rules, interactions with shelter staff and other residents, their emotional state, as well as their child's emotional state, temperament, and behavior all impacted how they disciplined and interacted with their child(ren). Bradley, McGowan and Michelson (2017) conducted a meta-synthesis of 13 qualitative research studies to explore what homeless parents believe about the effects of 
homelessness on their parenting behavior. Several themes were identified: "negative selfconcept in the parental role", "parental mental health", "material resources", "challenges to autonomy and self-efficacy", "daily hassles", "physical environment and service context", "stigma", "child characteristics" and "lack of support". This analysis revealed how homeless parents often experience parenting in a stressful environment, and how this impacts their mental health and parenting authority.

Research that has shown that parents who experience high levels of stress and who approve of $\mathrm{CP}$ and are at a higher risk for physically abusing their children (Crouch \& Behl, 2001). Park, Ostler and Fertig (2015) compared homeless and housed mothers and found higher rates of physical and psychological aggression towards the child in the group of homeless mothers, with child behaviors, maternal depression and stress as risk factors for increasing the risk of aggressive parenting behaviors.

\section{Effect of Homelessness on Children}

Homelessness has been shown to affect children's mental and physical health, their sense of safety, developmental status, and school performance (Buckner, 2008). According to the National Alliance to End Homelessness (2016), homeless children have an increased risk of serious health problems, are more likely to be separated from their families, and have higher levels of emotional and behavioral problems. Haber and Toro (2004) found that chronically homeless children were more likely to suffer from internalizing mental health disorders such as anxiety, depression, social withdrawal, and somatic symptoms. Other researchers also identified anxiety, depression, withdrawn behavior, and somatic complaints among homeless children age 6 years and older that 
worsened in relationship to number of weeks having lived in a shelter (Buckner, Bassuk, Weinreb \& Brooks, 1999).

Homeless children are also more likely to experience more school absence, change schools frequently, repeat a grade, be expelled, drop out of school, or have lower academic performance (National Alliance to End Homelessness, 2016). Fantuzzo, LeBoeuf, Chen, Rouse, and Culhane (2012) studied a group of homeless third graders and found that homelessness was associated with problems in classroom engagement. Frequent school changes due to homelessness were also related to both problems in classroom engagement and poor academic achievement.

\section{Summary}

While numerous studies on both $\mathrm{CP}$ and homelessness exist in the literature, significant gaps in the literature remain. More research is needed to further understand explore why $\mathrm{CP}$ continues to be socially acceptable. As this review of the literature showed, there are cultural and religious influences on perceived acceptability of hitting children; this, however does not explain why majority of American parents both approves of and uses some form of corporal punishment.

Garbarino (1977) argued that two conditions are necessary for child maltreatment to occur. The first is the social acceptability of hitting children; the second is poor social supports for parents. More research on the attitudes and beliefs about $\mathrm{CP}$, including parental beliefs about its efficacy, alternatives and reasons for it use can serve to address the first condition. Research of what types of support parents need and when can help to address the second condition. One group of parents who experience numerous stressors are homeless parents. This research study is a first step in addressing these issues. 


\section{CHAPTER III}

\section{METHODS}

\section{Study Objectives and Research Design Overview}

The purpose of this study was to examine homeless parents' attitudes and beliefs about the use of $\mathrm{CP}$ as a method of child discipline, to explore their perspectives on the shelter's No-Hit policy, and to determine what, if anything, the shelter's social services department can do to help these parents in their everyday lives. Although other studies have identified parents' beliefs about the use of $\mathrm{CP}$, intergenerational transmission of trauma, and the complex causes and results of homelessness, it was determined from a review of the literature that it is not known what homeless parents believe about the use of CP specifically, and what factors influence these beliefs. This is an important research question, as risk factors for child physical abuse by parents include: History of physical abuse as a child, current stress, poverty, substance use, or mental health concerns (Solis, Shadur, Burns, \& Hussong, 2012; Springer, Sheridan, Kuo, \& Carnes, 2003). All these risk factors are more prevalent among homeless parents (Shinn, Gibbons-Benton \& Brown, 2015). The literature also lacks any study of parents' viewpoints on No-Hit zones, most of which currently exist in pediatric hospitals and clinics, not elsewhere (Gunderson, 2018b). This study will address this question from the perspective of parents who live where a No-hit zone exists. Lastly, little is known regarding what homeless parents believe would be most helpful to maximize their family function. This study can begin to address the gaps in the literature and provide a foundation for further research, public and parent education, practice and policy change. 
This study employed a qualitative narrative design to guide the data collection and analysis. Qualitative research is "the systematic collection, organization, and interpretation of textual material derived from talk or conversation. It is used in the exploration of "meanings of social phenomena as experienced by individuals themselves, in their natural context" (Malterud, 2001, p. 483). The narrative approach allows the researcher to obtain textured and layered descriptions of participant experiences and the meanings they assign to these experiences (Wang \& Geale, 2015). This qualitative method is ideal to study social/behavioral phenomenon involving complex issues such as the questions being asked in this study, because this approach focuses on the participants' stories, thus allowing the researcher to gain a deeper understanding of the views and perspectives of the research participants (Lincoln \& Guba, 1985; Yin, 2106).

\section{Pilot study}

In order to determine the feasibility of this research project, the investigator conducted a pilot study in the fall of 2014. This research was conducted in the same setting (urban homeless shelter in a large Midwestern urban area), with 30 participants. The pilot study was a designed to explore potential relationships between Adverse Childhood Experiences (ACEs) and beliefs and practices about child discipline in response to the implementation of a new no-spank policy at the shelter. Study participants were mothers living in the shelter, between the ages of 18-60 years, with at least one child, aged newborn to age 18 years. Participants were asked to fill out two questionnaires: Adverse Childhood Experiences (ACE) Questionnaire and brief questionnaire (17 items; 16 yes/no items, 1 Likert Scale item) that asked the mother about her usual and customary child discipline practices, including the use of $\mathrm{CP}$. The study 
results revealed no significant correlation between participants' ACE scores and their disciplinary practices. However, almost half $(n=14)$ of the participants wrote comments on one or both quantitative instruments to explain themselves, make distinctions, or expound on their childhood experiences. The pilot study was therefore useful in identifying the need to use a qualitative approach to more deeply explore the attitudes and beliefs about $\mathrm{CP}$ in this population of parents.

\section{Sample}

The study participants consisted of homeless, low-income parents living in a shelter located in a large Midwestern urban area. Participants qualified to be in the study if they were at least 18 years of age, and had at least one child, age 1 to 12 years. Parents younger than age 18 years were not included in the study, as adolescent parents present potentially complex issues including higher rates of depression, economic disadvantage, high stress levels, and lack of social supports, particularly in ethnic minority adolescent parents (Huang, Costeines, Ayala, \& Kaufman, 2014). Individuals were also excluded from the sample if they were not native speakers of English or were native to a culture outside the United States. The rationale for these exclusion criteria was that study participants must be able communicate in English during the interviews. In addition, the

type, degree, intensity, and social acceptability of $\mathrm{CP}$ varies between and among cultures (Kolhatkar, \& Berkowitz, 2014; Lansford, 2010); this can affect study findings since there could be different definitions regarding what is acceptable versus abusive child discipline. 


\section{Procedures}

\section{Recruitment}

Both convenience and snowball sampling were used to recruit study participants, and recruitment continued until data saturation was complete. Convenience sampling was carried out through advertisement flyers placed in the shelter, and shelter staff was asked to recruit potential participants who met study eligibility criteria. Shelter staff was only asked to point out the recruitment flyers or introduce me to potential study participants; they were not involved in obtaining informed consent in any way, nor did the shelter staff see any of the data. I also recruited potential study participants by visiting the shelter and passing out flyers during communal meal times. Snowball sampling was also utilized among study participants living in the shelter. The advertisement flyers briefly explained the study and stated that eligible participants would receive a Target gift card in the amount of ten dollars upon completion of their participation. Participants were also able to contact me at a cellphone number listed on the advertisement flyer if they wished to participate in the study.

\section{Protection of Human Subjects}

\section{Institutional Review Board}

In compliance with the University of Missouri Institutional Review Board (IRB), permission for conducting the research was obtained. The Applications, Quality Improvement, Continuing Review, Amendments, Required Reporting Forms, and Administrative Forms were filed, and current CITI training was verified. A synopsis of the research included a description of the research project, the methods and procedures, participants, potential risks to subjects and the steps to be taken to protect the privacy and 
confidentiality of subjects. A copy of the study recruitment materials, oral consent script, written informed consent, are included in Appendices C and De, respectively. The questionnaire and interview questions were also submitted to the IRB, as well as a copy of the letter of permission from the shelter director to conduct the research study there.

\section{Informed Consent}

I obtained informed consent from each participant. The purpose and voluntary, confidential nature of participation in the study was clearly stated on the consent. To confirm the participant's understanding that taking part in the study was entirely voluntary, and that they could skip questions or withdraw from study participation at any point, a teach-back process was used. Appendix D outlines the oral consent script process that was used to ensure the study participants' understanding that the study is voluntary, and that they could skip questions or withdraw at any point. In the written consent, it also stated that study participation was voluntary, that participants could withdraw from the study at any time, and that their access to the shelter or shelter services in no way depended on their study participation. The reading level of the consent was simplified to a sixth to seventh grade level, and this was verified using Microsoft Word. Participants were also informed in writing that they could refuse to answer any question(s) with which they were not comfortable and could ask any questions about the study or interview questions at any time. As part of the informed consent process, it was made very clear to the study participants, both verbally and in writing, that I would not be asking any questions during the interview about how they disciplined their own children, and specifically, if they used CP. Additionally, participants were also made aware that the use of $\mathrm{CP}$ is legal in all 50 states, and that $\mathrm{CP}$ was not reportable to child protective 
services unless injury to the child was a result of the use of CP. Further, study

participants were notified verbally and in writing that if any disclosures of child abuse or neglect were made during the study, the Illinois Department of Children and Family Services must be notified as soon as possible, as I am a mandated reporter. A copy of the informed consent is in Appendix D.

\section{Risk to Subjects}

Overall, potential risks associated with participation in this study were unlikely and of low risk. The primary risks were related to the potential for psychological distress, and the potential for loss of confidentiality.

\section{Psychological Risks}

Participants were asked about their attitudes and beliefs regarding the $\mathrm{CP}$ of children, as well as some of their own childhood experiences with CP. At the beginning of the interview, all participants were informed of the non-compulsory nature of participation, and that they could leave the study at any time for any reason. None of the participants showed any psychological distress during any interviews. All participants were aware that the shelter has on-site trained case managers, counselors, and social workers for participant referral if necessary. In addition, the Federally Qualified Health Center that provides the shelter with weekly on-site medical care can also provide shelter residents with free services from psychologists, psychiatrists, and addiction specialists as needed.

\section{Physical Risks}

Interview subjects were not asked to perform any physical tasks as a part of the interview that could result in any physical harm. There was little likelihood of any physical risk or injury as a result of participation in this research project. 


\section{Potential Benefits of the Research to Participants and Others}

There may have been no specific benefit to those who participated in this study. However, participants may have benefited from knowing that they were adding to scientific knowledge, potentially helping other families in the future. They may also have benefited from this research by exploring their own attitudes and beliefs about CP, and perhaps thinking about and considering alternative methods of child discipline.

\section{Ethical Considerations}

\section{Minimizing Risks to Confidentiality}

The anonymity of participants and accuracy of data were protected by assigning a code number to each completed recorded interview and corresponding transcribed interview. Completed interview recordings were kept in a locked file drawer accessible only to me. Data were transcribed verbatim from these recordings and labeled with the number from the interview recording. Any references to names or other identifying information stated in the interviews were redacted from the written transcript of the interviews prior to analysis. Study participants were also assured that the information collected as part of the study would not be shared with shelter staff.

\section{Other Ethical Considerations}

Though confidentiality was assured to all participants, I am a mandated reporter and must report any suspected child abuse or neglect to the Illinois Department of Child and Family Services (DCFS). Appendix E outlines the parameters of reportable child abuse and neglect under Illinois state law. All study participants were notified in writing that their interview statements would be kept anonymous and confidential if they were not describing situations in which child abuse or neglect were taking place. Specifically, the informed consent outlined the limits to confidentiality, stating that laws require that 
researchers who are mandated reporters and learn of suspected or actual child abuse, report it to the Illinois Department of Child and Family Services (U.S. Department of Health and Human Services; NIH Office of Extramural Research, 2018). During the study, there were no instances of reportable child abuse or neglect observed.

Participants were also given the opportunity to decline participation in the study, and to withdraw from active participation in the study at any time. Opportunities were provided for participants to ask any questions. Placing such limits on confidentiality may introduce bias and reduce study enrollment, however, the ethical obligations to ensure the safety of the children of the study participants superseded any concerns regarding enrollment.

\section{Data Collection}

\section{Demographic Measure}

Data collection for each participant included the completion of a demographic background questionnaire (see Appendix A). Questions on this questionnaire included basic items such as age, gender, marital status, race, the number of children and their ages. Other items on the questionnaire asked the participant to indicate their income, level of education, military service and religion practiced. No specific identifying information was asked or obtained.

\section{Qualitative Interview Guide}

Semi-structured interviews consist of specific open-ended questions that guide the areas to be explored, while still allowing the interviewer and study participant to speak freely in order to expound upon or clarify a response in more detail (Creswell \& 
Creswell, 2018). The semi-structured interview for this study consisted of ten open-ended questions, all designed specifically not to elicit information that would be reportable to child protective services. That is, no specific questions were asked regarding whether study participants actually used $\mathrm{CP}$ on their own children, rather, the interview questions focused on what participants thought about the use of CP as a method of child discipline. Interview questions were derived from the study aims and purpose, as well as the theoretical framework. For example, using SEM as an underpinning, participants were asked their opinion about and personal experiences of CP (individual), about what they thought about the use of CP, their family's beliefs about CP (relationships), how their religious beliefs influenced and guided their discipline choices (community) and their personal beliefs about the implementation and enforcement of rules or laws prohibiting the hitting of children (society). Data collection was iterative with analysis. The interview questions were as follows:

1. When you think about disciplining kids, what do you think about?

2. Can you tell me about your own experiences with being disciplined (or punished or corrected when you misbehaved) when you were a child, and what that was like for you?

3. Were you spanked (whupped)? How did you feel about that?

4. Now that you are a parent yourself, can you tell me more about your beliefs and feelings about disciplining kids?

5. What does your family say about spanking kids or teaching them to mind or behave?

6. How do your religious beliefs guide how you raise your children? What do your religious teachings say about getting your child to mind/behave? What do the people at church say?

7. How do you think violence between two adults in a family compares to hitting or smacking kids in the family? 
8. What do you think about the no-hit rules at this shelter? Do they work? Why or why not?

9. Should spanking children be a personal decision? Why or why not?

10. When you look around the shelter at families, what kind of help do you think they need?

Clarification of responses were achieved using probes and prompts, which are tools for asking for more information from the interviewee (Yin, 2016). Probes were used to ask the interviewee to expand on their answer. Examples of probes included, "Tell me more about that", "What do you mean by that?", or, "Is there anything else you would like to mention?" (Yin, 2016). Prompts were used to ask the interviewee to expound upon brief answers and to encourage them to talk about anything they left out (Jacob \& Furgerson, 2012). With rare exception, the same questions were asked of each participant, with occasional questions evolving iteratively in response to participant answers. The interview questions and probes are presented in full in Appendix B.

\section{Data Collection Procedures}

Data collection began with a brief introductory statement to the participant regarding what the study was about, and then informed consent was obtained. All participants were notified that they had a right to decline participation at any time, and about the necessity of audio-recording the interview. Once consent was obtained, confidentiality ensured, and demographic information collected, the interview began. These face-to-face interviews took place in a private room in the shelter. Study participants were asked open-ended questions to which they provided responses in their own words. I sought clarification of responses as necessary, asking for examples and 
probing for additional meaning. Few prompts were used, as the participants eagerly elaborated on their opinions and experiences. Once the interview was completed, the participant received a Target gift card in the amount of 10 dollars. The interview questions, probes and prompts can be found in Appendix B.

Once each audio-taped interview was completed, it was assigned a code number, and after ensuring no identifying data were included, sent electronically via a secure file sharing service to a professional transcriber, who transcribed the interviews verbatim. The transcriber then returned the files via the secure file sharing service. The transcribed interviews were reviewed for any errors or omissions and corrections were made as necessary. No data were filled in if the participant was imperceptible on the audiotape, rather, the word "inaudible" was inserted in parentheses in that portion of the transcript. The files were then saved on my password-encrypted hard drive and then uploaded into the Computer Assisted Qualitative Data Analysis Software system Dedoose®. Interviews continued until data saturation occurred, with no new categories emerging to describe participants' experiences. Grady's (1998, p. 26) conceptualization of data saturation was used:

New data tend to be redundant of data already collected. In interviews, when the researcher begins to hear the same comments again and again, data saturation is being reached... It is then time to stop collecting information and to start analyzing what has been collected.

Another method that was utilized to ensure data saturation was the construction of a data saturation grid (Brod, Tesler, \& Christiansen, 2009). As interviews were transcribed and analyzed, emerging codes and categories were listed on the vertical axis, 
and the participant responses on the horizontal axis. The saturation grid was further refined with each interview that was analyzed, with the addition of new codes or categories as necessary, and the review of previous transcripts. Data collection stopped at 18 participants, as they had all expressed very similar ideas and comments in response to the interview questions.

\section{Data Analysis}

Data collected from the background questionnaire was entered into Microsoft Excel and analyzed using descriptive statistical analysis. The transcribed interviews were analyzed using the Dedoose ${ }^{\circledR}$ software program for qualitative data analysis. This process involved the following steps: (1) becoming familiar with the data in a "precoding" stage by utilizing the "query" and "word frequency" commands in the Dedoose software; (2) creating nodes and categorizing the data into codes; (3) generating themes from the codes and; (4) collapsing the themes into broad categories that are linked to the theoretical model (Social-ecological Model of Prevention), i.e., themes that link to individual beliefs about $\mathrm{CP}$, and those that have been influenced by others (relationships), the participant's community, and society overall (Saldana, 2016). This methodological approach integrates inductive data analysis (data-driven approach) with an a priori approach, which derives from the PI's prior theoretical understanding of the phenomenon being investigated (Stuckey, 2015). The last step in the data analysis was the formation of a narrative discussion of the findings and the results (Saldana, 2016).

The specific approach used to analyze the data was conventional content analysis (Gbrich, 2013; Hsieh \& Shannon, 2005). This method was chosen because it allows for analyzing the data both qualitatively and quantitatively, i.e., to keep a quantitative count 
of the codes and categories (Gbrich, 2013); this also assisted with determining data saturation. This contrasts with thematic analysis which is a purely qualitative analysis of data (Braun \& Clarke, 2006; Gbrich, 2013). Conventional content analysis begins with a preparation phase. That is, the researcher reads all the data several times to achieve data immersion and obtain a sense of the data as a whole (Vaismoradi, Jones, Turunen \& Snelgrove, 2016). As described in the previous section, interviews were transcribed and proofread, then read again, start to finish. During this reading, portions of the data were highlighted, and comments were made via track changes, as preliminary memos, a way to notice patterns in the data, and as a means to be further immersed in the data. These copies were saved on an encrypted hard drive and set aside. Clean copies of the transcribed interviews were then uploaded into Dedoose ${ }^{\circledR}$ to begin first cycle coding.

In the first cycle of coding the data were read line by line. This process also involved making reflective notes and memos as the codes emerged (Gbrich, 2013; Hsieh $\&$ Shannon., 2005). In this coding phase, the transcripts were analyzed individually and in chronological order according to the number the participant was given the day of the interview. Each transcript was coded line by line in Dedoose®. Data were rich and complex, and this required a hybrid approach to first cycle coding, using both descriptive and in-vivo coding. According to Saldana (2016), descriptive coding summarizes small chunks of data as a short phrase; in-vivo coding involves quoting the participant verbatim. For example, the participant in the excerpt below discussed personal experiences of child abuse at length throughout the interview. This particular excerpt was coded using both descriptive coding and in-vivo coding as illustrated here: 
"When I was a little girl, to me, I was abused, I was beaten. I was locked in closets, I was molested. Yeah, I was beaten. They starved us, me and my brother, we were in foster homes and they beat us with extension cords and phone cords and shoes and we was starved, we was locked in closets, we was molested by men and women. That was my first foster family. But my second foster mom... Yeah, she spanked me. If it weren't for my (second foster) mom spanking me I probably won't be the person I am today." [13]

The descriptive codes in the first cycle of coding for this interview excerpt were:

- severe abuse

- locked in closets

- starved

- beaten with instruments

- sexually abused

- sibling abused

- in foster care

- abused in foster care

- believes being spanked as a child was ok

- spanking better than beatings/starvation/being locked up

An in-vivo code for this interview excerpt was: "If it weren't for my (second foster) mom spanking me, I probably won't be the person I am today"

The density of the data in this study also required the coding technique described by Saldana (2016) as "lumping" and "splitting." That is, larger sections of data were both coded as a single piece ("lumping") and in a more detailed fashion ("splitting") which allows for both general and specific conceptualization of one section of data. An example of a lumping and splitting of codes for this study is shown here:

Nobody called or anything, they'll come over and they'll see me with black eyes or whips and bruises and everything and my two brothers and they'll be like why 
are you beating on them like that? They'll threaten her, "I'm going to call DCFS" or 'I'm going to get somebody involved who're going to get them away from you." But she'll go with the sob story, they're being bad, they're not listening because we were bad kids. We were. I'm not saying we were perfect kids, we wasn't, we were going through a lot of things. You know, with our mother and dad not being in our lives and we grew up, me, basically I grew up alone in my life. A lot of times, I cried at night. Alone. You know, I've been raped before by a family member and you know, I had been through a whole lot of things. So, at that point I was very rebellious, I was very hateful at that time. I couldn't understand why I was put in this world only to be mistreated. [8]

Lumping:

- severe abuse

\section{Splitting:}

- severe physical abuse

- physical trauma

- sexually abused

- feelings of betrayal by primary caregiver

- feelings of abandonment

- fear

- anger

- felt deserving of abuse

- felt alone

- severely depressed

The first cycle of coding led to a total of 1208 codes in Dedoose ${ }^{\circledR}$; this number of codes needed to be refined and the more dominant and pervasive codes needed to be determined and then sorted, with redundant codes removed. This led to the second cycle of coding. 
In the second cycle of coding, relationships between and among codes were identified and the number of codes collapsed, then placed into categories based on these relationships (Saldana, 2016; Vaismoradi, Jones, Turunene \& Snelgrove, 2016). In this study, there were several instances of code name overlap (e.g., "spank", "spanks"; "tap", "pop") and those codes were simply merged. To categorize the codes, pattern coding was used which involves re-coding the existing codes for similarities, differences, frequency, sequence, correspondence and causation (Hatch, 2002). Many of the codes, when recoded, showed clear patterns emerging when seen in the context of the data set as a whole. The process of merging codes and pattern coding resulted in a total of 78 codes.

\section{Formation of Categories}

After second cycle coding, the next step in data analysis was to sort the codes into categories (Hsieh \& Shannon., 2005). This involved grouping codes by topic, clustering the similar topics, then labeling them according to descriptive concepts or phrases (Creswell \& Creswell, 2018). In this study, category formation totaled 15 categories and 32 sub-categories. The process of category formation lead to the final stage of data analysis, theme development (Vaismoradi, Jones, Turunene \& Snelgrove, 2016).

\section{Development of Themes}

The most abstract way of describing the participant's experiences is through the expression of themes. In the final step of data analysis, the categories were classified and compared until a theme emerged that was a unifying concept that characterized the meaning of the data contained within that category. Ultimately, data analysis in this study yielded five themes: 1) substantial experiences of participant childhood physical and 
emotional trauma; (2) clear conceptual definitions of and reasons for hitting children; (3) participant perspectives on interventions and policies related to corporal punishment; (4) strong family, community, religious and cultural influences on participant beliefs about hitting children; and (5) financial help from shelter and help with housing is a main priority need expressed by participants.

\section{Credibility and Trustworthiness}

In qualitative design, the researcher seeks to determine the credibility and trustworthiness of qualitative findings. Credibility refers to the whether the data or the participant views and the interpretation and representation of them by the researcher are true and accurate (Polit \& Beck, 2017). Trustworthiness refers the dependability and confirmability, of the research findings (Cope, 2014; Houghton, Casey, Shaw, \& Murphy, 2013; Polit \& Beck, 2017). Dependability can be achieved by seeking out multiple perspectives to arrive at consistency across data sources or approaches (Cope, 2014). Confirmability refers to the researcher's ability to demonstrate that the research study's findings represent the participants' responses, narratives, and words versus the researcher's biases or viewpoints (Polit \& Beck, 2017; Shenton, 2004). In this study, credibility and trustworthiness of the research findings was determined using Creswell and Miller's (2000) suggested validation strategies, which are prolonged engagement in the field or research site, triangulation, peer review, clarifying, member checking, rich, thick description, and external audits. Each strategy is discussed below.

\section{Prolonged Engagement in Field or Research Site}

Prolonged engagement in the field or research site is necessary to develop an indepth understanding of the setting, and to build trust with study participants. This also 
adds to the credibility of the findings (Creswell \& Creswell, 2018). To achieve this, I spent a significant amount of time in the common area of the shelter and in the dining hall during dinner to become immersed in the setting and to build trust and rapport with the participants. This shelter was also a former practice site for me and as such, the culture of the shelter, the shelter staff, and the specific neighborhood were already wellknown to me.

\section{Triangulation}

Triangulation is another way to determine credibility and dependability in a qualitative research study. This process occurs when other researchers review the qualitative data and concur with the decision regarding data interpretation (Birt, Scott, Cavers, Campbell, \& Walter, 2016). Triangulation was achieved not just through the interviews for this study, but also through participant observation, the recording of field notes and reflective journaling, and by having two researchers cross check the data analysis and interpretations, namely me and my project advisor. Method triangulation was also used in this study; this involved the use of various methods in collecting data in a qualitative study, such as the use of interviews, observation and field notes (Polit \& Beck, 2017).

\section{Peer Review}

Peer review in qualitative research entails frequent debriefing sessions between me and the project director or supervisor. These sessions function as a "check" on the research process, an opportunity for others to ask questions about the researcher's chosen methods and data interpretations (Anney, 2014). The peer debriefing process has been described by Lincoln \& Guba (1985) as “devil's advocate" session, which ultimately 
strengthens the research methods and design. In this study, the peer reviewer was the project advisor.

\section{Clarifying}

One potential threat to trustworthiness, authenticity and credibility in qualitative research that must be clarified is researcher bias (Creswell \& Miller, 2000). Researcher bias may result from selective observation and interpretation of data, and from allowing one's personal views, opinions, assumptions and past experiences to affect how the research is conducted and how the data are interpreted. Clarifying the data was achieved through the process of reflexivity, an essential strategy to minimize bias in this study. Reflexivity is the continual self-reflection and evaluation of investigator objectivity that is necessary in the qualitative research process, and aids in establishing credibility and trustworthiness (Berger, 2015). One way that maximum objectivity was achieved is through the recording of extensive, detailed field notes and a reflective journal. These field notes not only helped to maintain objectivity, they enhanced the credibility of the coding and categorizing of participants' interviews. Another technique that was used to minimize research bias was to record thoughts and interpretations in a reflective journal. The notes in this journal contained written observations on the data collected during the interviews, participant interactions with their children and partners, the participants' living environment in the shelter, and the neighborhood in which the shelter was located. Further reflections included the influence of race, gender, age, poverty, homelessness and how these constructs were inter-related regarding violence against and among vulnerable people. The data in the field notes and reflective journal helped to support the findings of the interview data. 


\section{Member Checking}

Member checking involves giving the participants in a qualitative study the opportunity to review their statements for accuracy. The purpose of member checking was to further establish the accuracy, credibility and validity of qualitative research (Anney, 2014; Lincoln and Guba, 1985). Member checking was conducted at the point in data analysis where second cycle coding was completed, and categories had been formed. Because many of the shelter residents do not stay at the shelter for a prolonged period of time by the time data analysis was at the point that member checks could be done, only eight participants remained. Because of the nature of the study questions, member checking was not done in focus group format, it was conducted privately with individual participants. Also, not every participant experienced the same type and degree of childhood abuse or trauma, so feedback was only sought on the categories associated with themes two through five (see Table 4.2). Most of the member checks were less than one hour in length. Of the eight participants who were asked to review the findings, all agreed that their ideas and opinions were accurately captured in their interview.

\section{Rich, Thick Description}

A detailed description of the research findings is another method of adding to the credibility of qualitative research (Creswell \& Creswell, 2018). The goal of providing such detailed description is to provide more than one perspective, (Creswell \& Creswell, 2018), thus allowing the reader to make independent decisions about transferability of the research findings (Cope, 2014). In this study, rich, thick description of participants' words were used to give the reader a sense of the intensity of their experiences and how these experiences can influence the participants' beliefs about the appropriateness of 
hitting children. Examples of participant quotes were also used to illustrate their feelings of responsibility for being beaten and abused as children, their definitions of and reasons for hitting their own children, outside influences on their beliefs about hitting children, and what they want or need in terms of help from the shelter's social services. The data were described in rich detail to maximize objectivity and to demonstrate how well the research findings are supported by the data. This was carried out by including direct participant quotes that illustrate each emerging theme, another method of evaluating the confirmability of the study findings (Cope, 2014).

\section{External Audits}

Another tactic to ensure credibility throughout data collection and analysis was the use of an external auditor. An external auditor should have no connection to the research project to maximize objectivity and interrater reliability as he or she assesses the data analysis, interpretations and conclusions (Creswell \& Creswell, 2018; Lincoln \& Guba, 1985). In this study, my project advisor independently reviewed the data in Dedoose ${ }^{\circledR}$, from the level of raw data to analysis to interpretation.

\section{Summary}

The data gathered in this study were complex and multilayered and required the melding of field notes and memos, reflexive journals, triangulation, and the use of conventional content analysis to analyze the eighteen interview transcripts. A variety of methods were also used to ensure confidentiality, rigor, credibility and trustworthiness of the analyses. The results of this analyses are presented in Chapter IV. 


\section{CHAPTER IV}

\section{FINDINGS}

This study addressed three major questions: (1) Participants' attitudes and beliefs about CP in general, (2) their beliefs about the shelter's No-Hit policy and any other rules or laws related to the prohibition of spanking, and (3) given participants' current social situation, how the shelter staff and related social services could help. Most participants in this study believed that the use of CP was normal, expected and a parent's prerogative, that any rules prohibiting $\mathrm{CP}$ were inappropriate and infringed on parents' rights, and the best way that shelter staff could help would be with aid in searching for employment and housing. The analysis of the data revealed five broad themes as explanations for participants' endorsement and use of $\mathrm{CP}$ which are described in detail below.

\section{Sample}

This study of homeless parents' attitudes and beliefs about the CP of children included 14 women and four men residing in a homeless shelter in a large Midwestern urban area. The sample was diverse. Eleven were African American, six were Hispanic (two of the six were Hispanic White), and one participant was multi-racial. The oldest was 57 years old and the youngest was 20 . The average age of the study participants was 33 years. Six participants were married, four were partnered in a romantic relationship, one was divorced, and seven had never been married. Eight had a romantic partner or spouse living at the shelter with them at the time of the interview. The number of children ranged from one to nine per family, with ages of the children ranging from three weeks to twelve years. In total, the 18 participants were parents to a total of 66 children, with gender being divided equally between girls and boys. The amount of time that participants were homeless also varied, ranging from one month to seven years, with four 
participants reporting they have been homeless for two years. Three participants did not answer this question.

The education level of the group also varied. Six participants had not finished high school, and nine had high school diplomas or completed the GED. One participant had some technical training, one had taken some college courses, and one participant completed an associate degree. None of the 18 had ever served in any branch of the U.S military. As expected, all reported income that fell far below the U.S. Federal Poverty Guidelines (U. S. Department of Health and Human Services, 2018) for their respective family size, with seven participants reporting having no income. The highest income reported was $\$ 15,000$ for a family of four. In addition to speaking English, four participants also spoke Spanish fluently.

Fifteen participants reported that they practiced their religion regularly and believed in a god; three did not. Eight participants indicated that they practiced Protestant Christianity, five practiced Catholicism, and two stated that they were nondenominational Christian. For most of these participants, their religious faith was very strong $(\mathrm{n}=8)$ or somewhat strong $(\mathrm{n}=6)$; and one $(\mathrm{n}=1)$ not very strong. The frequency data and participant demographics are summarized in Table 4.1. 
Table 4.1

Demographic Data

\begin{tabular}{|c|c|c|}
\hline Variable & & $\mathrm{n}$ \\
\hline \multicolumn{3}{|l|}{ Age } \\
\hline & 20 & 1 \\
\hline & 22 & 1 \\
\hline & 24 & 1 \\
\hline & 25 & 1 \\
\hline & 26 & 1 \\
\hline & 27 & 3 \\
\hline & 29 & 1 \\
\hline & 30 & 1 \\
\hline & 33 & 1 \\
\hline & 34 & 1 \\
\hline & 36 & 1 \\
\hline & 42 & 1 \\
\hline & 49 & 1 \\
\hline & 53 & 1 \\
\hline & 57 & 1 \\
\hline & No answer & 1 \\
\hline \multicolumn{3}{|l|}{ Gender } \\
\hline & Female & 14 \\
\hline & Male & 4 \\
\hline \multicolumn{3}{|l|}{ Race } \\
\hline & African American/Black & 11 \\
\hline & Hispanic White & 6 \\
\hline & Non-Hispanic White & 0 \\
\hline & Multiracial & 1 \\
\hline \multicolumn{3}{|l|}{ Marital status } \\
\hline & Never married, no partner at shelter & 6 \\
\hline & Married, partner at shelter & 4 \\
\hline & Married, no partner at shelter & 2 \\
\hline & Divorced, no partner at shelter & 1 \\
\hline & Cohabitating with partner at shelter & 3 \\
\hline & Cohabitating, no partner at shelter & 2 \\
\hline \multicolumn{3}{|c|}{ Number of children in family } \\
\hline & 1 child & 2 \\
\hline & 2 children & 8 \\
\hline & 3 children & 1 \\
\hline & 5 children & 3 \\
\hline & 7 children & 3 \\
\hline & 9 children & 2 \\
\hline $\begin{array}{l}\text { Length of } \\
\text { homelessness }\end{array}$ & & \\
\hline
\end{tabular}




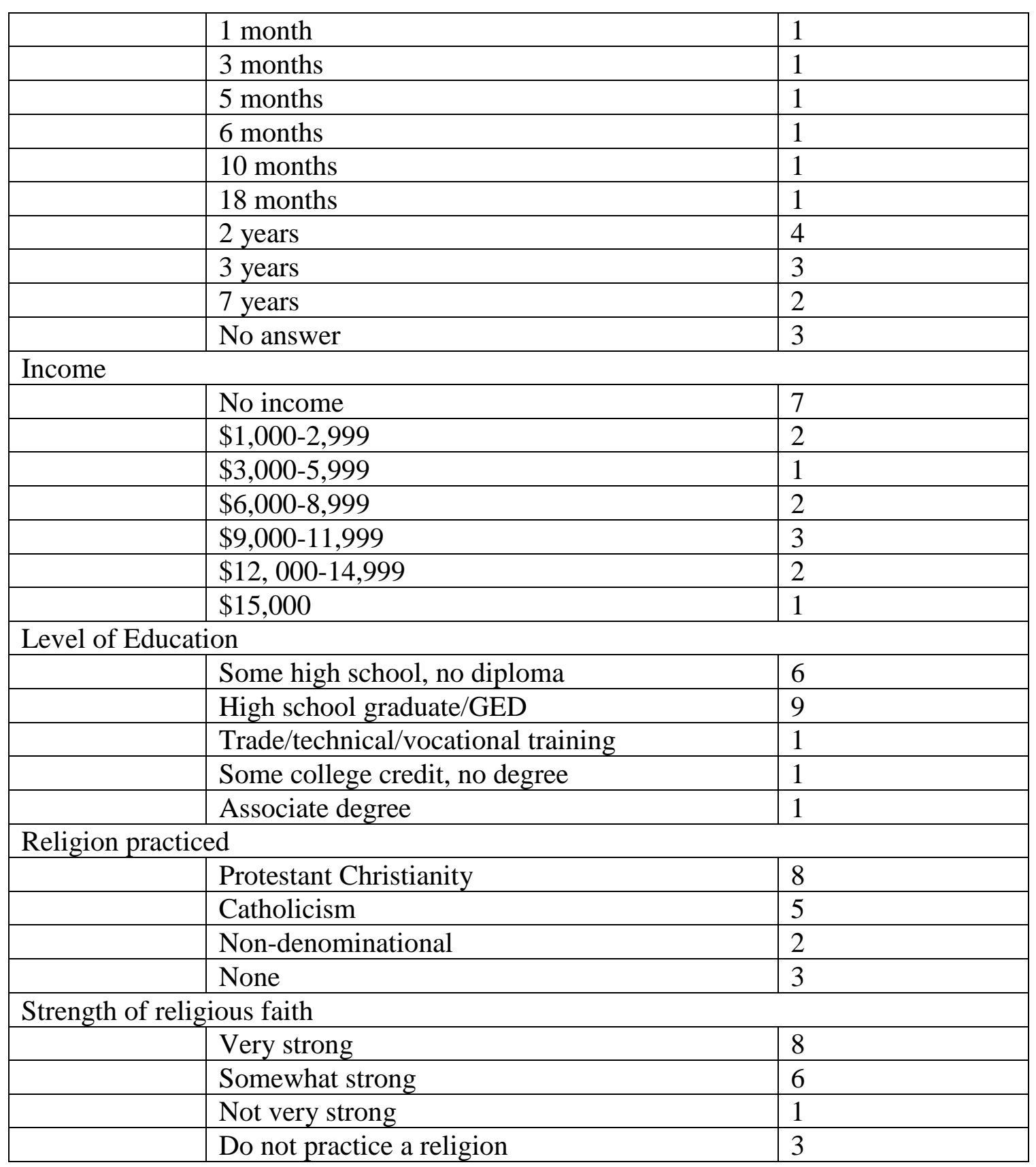




\section{Findings}

The final analysis of the data yielded five themes, 15 categories, $32 \mathrm{sub}$ categories, and 78 codes. The findings are organized below by theme, with one or more or the categories or sub-categories referenced or highlighted under each theme. This was done to create the most detailed discussion of participant experiences and statements possible. Likewise, direct interview quotes were used to illustrate the findings. All personal identifying information in any quotes have been redacted; only the participant number appears at the end of the quote to provide context. The themes, categories and sub-categories are summarized in Table 4.2.

Table 4.2

Summary of Findings

\begin{tabular}{|c|c|c|}
\hline Themes & Categories & Subcategories \\
\hline $\begin{array}{l}\text { 1. Substantial } \\
\text { experiences of } \\
\text { participant } \\
\text { childhood physical } \\
\text { and emotional }\end{array}$ & $\begin{array}{l}\text { 1.Childhood experiences } \\
\text { of physical trauma and } \\
\text { abuse as a method of } \\
\text { discipline }\end{array}$ & $\begin{array}{l}\text { 1. Experiences being beaten with various } \\
\text { instruments, intentionally burned, stabbed, } \\
\text { pistol whipped, placed alone in dark rooms, } \\
\text { and intentionally starved by a parent or } \\
\text { parent figure }\end{array}$ \\
\hline trauma ( 21 codes $)$ & $\begin{array}{l}\text { 2.Feelings after being hit } \\
\text { as a child }\end{array}$ & $\begin{array}{l}\text { 1. Feelings of shame, anger, sadness, } \\
\text { humiliation, helplessness or betrayal after } \\
\text { being beaten; feelings that they deserved the } \\
\text { beatings because they were inherently bad or } \\
\text { evil as children. }\end{array}$ \\
\hline
\end{tabular}




\begin{tabular}{|c|c|c|}
\hline & $\begin{array}{l}\text { 3. Increased tolerance of } \\
\text { violence }\end{array}$ & $\begin{array}{l}\text { 1. Participants who suffered extreme } \\
\text { physical abuse as children had higher } \\
\text { thresholds for the acceptability and degree of } \\
\text { hitting of children }\end{array}$ \\
\hline \multirow{8}{*}{$\begin{array}{l}\text { 2. Clear } \\
\text { conceptual } \\
\text { definitions of and } \\
\text { reasons for hitting } \\
\text { children ( } 36 \\
\text { codes) }\end{array}$} & \multirow{7}{*}{$\begin{array}{l}\text { 1. Beliefs about and } \\
\text { definitions of hitting } \\
\text { children }\end{array}$} & $\begin{array}{l}\text { 1. Tapping and spanking differ from true } \\
\text { hitting }\end{array}$ \\
\hline & & $\begin{array}{l}\text { 2. Spanking is one swat with open hand on } \\
\text { buttocks }\end{array}$ \\
\hline & & $\begin{array}{l}\text { 3. Tapping and spanking are acceptable and } \\
\text { normal }\end{array}$ \\
\hline & & $\begin{array}{l}\text { 4. A "whipping" is actual hitting, i.e., more } \\
\text { than one hit on the buttocks, may or may not } \\
\text { involve a belt }\end{array}$ \\
\hline & & $\begin{array}{l}\text { 5. A whipping becomes abuse depending on } \\
\text { degree of force; i.e., if it leaves a mark, } \\
\text { draws blood, or involves instruments other } \\
\text { than a belt }\end{array}$ \\
\hline & & $\begin{array}{l}\text { 6. Hitting on the face is always abuse, no } \\
\text { matter the force }\end{array}$ \\
\hline & & $\begin{array}{l}\text { 7. Spanking or whipping does not work } \\
\text { because a child gets numb to it and then } \\
\text { ignores the parent }\end{array}$ \\
\hline & $\begin{array}{l}\text { 2. Age is relevant in } \\
\text { decision to spank }\end{array}$ & $\begin{array}{l}\text { 1. A child must know the difference between } \\
\text { right and wrong for spanking to work }\end{array}$ \\
\hline
\end{tabular}




\begin{tabular}{|c|c|c|}
\hline & & $\begin{array}{l}\text { 2. Not appropriate to hit a baby or older } \\
\text { adolescent }\end{array}$ \\
\hline & \multirow{3}{*}{$\begin{array}{l}\text { 3. Reasons parents spank } \\
\text { or hit }\end{array}$} & 1. Spanking is a way to show love or caring \\
\hline & & $\begin{array}{l}\text { 2. Spanking is done to discipline or teach a } \\
\text { child }\end{array}$ \\
\hline & & $\begin{array}{l}\text { 3. Parents spank or hit mainly because of } \\
\text { frustration or anger }\end{array}$ \\
\hline & \multirow[t]{2}{*}{$\begin{array}{l}\text { 4. Alternatives to hitting } \\
\text { children }\end{array}$} & $\begin{array}{l}\text { 1. Hitting is not a parent's first choice in } \\
\text { discipline and is often preceded by a warning }\end{array}$ \\
\hline & & $\begin{array}{l}\text { 2. Most participants use time outs and } \\
\text { confiscation of toys/electronics before hitting }\end{array}$ \\
\hline \multirow{6}{*}{$\begin{array}{l}\text { 3. Perspectives on } \\
\text { interventions and } \\
\text { policies related to } \\
\text { corporal } \\
\text { punishment (10 } \\
\text { codes) }\end{array}$} & \multirow[t]{2}{*}{$\begin{array}{l}\text { 1. Thoughts on being hit } \\
\text { at school as a child by } \\
\text { school personnel }\end{array}$} & $\begin{array}{l}\text { 1. Participants were hit by parents as } \\
\text { children, but parents were irate/incensed } \\
\text { when school personnel hit their child }\end{array}$ \\
\hline & & $\begin{array}{l}\text { 2. Participants believed it was ok for parents } \\
\text { to hit them but not their teacher or principal }\end{array}$ \\
\hline & $\begin{array}{l}\text { 2. Parents can hit their } \\
\text { child but no one else can }\end{array}$ & $\begin{array}{l}\text { 1. Children belong to their parents; decisions } \\
\text { about whether they are hit should be left up } \\
\text { to the parent and only the parent }\end{array}$ \\
\hline & \multirow{2}{*}{$\begin{array}{l}\text { 3. Disagree with No Hit } \\
\text { rules and they do not } \\
\text { work }\end{array}$} & $\begin{array}{l}\text { 1. No Hit rules or any laws banning spanking } \\
\text { interfere with parents' rights }\end{array}$ \\
\hline & & $\begin{array}{l}\text { 2. Parents abide by No Hit rules because } \\
\text { they have no choice }\end{array}$ \\
\hline & & $\begin{array}{l}\text { 1. Hitting a child for discipline is a parent's } \\
\text { own personal decision }\end{array}$ \\
\hline
\end{tabular}




\begin{tabular}{|c|c|c|}
\hline & $\begin{array}{l}\text { 4. No one should tell a } \\
\text { parent he/she cannot } \\
\text { spank their child }\end{array}$ & $\begin{array}{l}\text { 2. It is never acceptable for a man to hit a } \\
\text { woman, but it is acceptable to hit a child } \\
\text { because it is discipline }\end{array}$ \\
\hline $\begin{array}{l}\text { 4. Strong family, } \\
\text { community, } \\
\text { religious and } \\
\text { cultural influences } \\
\text { on participant }\end{array}$ & 1. Family endorses CP & $\begin{array}{l}\text { 1. Family, friends and strangers tell } \\
\text { participants to hit their children, stating they } \\
\text { "need" to be hit } \\
\text { 2. Heard own parents cite "spare the rod, } \\
\text { spoil the child" }\end{array}$ \\
\hline \multirow[t]{3}{*}{$\begin{array}{l}\text { beliefs about } \\
\text { hitting children }(7 \\
\text { codes) }\end{array}$} & $\begin{array}{l}\text { 2. Religion influences } \\
\text { beliefs about CP }\end{array}$ & $\begin{array}{l}\text { 1. Most participants heard religious leaders } \\
\text { endorse hitting children, citing "spare the } \\
\text { rod, spoil the child" }\end{array}$ \\
\hline & & $\begin{array}{l}\text { 2. Religion is an influence on participants' } \\
\text { own beliefs about hitting children; believe in } \\
\text { "spare the rod, spoil the child" }\end{array}$ \\
\hline & $\begin{array}{l}\text { 3. Culture influences } \\
\text { beliefs about } \mathrm{CP}\end{array}$ & $\begin{array}{l}\text { 1. Hitting children is part of African } \\
\text { American culture, e.g., "Big Mama"; needed } \\
\text { to keep children under control and avoid } \\
\text { encounters with police }\end{array}$ \\
\hline $\begin{array}{l}\text { 5. Financial help } \\
\text { from shelter and }\end{array}$ & $\begin{array}{l}\text { 1. Survival needs } \\
\text { superseded all others }\end{array}$ & $\begin{array}{l}\text { 1. Most participants expressed clear desire } \\
\text { for help finding a home and a job }\end{array}$ \\
\hline $\begin{array}{l}\text { help with housing } \\
\text { is a main priority } \\
\text { need expressed by } \\
\text { participants ( } 4 \\
\text { codes) }\end{array}$ & & $\begin{array}{l}\text { 2. Several participants said therapy to help } \\
\text { with parenting stress or a parenting class } \\
\text { could help, but some associated classes with } \\
\text { negative assumptions about their parenting } \\
\text { abilities }\end{array}$ \\
\hline
\end{tabular}




\begin{tabular}{|l|l|l|}
\hline & $\begin{array}{l}\text { 3. Some participants expressed hopelessness, } \\
\text { stating they could not name a way they could } \\
\text { be helped }\end{array}$ \\
\hline
\end{tabular}

\section{Attitudes and Beliefs about Corporal Punishment}

\section{Theme 1: Substantial Experiences of Participant Childhood Physical and Emotional Trauma}

The first research question addressed participants' attitudes and beliefs about the use of $\mathrm{CP}$ to discipline children. The primary theme that permeated the data was substantial participant experiences of being a victim of and witness to physical and emotional trauma as a child. This was a topic that most participants returned to again and again during the interview. For example, when asked questions about definitions of and opinions and beliefs about spanking children, in many cases, the questions were answered briefly, then the participant elaborated on a childhood experience of physical abuse. Most of the participants described being beaten with belts, extension cords, jump ropes, telephone cords, tree branches ("switches"), clothes hangers, broomsticks, house slippers, sandals and shoes; hit and slapped with spatulas, combs and hairbrushes, and being both stabbed and burned with a grill skewer. One participant was pistol whipped in the face by her father. Some participants were forced to do prolonged, strenuous exercise or hold heavy items with their outstretched hands as a method of discipline. Still others were placed in solitary confinement for days or weeks at a time as punishment; two described being fed only saltine crackers and water as punishment. Some participants who were severely physically abused were sexually abused as well. 


\section{Participant Descriptions of Severe Childhood Physical Abuse}

All but two study participants talked at length about being beaten with various instruments, intentionally burned, stabbed, pistol whipped in the face, placed alone in dark rooms, and intentionally starved by a parent or parent figure. Participants spoke

freely and candidly about these childhood experiences. Some participants spoke matterof-factly about being hit with an instrument, as if this was normal and expected. Participants stated that being hit with a belt was acceptable, even normal and an effective method of discipline, but for all participants who experienced it, being hit with an extension cord crossed a line into abuse. The participants who were hit with a belt as children discussed this experience matter-of-factly: "So, my mom, she was a real loving mom. She spanked us when we needed it. When we got spanked there was a belt.” [1]. Several participants were hit as children with instruments other than a belt:

I was abused by my dad...my dad would really get harsh with the belt. I mean... he used to have a bunch of guns in our house. He found out my mother was cheating one time and confronted me to go. He thought I knew where she was with her boyfriend. He told me to go get her, tell her to come home and I came back and told him I already told her, she's supposed to be on her way. He had a gun and he pistol whipped me across the face. [7]

I was hit with the belt, a sandal, extension cords, a belt, a hanger. I was physically abused and I was also sexually abused. (Hit on) face, arm, my legs, wherever my mom could hit me, it didn't matter. My mom was a crack addict. [18] 
For some study participants, in addition to being hit, they were forced to do vigorous physical activity or to hold heavy items for a prolonged period of time: "I got disciplined by spanking, exercise, dark rooms, whippings with belts. It'll be like push up position for a duration of time or like hold heavy books with your arms out." [11]. Still others were placed in solitary confinement, locked in closets, or starved:

My mama would use a belt or solitary confinement. Like so whenever I acted up I had to sit in my room for weeks at a time. You can't come out unless you got to eat or pee. The one-time punishment for two weeks, I was in my room two weeks. I would have liked a whipping because I would have cried for a few minutes or I would have cried been a little hurt, probably would have been a little angry but at least I could have went outside and watched TV. [4]

That was our punishment... She'd give us two crackers and a glass of water for the day. Because like she said, she always was about that, she says I'm not obligated to feed you but I got to feed you just to make sure that you survive. [8]

\section{Participant Feelings Related to Experiences of Childhood Abuse}

Most of the study participants who were severely physically abused or beaten as children expressed feelings of shame, anger, sadness, betrayal, humiliation or helplessness at being hit by their parent or parent figure. Many also spoke of feelings that they deserved these beatings because they were inherently "bad" or "evil" as children:

It was hurtful. I felt like I was not wanted, and I always felt like maybe something I was doing wrong when I never understood what I did wrong when I was a child, cause it was always with screaming, "you don't do this, you don't do 
that" or you get a whipping or you get something thrown at you. And I got whipping with extension cords when I was a child. [3]

I still was bad, I still was bad growing up like I was horrible. I can honestly say I was a bad child. I was a bad teenager, a rebellious teenager and the punishments that they gave me didn't really work because I still did what I wanted to do. [4]

I only got spanked on the butt once because I was messing with something and I wasted it all over the room so I understood why I got that...But I know I deserved it because I shouldn't have been wasting toothpaste and trying to mess with everything. [10]

Participant 9 described how both his parents and the police together humiliated him:

I got caught throwing eggs and I was taken home in the cop car and I had an egg in my glove because it was cold outside and I tried to stick the egg under the cop car in the seat and there was no opening there, a little small opening like that. And I tried to force it and it busted all over, so I got out of the car and they seen it, and they told my mom and my dad came up and he slapped me around a bit, spanked me right in front of the cops and the cops are like that's what you get. The cop came back the next day and I had to clean it up. He said I bet you won't think about that and do that again, and I never did. Never threw another egg in my life because the discipline in front of the cop and having to clean it right there in front of my friends, in front of my house and the two cops standing there laughing at me, telling the neighborhood kids this is what happens when you disrespect the police. [9] 
Feelings of "deserving" abuse. Most of the participants, as they described being hit or beaten as children, stated that they believed that they deserved the beatings that they received because they were "wrong," an "extra bad" child, "rebellious," or unusually “stubborn." Two participants stated that their childhood beatings were justified because, as children, they were inherently "evil." Some stated that they would never hit their children because of what they endured as children, yet it became clear as the study progressed that for these participants, "hitting" and "whipping" were two different things. These participants agreed with "hitting" a child who misbehaved, but not "whipping" them. As this participant explained:

There's a difference between punishment and abuse. The difference between like a punishment is I'm taking something from you or I pop you because you know that was wrong. But just being punched on as a kid and smacked hard like things in certain areas - like hitting them in certain spots is not okay. Like hitting them so hard that you feel like you really can hit an adult that hard that it would hurt them, it's just not okay. [14]

This participant repeated numerous times during the interview that he was deserving of the abuse he received, or it was somehow his fault:

To this day I can, if I sat and just think about all the spankings and beatings, not beatings but smacks we got and like my mom -it was our fault, we got caught smoking marijuana in the house and she had a broom in her hand and she just lashed out and she broke it over my arm and broke it over my brother's arm. Just thinking about those things will make me want to cry...I mean every one of my friends got spanked or hit or beaten by their parents just because of we were just 
evil kids back then. I mean we used to shoot bottle rockets and Roman candles at each other, at each other in the face. That's wrong, that's evil. This is not something you're supposed to do. And now that I'm an adult I realize oh, my God, I messed up so bad. I put my parents through a lot of bad things. [9]

When speaking about being beaten by his grandmother, who forced him to choose his own switch from the tree:

She'd smack us on the back of the thighs and it would leave a couple of welts and we never did it again, it hurt so bad. And you couldn't come back with a little cheap one [laughing]. It had to be nice and thick so that when you whipped, and, in the wind, it went whoop. It didn't really phase our mom because she knew how we were, I suppose, we weren't always good and that we would mess up. You know, once in a while and then we deserved it. We were a very loving and close family, don't get me wrong. But you know, we were kind of evil kids back then, kind of. [9]

Participants also described similar feelings after being hit by their teachers:

I felt like it was wrong, it felt hurtful, in a way I felt like I shouldn't say anything because of her being a teacher or trying to help or whatever. That hurt me for a while and after so many times of her doing it or seeing her doing it to someone else it made me speak up. [11]

I deserved it because I was being acting up in school. I felt like now that I'm grown, I felt like it was the right thing for her to do that because I was acting up in school and showing off and stuff like that. [13] 
Some participants felt empathy for the adult who physically abused them:

(My mother) was chasing me and I slipped and I kind of hit my face and I scraped the bed. And when I got up she didn't realize what I did, she was whipping me with an extension cord. When I got up she just whacked me and put two bigger whacks. So, it was this and there was the bigger whack one across my face. I was about 8 years old and I remember her panicking, she was very upset, and she was very apologetic to me and she said my anger got the best of me. She said please, do not tell on me. And I went to school and she gave me the story to give to the teachers and everybody, and me being a kid I messed the story up because I was nervous. I said it backwards, so they're looking at me like okay, and I just cried, I said please, I love my mother, please, she didn't mean any harm. I was bad, I shouldn't have done what I did. And they investigated her for a while but at the end of the day my mother was a struggling single mother. She took care of me very well, she really did. [5]

\section{For most, mental pain was worse than physical pain of beatings. When}

reflecting on their own childhood experiences of corporal punishment, most participants stated that the mental pain of being hit or beaten was worse than the physical pain: "The mental because the physical, yeah, it hurts, and it leaves scars and eventually they clear up, they go away, and the pain goes away. But the mental and the emotional hurt is what stays." [5]. "I would say more emotional and just because physical heals. Emotional it stays with you. I mean I'm 49 years old and I still recap some of these memories and I would sometimes have nightmares about it. [7]. 
Other complex feelings when recounting childhood experiences. Participants also described their feelings as they witnessed their siblings being abused, and of being desperately fearful of being separated from these siblings if Child Protective Services became aware of the abuse. Participants shared their feelings of anger, rage, sadness, hurt, humiliation and betrayal at the physical pain that was inflicted upon them by their caregivers. For most of the participants who were beaten repeatedly, especially when an instrument was involved, they stated that the physical pain was worse than the mental pain of being hit as a child. For the participants who were both beaten and were simultaneously humiliated or verbally abused, they stated that the mental pain exceeded the physical pain of being hit as a child.

\section{Adaptation to Violence}

For those participants who described experiences of severe childhood physical abuse, there seemed to be an increased tolerance of violence and resultant adaptation to or recalibration of levels of acceptability of physical violence that an adult can inflict on a child in the name of discipline. These participants also described being hit by teachers, parents, grandparents and foster parents. These participants also witnessed severe violence in the form of beatings inflicted on their siblings and classmates; some witnessed community and gang violence. They also described pervasive fear, not just of being assaulted, but fear of being separated from siblings. These participants had become so accustomed to physical and emotional violence because of their own victimization that their threshold of acceptability of violence was lowered. The passages below illustrate this thread of Theme One. Note that the daughter of Participant 8 lives with her father; Participant 13 has an open DCFS case with two of her children: 
Some kids you got to get straight down to beatings with them, spanking don't work, you got to hit the buttocks. But some kids you have to spank them one time like my child, for instance, once I spank my baby this month, I had to whip no more for the next six, seven months, she's 14 now. Oh, you want to be on the phone or Facebook, no Facebook. I log out their account. You don't want to cooperate don't watch my TV and if you keep doing that I'm going to discipline you how my grandma used to do us when we showed rebellion during the daytime. She'd give us two crackers and a glass of water, that's it. [8]

I believe there should be spanking. Because when I was growing up and I did something, and I knew I wasn't supposed to do that, I was getting my butt whipped by my mama friend...I believe that there should be spankings and I believe that kids should get disciplined because it bring structure. And without no structure there's no safe environment... Like I got DCFS called on me for tapping my son on the shoulder for not listening... I think that was just wrong because he's not abused, he's not none of that. Like he went through more abuse being in a hospital and then they checked him out and he is not knowing what's going on with him and me popping him on his shoulder. I felt that was wrong. [13]

\section{Participants' History of Abuse Did Not affect Desire to Use CP}

Some participants who had talked about experiences of severe childhood physical abuse cited the shelter's No-Hit policy as a frustration to their desire to use CP. These participants threatened their children with abandonment or calling the police on them as an alternative to hitting: "He has a father that lives in Mexico. And I told him it's either he shapes up or I'll have to ship him out. Because he will not listen to me.” [7]. 
This participant stated she does not use CP because of how she was beaten as a child, however:

I might tell them if you don't stop I gonna call the people on y'all. And I be taking about the police. So, I get the phone-- Yeah. I got to call the people, the popo, they're going to come to get you. They'll be like, my little one be like no, no, I don't want to go to jail! I don't want to go to jail! So that's how I scare them (laughing). [3]

\section{Theme 2: Clear Conceptual Definitions of and Reasons for Hitting Children}

At the beginning of the interview, participants were asked to define child discipline. Participants expressed clear conceptual definitions of and reasons for hitting children. All but one participant stated that spanking is not his or her first choice for discipline, that confiscation of toys and electronics or the use of time outs is done first, and if not successful, then physical discipline is next. Ten participants said they warn their children before they hit them.

\section{Beliefs about and Definitions of Hitting Children}

When asked to define spanking, study participants were very clear in delineating what is and is not "hitting," and when "normal" hitting crosses the line into abuse. That is, tapping and spanking were not considered "true hitting," rather, a "whipping" is true hitting. When participants stated whether they endorsed hitting, they meant whipping, not one slap on the hand or one swat on the buttocks but hitting a child on their body anywhere more than once, with or without an instrument. All participants derived these beliefs from family teaching about parenting and acceptable boundaries of child behavior, 
religious teachings from family, preachers and the Bible, and the overall social acceptability of hitting children.

\section{Spanking is Acceptable and Normal}

Spanking (vs. whipping) was viewed by all but two study participants as normal and necessary, a way to show a child that the parent cares and loves the child, to discipline and teach the child how to be in the world. Several participants stated that a parent would even be derelict in his or her duty to not spank the child. Most participants also stated that parents do not plan to hit their children, but most often do so because of frustration or anger, especially if the child continues to repeat the action for which he or she has been hit. Lastly, most participants agreed that hitting a child does not work, as the child becomes accustomed and numb to this action eventually ignores the hitting, necessitating escalating of physical discipline which participants said they cannot do, as this will jeopardize their stay at the shelter and risk involvement of child protective services.

Tapping and spanking differ from true hitting. Every single participant in this study stated that they do not consider tapping/popping or spanking to be actual hitting and are essential to discipline a child "right." Each participant defined hitting as more than one hit anywhere on the body other than the buttocks, with or without an instrument. This has implications for how the shelter residents interpret the No Hit policy, and how the shelter staff enforces it: "So maybe you just tap him on the hand, 'no, baby, don't do that, Johnny, don't do that.' To me that's not spanking, that's just you're just tapping the kid." [1]. This participant was more detailed: "A pop may be something like a pop on the 
hand or a pop on the arm like it's a little different in that. A whipping is on the butt with the hand. Different from tapping or popping." [11]

\section{Definitions of Spanking}

Parents were clear that spanking is one swat with open hand on buttocks: "If anything, it (spanking) would be like on the butt, you know, maybe the back of the legs or something around like that. And there's nothing that if you have to like reach back and you're already overdoing things.” [2] ... "Spanking is with an open hand. I don't think it's with a belt or anything like that, it's an open hand on your butt." [18]

All but three participants explicitly stated that tapping and spanking (as opposed to whipping) are acceptable, normal, and even necessary:

I also believe that there's a right way to spank kids... You know, well, I think if a parent, a father or mother spanked their kid in a proper way which is a loving way without abuse. A loving way would mean like you're not going overboard as far as the force you're using where you turn it into abuse. And you're also before you ever spank the kid you talk to the kid and explain to him [1]

Honestly, it's a form of discipline. You know I'm saying sometimes when words don't usually stay with the child we usually as parents tend to look for physical force. Not harsh, but in some cases it's like, look, if you're not listening to me maybe if I spank you you'll really understand. (Spanking works). Sometimes it does. [18]

It's just normally when a child needs a whipping is when they know they're doing something wrong like touching the thing on the stove or touching a socket or 
cussing at their parents and stuff like that. That's when I feel that a child should be spanked or disciplined [13]

\section{Spanking is a Way to Show Love and to Teach a Child}

Many participants stated that spanking and hitting is a way to show love or caring: "Whipping is a form of parental love. Yeah. It does. Spare the rod, spoil the child." [4]... "Spanking is something totally different, you care about your child." [13]. This participant explained that children should also be told that spanking means love:

And I believe also if you do happen to spank a kid then you should at least talk to the kid and tell them why he's getting spanked and the consequences so that they understand, so they know you're doing out of love. [1]

Participants also were clear about the role spanking plays to discipline or teach a child: "It (spanking) teaches them in life kind of to not be a bad person when they get older." [10].

Spanking to me means I would say, well, it's a form of discipline, one form of discipline... say like you're trying to teach the toddler because you don't like you said a toddler will be a toddler. So, you're trying to teach the kid the things that they shouldn't do, that's not right... So maybe you just tap him on the hand. [1]

To discipline them. To teach them right from wrong, to teach them stop doing bad stuff which is don't play with sockets, don't mess with stove, don't mess with nothing that could harm you, in harm's way like messing with stoves, playing with lighters, messing with sockets; touching hot stuff, period. [6] 


\section{Spanking and Whipping are Different}

Participants were clear in delineating the difference between tapping, spanking and whipping. Participants were clear that a whipping is actual hitting, involves more than one hit on the buttocks, and may or may not involve a belt: "A whipping...I think most people, they will use the belt on the kid." [3]... "A whipping when you get multiple hits like...with the belt." [6]...” “Oh, whipping I think is with the clothes down, I don't do that. That the difference between a spanking and a whipping is if you pull your pants down." [17] ... "(Spanking or tapping is) like popping them on their hands or their butts. Whipping, that sound like a more aggressive term. A whipping to me is like they hit them anywhere." [14].

"Normal" versus abusive hitting. Participants were also clear about the line between a "regular" whipping and abuse, stating that the line in crossed into abuse depending on degree of force; i.e., if it leaves a mark, draws blood, or involves instruments other than a belt: "The best way I would explain the line is my main focus point would be force. That means don't leave a mark." [1]..." "That's not how you whip no kids with the extension cord, that's brutalizing the kid. That's actually putting the kid in a frame of torture mode. I don't do that, no, no, that's way big difference." [8]. These participants were more specific:

Well, for me I feel that hitting a child that you draw blood out of that is unacceptable. Hitting a child that you cause a bruise or scrape, or anything sort of marks and things like that I think that that is you've overdone it. [2]

When it goes beyond spanking and just you know, no, light taps of no when it becomes where a person is beating a child and getting kind of aggressive, more 
aggressive than they should get I think that that's kind of like hitting the lines of abuse because it's kind of going away from proving a point to the child and teaching a child right from wrong. I mean it doesn't take all of that to get a point across. When it leaves just light taps on the buttocks or not even on the buttocks maybe on the hand or something like that when it exceeds that I think it's pushing, like I said it's pushing abuse at that point. [5]

Several participants stressed that slapping a child in the face crosses a line into abuse, no matter the circumstances: "Never in the face, it's never upper body or anything like that." [2]

Whacking them in the face or hitting them across their body other than their butt with a belt, other parts of the body, that's a beating. Now if you get spanked on the butt with a hand or a belt that's a spanking. But if you're just outright hitting your child everywhere, like on the face because you're mad then to me, you're beating your child. [13]

Because I told my mom that my brother went to go tell on me, and she slapped me on the face and I'm like okay, you wanna slap me in the face? Slap me on the other side and she did, and I was like wow, you've actually, like, you've really hit me on my face. And she didn't give a shit, she didn't care. I just don't like it. I honestly can't explain or describe the severity of it and why I don't really like it, I just hate it. It's abuse if you if you hit the kid anywhere in their identity. [18] 


\section{Age is Relevant in the Decision to Spank}

Participants also stressed that age is relevant in decision to hit a child, that a child must be old enough to know the difference between right and wrong: "Yes, it's much better for older, spanking is for older kids because they know better.” [8]... "(A kid should be) like probably 8-9 (when you stop spanking). Because they're getting more mature they should know better. (But if they keep doing it) then they need a whipping." [12].

Hitting is not a parent's first choice. Several participants stated that they do not immediately hit their children for "every little thing," and often warn their children to stop the undesired behavior before they hit them. Other confiscate toys or electronics before they hit. Study participants stated that if these warnings do not work, then they will spank. Some discussed alternatives to hitting that they have tried; most participants used standing in the corner as discipline, with a few making their children write a penance (e.g., "I will stop teasing my sister"): "I put them in a corner. I spank, well, I hit their hands, but not going all out on them." [12]" They could stand in the corner, they could sit down, write a punishment if they know what it is." [16]. This participant confiscates toys or electronics first:

I try by taking stuff away from them like the things they like, like phones or tablets or just watching TV, you know, just basic things they would do on a normal basis. And think that you know, maybe if I do that they'll listen. Okay, if that don't work then I try grounding them, like I say you're grounded. [10] 
Reasons parents hit. Other participants said that they believe that parents hit mainly because of frustration or anger:

So that's like me already there's no more taking away the phone, there's no more time outs and everything else, you're just done for the day. Period. And that's like me that I've already exhausted and I'm just at that point where I want to spank you now because you're just frustrating me to the point. [2]

(Parents spank) like they know better but it frustrates them because the kids - and that's another thing, kids don't keep their focus so that's another reason why they got a spanking. I lost my cool a few times and I had popped my children before then. [14]

Sometimes that (spanking out of anger or frustration) can happen. I'm not a saint, I've done it before. Being with their father; I went through a lot with him as well and I guess because the anger that I felt was still not subsiding. With their father. It just wasn't subsiding or whatever we were going through, whatever anger I felt with him if my kids just go "mom, mom, mom”, I was like, "Oh my God what!?” You know, unfortunately I took it out on my kids. I wasn't -- when I first had my daughter I wasn't the best mother. I treated my daughter like crap. [18]

Spanking does not work. Most of the participants who disagreed with spanking or whipping did so because they believed that eventually a child gets numb to it and then ignores the parent: "Whipping them (doesn't work). They're going to go back and do the same thing." [12]... "But I just feel like popping don't or spanking your child all the time 
does not necessarily, is not always an effective way to get them."[4]. This participant described why and how children outgrow the effects of being hit:

And it ends up like you can outgrow a whipping; it won't work anymore. Eventually it bothers them but sometimes it just don't work. Sometimes kids get immune to the whuppings and it like, okay, I'm still going to do it. I'm only going to go cry for a few seconds. [14]

\section{Theme 3: Participant Perspectives on Interventions and Policies Related to Corporal Punishment}

The second research question focused on participants' opinions about the shelter's No-Hit policy, and other rules or laws related to prohibiting CP. The overwhelming majority of participants strongly believed that hitting a child for discipline is a parent's own personal decision, that no one can tell a parent that they can or cannot hit their child. This belief applied to anyone, including family members, health care providers, teachers and shelter staff. The majority also strongly disagreed with the shelter's No-Hit rules or any law prohibiting the spanking of children. In contrast, most participants strongly repudiated Intimate Partner Violence (IPV), while endorsing the hitting of children. One woman, however, found IPV justified in cases of partner infidelity: "I think she could be given a smack for anything like cheating." [12]. One man found both IPV and CP to be equally acceptable: "When it comes to husband and wife not necessarily. It's a family matter. No, I don't think it's necessary to call the police. That should be the same thing with kids, it's a family matter." [11]. 


\section{Hitting a Child is a Parent's Personal Decision}

The overwhelming theme throughout this portion of the interview was that a parent's child is their child and as such, any decisions pertaining to that child are the parent's decision to make, including hitting. This participant described this concept thusly:

They still hit them. And no matter they got the no hit rules, they don't - 'I brought them in this world I could take them out', that's what they go saying. Yeah. I carried this baby for nine months, I can hit my own baby. Yeah. I've heard lot of people say that. I think she just... what she do, she hollered at him and she pushed him on the ground or something like that. And they (shelter staff) like uh, uh, you cannot hit that little baby, she say I've brought this baby to the world, I carried this baby for nine months, I can do whatever I want to do with my baby. You ain't bring this baby in the world. So, she got kicked out. [12]

All but four participants in the study expressly stated in clear, concrete terms that spanking should be the parent's personal decision, and no one else. These participants were most clear in stating their opinions: "Yes, it should be a personal decision. Nobody should tell you how to chastise your child. Yes, that is a personal choice." [6] ..." You can't tell another adult not to touch their child because everybody don't feel the same. Time out, not everybody don't believe in those. They believe in physical pain." [14]. Another participant was more specific:

I feel like how I discipline my child shouldn't have no effect on nobody else. As long as I'm not beating my child and having to take my child to emergency room 
because I had hit my child too hard or have hit my child the wrong way and something is wrong or I didn't swing my child into a log or throw my child into a door then I believe no one should say anything. [4]

Most participants strongly disagreed with the shelter No Hit rules or any laws banning spanking:

And I feel actually that the no-spanking rule in the shelter should not exist because it makes us parents frustrated for one, for two, our kids continuously not listen to us, they don't - it's not sinking in their head when we're talking to them. It makes them think it's okay for them to do whatever it is they want to do. [10]

The no hit rules here? I don't think it's right. Whether you hit your kids, no. Because at the end of the day those are your kids, so no. (A law) about no spanking? Yeah, oh, that's a big problem. [17]

Yeah, I agree in spanking. Well, I think, I would think that would be wrong (to tell parents they cannot hit their children) because now you're trying to tell me how to raise my child. Nobody else's business because whatever I do with my child, if I'm not abusing, you don't see beating or no neglect or none of that then you shouldn't have no say so on what I do with my child because I had that baby. I had to go through nine months and labor. Cut five times. So, with me, it's like you can't tell me how to raise my kid because at the end of the day, I'm raising my kids right in my eyes. I'm not beating them, I'm not starving them, and I'm not neglecting them. So therefore, if I decide to spank my child because that child is doing wrong, I have the right to. [13] 
A few participants did not object to the No Hit rules in the sense that they recognized that these rules were a condition of their stay at the shelter, and they needed to abide by these rules because they had nowhere else to go. These objections did not relate to the philosophical opposition to hitting children.

Well, it's kind of like... the way I try to look at these for me is that this is not my home. I am here, this is a temporary thing and this facility belongs to someone else. They're just letting me stay here and whatever rules that they have I have to abide by it. So, I really don't have much opinion on that. [2]

You're in a shelter, it's not your home. You know, there's rules and you have to follow rules. And spanking would be one because you don't want to get DCFS involved and your children being hit or whatever the case may be. [11]

\section{Parents Can Hit Their Children; Others Cannot}

Participants also described similar opinions and beliefs that were held by their own parents, i.e., that they could hit their children but no one else could. Many participants discussed being hit by their parents as children, but their parents were irate and incensed when school personnel hit their child:

I think you know what, one time I think I was in 2nd grade, and me and a classmate, we were arguing, and the teacher said be quiet and then kept talking and so she took us in the coat room and she had a yardstick. She spanked us with a yardstick, but I went home, and I told my mother and she blew up. She went 
ballistic, she's like you're a teacher, you're not supposed to touch her and this and that, and I'm looking at my mother and again, I'm a kid and I'm looking at my mom like she just did what you were going to do when I got home later anyway. So what difference does it make? [5]

I do remember there was an incident that there was a girl who was sitting behind me and she smacked me, and my reaction was I smacked her back. The teacher came, and he hit me. So, my mom and dad both came to the school and well, let's just say that they had to get the teacher out of there because my dad wanted to just really beat the crap out of him. And then the mother of the girl came to school she, the mom, was irate and stuff and talking about boys shouldn't be hitting girls and all this other stuff and etc., etc. and my mom just wanted to just beat the crap out of her too because they were all trying to put the blame on me. [2]

Even participants agreed that it was acceptable for their parents to hit them, and they can hit their own children, but school personnel cannot hit any child. This participant put it very simply: "Why would a teacher hit me? They ain't my parents." [16]. Other participants were more specific:

I do not think teachers should be able to paddle kids in school. That is not their place to do that. I don't agree with that one bit. I feel that the teachers are supposed to just teach and guide your children. I don't feel that anybody, I would not like for anybody to put their hands on my kid, on my daughter, I don't give a crap what reason they have. You bring it to me, if I deem necessary to do so, then I will. [2] 
With the family I felt like I deserved to be spanked because I knew I was doing a lot of wrong things. I knew eventually I'd get a spanking while with the teacher I didn't expect the teacher to spank me at all, I felt she had no right to spank me.

We used to get pinched if we act up in school. Yeah, we used to get pinched or we used to get hit with a ruler on our hands. Even though I know I was in the wrong I'm still going to go off on you, like you're not my mother so why are you putting your hands on me? [13]

\section{Intimate Partner Violence and Corporal Punishment are Obverse}

Participants were very clear in stating that it is never acceptable for a man to hit a woman, but it is acceptable to hit a child. When asked the interview question, "How do you think violence between two adults in a family compares to hitting or smacking kids in the family?" several participants answered quickly and simply: "Oh, that's different." [12] ..." I think that's two different things." [16] ..." No, I feel like that's two different things. Yeah, I think it's two different things.” [17].

Other participants expounded on their answers to explain how hitting an adult is violence, but hitting a child is discipline: "It's different. When you hit a child it's discipline, when two adults hit each other that's violence. We're not disciplining one another." [18]. These participants were more detailed in differentiating why hitting an intimate partner differs from hitting a child:

By any means necessary it's wrong. If a man puts his hands on a woman, it's wrong, period. Yes. It's wrong to put your hand on a female, that's wrong, people 
should have more respect for the female. But don't get me wrong, I chastise my baby, I probably spank her every once in a while, when she do something real bad but if she doing something like a kid normally do that's no reason to whip your child for. [6]

It's kind of different because like I said, a child is a child. Yeah, a child is not an adult. A child only being a kid you know, they're going to do things like I said sometimes the frustration part of the parent that makes the child get into trouble. (With adults hitting each other) bad things happen, police get involved. [11]

\section{Influences on Participant Beliefs about Hitting Children}

\section{Theme 4: Strong Family, Community, Religious and Cultural Influences on Participant Beliefs about Hitting Children}

The majority of study participants described experiences of partners, parents, siblings, grandparents not only endorsing the hitting of children as a method of child discipline, but also telling participants when and why they need to hit their children. Likewise, most participants not only grew up hearing religious teachings and Biblical references regarding the hitting of children, and they stated that they still hold those beliefs today. These teachings came from church sermons, Sunday school, parent teaching and the Bible. Only one participant described a preacher who saw so much evidence of child physical abuse in his Sunday congregation that he used his sermon to discourage corporal punishment, but only to a certain extent:

Yeah, because there's a lot of kids at that time coming to church with black eyes, he (the preacher) had called DCFS on several kids. Because my pastor, like, he 
say like me, why bring these kids in the world only to beat them and mistreat them? He had came at the pulpit and pointed parents out. This child need all the help she can get. That's exactly what he said. Those were the kids with the black eyes and the bruises. He basically was saying so somebody can see it. Because he don't want to be the one, but him being a man of God, he didn't want to be the one to incriminate them. So, he would put it on somebody else. (He wouldn't call the hotline) because like I said, he feel like he is a man of God and that he's not supposed to get in the middle of that. [8]

Most participants had family, friends and strangers tell them to hit their children, stating they "need" to be hit:

So, I don't really pop my daughter. Like she does a lot of stuff that would say she need to be popped, or other people's views would say you need to pop her or you need to spank her on her leg. A lot of people, friends, family, a lot of people (tell me to spank my daughter). People that don't know me like if we're at the doctor's office and you know, my kid don't want to sit there or she wants to run around like a baby, I'll give you the pop unless you sit down. Popping is not necessarily going to help. (Perfect strangers) ... Like you'll be amazed at the type of people that actually talk to me and they tell me a lot [4]

And my mother has told me this, several people have told me, "your children are spoiled and they're bad and you don't whip them and that's why they act that way, and you need to whip them". And I have tried, I have picked up a belt and said you did this and then I'll sit there and at one point I'll start crying because I couldn't do it because I knew how bad - I think of every lashing from the belt, 
how bad it felt to me, how bad the marks felt when they were left on my body how long they took to heal. I remember this as a kid and I look at my kids and I can't. [5]

(My family say) a hard head makes a soft butt. It's the saying that they use, if you be hard-headed...it's kind of like spare the rod and spoil the child. These are the sayings that they use if you let the child do whatever they want they're going to constantly do whatever they want. Spare the rod, I mean, like if you don't whup the child, he's going to be spoiled and do whatever they want. Just generations of people (say it to me). [11]

\section{Religion as an Influence on Beliefs about CP}

Most participants heard religious leaders, and/or their parents endorse hitting children, citing "spare the rod, spoil the child": "Yeah, I’ve heard that (spare the rod and spoil the child). Preachings (at church)." [15] ... "And they (the preacher) would be like, "in the Bible it says spare the rod spoil the child". And then you know, everybody gets clapping, yeah, "I know that's right" (laughing). Yeah, I know that's right.” [13]. This participant had a different perspective:

Yes, spare the rod, spoil the child. That's the thing, that's the excuse that my fellow African Americans use that it's in the Bible. Spare the rod, spoil the child. My mother says it to me all the time, you need to whip her, spare the rod, spoil the child and I'm like that can't be all of that, I think you guys are taking what you want to take out of that and kind of running with it. [5] 
For most participants, their religion is an influence on their own beliefs about hitting children, and they believe in "spare the rod, spoil the child":

Spare the rod - that thing, yeah, he (preacher) talks about that a lot. Spare the rod, spoil the child I believe. And I feel like that's fine because if you don't your child grows up to be very, very rebellious. [4]

Well, Christianity had influenced the family upbringing... (People at church), they'll say stuff like, man, you know, these young kids coming up today they're so disrespectful. They don't listen to nobody; can't nobody tell them nothing. And I agree with them. I'm a tell ya now, I would say, I do hear, I've heard people say that's because these kids today, they don't get disciplined. They actually say spanking too. I mean they say stuff like okay, when we was growing up, we know our mom and dad believed in spankings. Our mom and dad believed in discipline. [1]

\section{Cultural Influences on Beliefs about CP}

Most of the African American participants stated that hitting children is part of African American culture, and is necessary to keep children under control and avoid encounters with police:

My grandmother came over here from Mississippi when she was young and that's where this comes from because you know a lot of that was going on in the South. A lot of folks that came up here from the South came up here with that. So that's why it is embedded in the African American home so deeply because a lot of our matriarchs came up here with that mindset already. Back then pretty much the 
matriarch of the family this is kind of like the picture that they have African Americans just painted in our culture. The matriarch of the family whatever she can pick up, the Medea figure, whatever she could pick up and smack a kid with that's what she did. You have people like Tyler Perry who does Medea, that's pretty much how that lady acts is how the matriarchs in our families, a lot of African American matriarchs are or were. So, we could relate to that because I mean she's real just in your face and Medea did this and I'm going to beat the kid, that's how a lot of older black African Americans really, they kind of go by that ritual still to this day. [5]

Some people whip their kid because they don't want their kids to grow up and be a statistic, my mom always she used to tell me I don't want you to be another statistic out there in the streets. My second foster mom used to tell me this because she used to spank me and after she used to spank me she would sit me on her lap and she'd say well, baby, I don't want you to go grow up and be another statistic, I want you to be my princess. I want you to grow up, I want you to go to school, I want you to finish school, I want you to go to college, and get something to fall back on. That's what my mom always used to tell me...see, when Big Mamas are around, you know you're not supposed to do nothing you're going to act right because if you didn't, Big Mama's going to tear that butt up. That's in our society as black people. They're not no Big Mamas no more. [13]

This participant felt pressure from those in the African American community to spank her children and not to use a "time out: "I say...if you don't stop, you're going to 
have a get in a time out. But people say oh, that's just white people stuff. But sometimes for me I feel like it works." [3]

This participant had a different perspective regarding why she believed that many African Americans see CP as part of their culture:

Honestly, I think it started from slavery, I really do. I honestly think because if you think about - I thought about this as a child a lot and I thought about the nature of some of my whippings that my mother would give me, you know, the ones that were with the cord or whatever and how she would hit me and I would look at my arms and I'm like this is kind of like how what Kunta Kinte had to go through in "Roots" and this kind of reminds me of slavery a little bit. It's just my mother that's doing it, it's not a slave master it's my mother so now as a child I went through a phase in my life I was looking at my mother like a slave master because I was learning black history in school and I was seeing a lot of it and I'm looking at my body and I'm like this is what our ancestors went through and they fought so hard for us not to go through it and now we have to go through it in our own homes... This is my thought very much so because that's something now if we watch TV shows like Bernie Mac, they glorify that. Bernie Mac, he makes jokes, "I'm a bust your head to the white meat", he says stuff like that all the time and it's funny, it's funny to African Americans because like I said, that's something that has always come with the territory with African American households. [5] 


\section{Participant Needs}

\section{Theme 5: Financial Help from Shelter and Help with Housing is a Main Priority Need Expressed by Participants}

At the end of the interview, participants were asked how they thought the shelter and its social services could help the families and children living there. Overwhelmingly, both male and female participants stated that assistance in finding a job and their own home is their number one priority, and that privacy, security and autonomy were very important to them. For some participants, this autonomy meant disciplining their children the way they saw fit, including hitting. One participant stated,

Be freely to be able to raise our kids our way the way we think is right, not the way they say. That we were able to choose the one thing that we could use as a method to discipline our kids to where we could keep them in line. Spanking should be our choice, not theirs. [10].

Several participants also discussed parenting classes, but in the context of parental support versus learning about normal growth and development, or nonviolent methods of child discipline. Some parent participants associated these classes with negative assumptions about their parenting abilities. A few participants suggested stress reduction strategies:

I would say either psychiatric help or like a therapist, you know, some kind of therapist because a lot of families here do - all families that are homeless, most families that are homeless do go through a lot. A lot, and it does take a toll on the children. [7] 
I think they need emotional help, maybe someone to talk to. [15]

So, I think they would probably need I think maybe a support group to start just an outlet where because I know a lot of these women in here, they work hard, and they take care of their kids, they really do... just to kind of keep them from tapping into the violent side. [5]

Parents feel invaded when someone else comes in to tell them hey, maybe you should take a parenting class. Right away, I have no idea why people start getting offensive or get on the defensive mode... So, and which I actually did go take some parenting classes and what not for the sake of you know, I need help. Everybody needs help with their kids at some point of time or what not. They say they don't, but they must be really great at what they do. [2]

Some participants could not name any way that the shelter could help them or their family. Most participants expressed a clear desire for help finding a home and a job: "Housing and more jobs...So most of us, it's like parents just need a home like, it's better to have a home to raise your kids." [11] ..." More housing." [12] ..." The only thing they can give me is resources, financial resources. The only way the shelter can really help is help me get up out of here because that's the only way I need help." [16].

Lastly, some participants expressed a sense of hopelessness, stating they could not name a way they could be helped: "I don't know...like nothing can help us." [13] ..." I don't know what I would need (laughing).” [17] ...” There's nothing that can be done. I mean there's all these programs, all these things that women can use as resources to get help or sort of take your stress out there. There's nothing or anything that anybody can do if a mother is stressed." [18] 


\section{Summary}

The analysis of this research yielded the unique perspectives of homeless parents with respect to their beliefs regarding the hitting of children. All 18 participants had a history of one or more types of trauma, including being the victim of or witness to physical abuse, sexual abuse, intimate partner violence, community violence, verbal abuse, emotional abuse and/or abandonment, and chose to discuss their experiences at length with the researcher. These experiences did not cause the participants of this study to refute $\mathrm{CP}$ as a method of child discipline. In fact, most disagreed with any type of rules, policy or laws against the hitting of children. Lastly, when asked, the majority asked for financial help, and help with parenting was not a priority while homeless. Next, a discussion of these findings is explored in Chapter V. 


\section{CHAPTER V}

\section{DISCUSSION}

The purpose of this qualitative narrative study was to explore and describe homeless parents' attitudes and beliefs about the use of CP to discipline children, their opinions about the shelter's No-Hit policy, and to ascertain what type of support or help, if any, they would need from the shelter staff. This chapter contains a discussion of the major findings of the study, and how they connect to the Social-ecological Model of Prevention (SEM) and other related theories. Also included is an examination of the strengths and limitations of the study. The chapter concludes with a discussion of implications for future research, education, practice, and policy.

\section{Major Findings}

There were three major research questions addressed in this study. The first question was to explore the attitudes and beliefs regarding the use of $\mathrm{CP}$ among a group of homeless parents living in a shelter. The study participants articulated clear conceptual definitions of and reasons for hitting children, consistently delineating the difference between tapping/popping, spanking and whipping. For these participants, tapping/popping and spanking was acceptable and normal and differed from true hitting. Tapping (popping) and spanking were described as an act of teaching or discipline, a demonstration of love or caring, and a way to keep a child safe. Parent participants considered "whipping" true hitting, with or without the use of a belt, and all study participants stated that they rarely whipped their child, but they did tap and spank when they deemed it necessary. These findings are consistent with those of other researchers who found that the use of $\mathrm{CP}$ was common and considered normative, and words such as 
"tapping" and "popping" corresponded to a light hit on the top of the hand, usually to convey to a young child that he/she is not supposed to touch something (Ispa \& Halgunseth, 2004; LeCuyer, Christensen, Kearney, \& Kitzman, 2011; Taylor, Hamvas \& Paris, 2011).

Another theme to emerge from the data analysis was significant participant childhood experiences of physical and emotional trauma. Fourteen participants described experiences of extreme physical, emotional and verbal abuse; abandonment, and/or sexual abuse. They spoke at length during the interviews about what happened to them and their past and current feelings about this abuse. Most of them stated that the mental pain was worse than any physical pain they endured during beatings, and they believed that they were hit and beaten because they were inherently evil, bad, or wrong, and that they deserved the beatings. As adults, these participants were more likely to have had contact with Child Protective Services and express surprise that their use of CP with their children had been considered excessive. Questions about substance abuse, depression, anxiety, or stress-related illness were not included in this study, however, during the interviews, most participants discussed having problems in these areas. This is consistent with the body of research on Adverse Childhood Experiences which links stressful or traumatic childhood events to future violence victimization and perpetration, and poor physical and psychological health later in life (CDC, 2016; Monnat \& Chandler, 2015; Reavis, Looman, Franco \& Rojas, 2013).

Participant attitudes and beliefs about CP also arose from a variety of social influences, such as their extended family, religious and cultural beliefs. These findings are congruent with that of other researchers who identified relationships between 
perceived approval of $\mathrm{CP}$ by close family, friends, religious leaders, and health care providers, and parents' positive attitudes regarding the use of CP (Taylor, Hamvas, Rice, Newman \& DeJong, 2011). Many participants specifically quoted their belief in the axiom, "spare the rod, spoil the child," and had heard it spoken at both church and at home. These findings are analogous to other research findings that have shown relationships between religious beliefs and the endorsement of CP (Ellison, Bartkowski \& Segal, 1996a; Ellison, Bartkowski \& Segal, 1996b; Ellison \& Bradshaw, 2009; Ellison \& Sherkat, 1993; Grogan-Kaylor \& Otis, 2007).

African American participants in this study cited a cultural influence on beliefs regarding the use of $\mathrm{CP}$, stating that $\mathrm{CP}$ is a traditional and necessary part of parenting, that the use of $\mathrm{CP}$ is normative and expected, and learned through family and church leader teachings. Similar findings have been previously documented in the literature among low-income, African-American parents (Denby \& Alford, 1996; Ipsa \& Halgunseth, 2004; Taylor, Hamvas \& Paris, 2011). Other non-African American participants did not discuss the use of $\mathrm{CP}$ being culturally normative and expected but did state that its use was sanctioned by their church's teachings. These same participants described being hit with a switch (tree branch) as children; each of these participants either grew up in the southern part of the United States or visited grandparents there who hit them with a switch. This form of corporal punishment is more common in the Southeastern United States (Davis, Chandler, \& LaRossa, 2004).

The second research question asked the study participants to discuss their views on the shelter's No-Hit policy that applied to all shelter residents, including children. Parent participants in this study were overwhelmingly opposed to this policy because 
they believe spanking is necessary, is different from whipping which is true hitting, and that the decision to use CP must be left up to the parent and not an outside entity. This finding was consistent with national surveys that show that the majority of Americans approve of CP (Child Trends, 2015). Other research has confirmed the strong approval of CP. A recent study was conducted involving a random sampling $(n=581)$ of nearly 1,000 online comments that were placed in response to a 2010 article published in Time Magazine as covered by Yahoo! News, regarding the American Academy of Pediatrics' position statement against the use of CP. Of the responses sampled, $70.9 \%$ of those persons commenting on the piece approved of $\mathrm{CP}$, and explained why they supported $\mathrm{CP}$ (Taylor, Al-Hiyari, Lee, Priebe, Guerrero \& Bales, 2016). This emphasizes the need to continue research that aims to reach a deeper understanding regarding why American adults continue to endorse and use $\mathrm{CP}$, despite its harmful effects.

The third question related to what types of support and help parent participants need, and how the social services provided by the shelter help them meet these needs. Most participants stated that the best way shelter could help was by providing assistance with finding a job and permanent housing. A few parents stated that parenting classes would be helpful, but when asked to explain, they described what would actually be a parent support group aimed at helping to alleviate parent stress versus focusing on positive parenting skills or effective discipline. Other parents were very clear in stating that the shelter could help by providing parent support groups or therapy beyond what the shelter already offers. Lastly, a few parents stated that the shelter could not help them at all. This finding is congruent with the work of Maslow, implying that the most basic needs must be satisfied before other needs can be addressed (Maslow, 1943). This finding 
also overlaps with the findings associated with the second research question, i.e., these parent participants were clear about wanting to make their own decisions about parenting.

\section{Theoretical Links: The Social-ecological Model of Prevention}

The findings that emerged from this study of homeless parents and their views on and experiences of CP are consistent with the Social-ecological Model of Prevention (SEM). The data analysis showed that the factors that influence and precipitate the hitting of children do not exist in isolation but are interrelated. For example, these research findings illustrated how certain aspects of a parent's personal history, and their attitudes and beliefs about CP (individual) merge with what they learned from their family of origin, partner or friends (relationships); school and religious leaders (community); social norms and laws (society) to create their overall perspectives about hitting children.

\section{Individual}

For each of the participants in this study, individual social characteristics influenced their beliefs about hitting children, including what they defined as hitting, how they differentiated CP from physical abuse, and when and why it is appropriate to hit a child. These characteristics also include past history of abuse, participant level of education, and income level. Each of the study participants had a history of various types of abuse, including physical abuse. This abuse varied in terms of type and degree of severity among participants. It is notable that a personal history of being the victim of physical abuse as a child increases the likelihood that a parent will then use CP to discipline their child, particularly if the parent experienced multiple types of maltreatment as a child (Bartlett, Kotake, Fauth \& Easterbrooks, 2017). This was borne out in the findings of this research study, in fact, the more severely a participant was abused, the more likely he or 
she was to endorse hitting children as discipline. These specific participants also had a greater tolerance for more frequent and severe hitting.

Likewise, a low level of education increases the likelihood that a parent would be unaware of a child's developmental stages and needs, leading to parental frustration and increasing the probability of hitting the child (Berlin et al., 2009). A finding in this study included frequent mention of parental frustration as being a primary precursor to hitting a child for things like "not listening," "ignoring" the parent, or being disobedient. A low income, reported by all study participants, is also an individual risk factor harsh parenting and child maltreatment, due to the stress that financial insecurity causes (Berlin et al., 2009; Rodriguez-JenKins \& Marcenko, 2014). Many participants in this study did state that stress can lead to the use of $\mathrm{CP}$; this construct also overlapped with parental frustration.

\section{Relationships}

The second level of the SEM addresses close interpersonal relationships that may influence the risk for being the victim or perpetrator of violence. An individual's family members, partner, friends and peers' attitudes and beliefs about hitting children shape their own beliefs about the acceptability of and reasons for hitting children. This aspect of the SEM was woven throughout the entire study, with 13 of 18 participants discussing how family members, partners, and even complete strangers tell them when and why they should hit their children. Most of these participants spoke about extended family members encouraging them to spank, making statements such as, "a hard head makes a soft butt," as well as experiencing frequent pressure to hit their children so they would 
"behave" and be "respectful." The reverse was also true; some participants described instances in which they hit their children and a family member disagreed:

My mother, she told me not to hit my daughter. My oldest daughter. She told me not to hit her. And I turned around and told her lady, don't tell me what to do with my kids. And then after that it just went to a bigger argument because my sister thought I was talking back and this and that, and my sister want to fight me and my brother want to fight me. [13]

\section{Community}

The third level of the SEM encompasses the settings in which the child and family live, play, and work, such as neighborhoods, schools, workplaces and faith communities. These settings are where social relationships take place, where parents can receive support and help, and where the surroundings can impact the risk of becoming a perpetrator or victim of violence. The shelter is located in a high crime area which not only increases risk of becoming a victim of violence, but because it is not safe for parents to take their children outside, this potentially increases parental stress and isolation, therefore heightening risk of using $\mathrm{CP}$ to cope. Most of the participants stated that they were religious but did not attend services because of the cost to travel to their church. In terms of social support, most of the shelter residents relied on each other because of cost of travelling to visit friends and family and because the shelter had a strict curfew. The shelter does conduct parenting support groups, but they are poorly attended. During study interviews, when participants were asked to tell the researcher how they believed that the shelter staff and social service programs could best help them with their children, most were vague and non-specific when responding about wanting help to cope with parenting 
stress. However, several participants responded quickly, clearly and concretely that the best way they the shelter could help was to find them economic and housing opportunities.

\section{Society}

The fourth level of the SEM consists of cultural norms, policies, and laws about what type of violence is and is not acceptable. It also includes agencies and institutions that protect children from violence. This level of the SEM was threaded throughout the entirety of this study. For example, cultural norms were reflected in participant responses regarding the acceptability of $\mathrm{CP}$, and that hitting an adult is unacceptable. These attitudes reflect societal norms that IPV is unacceptable and hitting children is acceptable. Laws on the federal and state levels reflect this as well; it is legal in all 50 states to hit a child for "discipline" as long as no injury occurs. In Illinois, where this study took place, $\mathrm{CP}$ is legal, and parents can hit their children as long as there is no injury. Physical abuse is defined by law as when an adult caregiver "inflicts excessive corporal punishment" on a minor under the age of 18 years (State of Illinois, 2015). This definition is very vague and was even cited by some study participants who have had previous contact with the Illinois Department of Children and Family Services to bolster their argument that a NoHit policy in the shelter is unreasonable and spanking their child does not break the law.

$\mathrm{CP}$ is also legal in schools in 19 states in the United States (Gundersen Center for Effective Discipline, 2018a). It is noteworthy that as children, many participants experienced $\mathrm{CP}$ inflicted on them by teachers or principals, and felt more anger, powerlessness and fear than they recalled feeling when hit by a parent or caregiver. As 
noted in Chapter IV, these participants said they expected to be hit by their parents, but not by a teacher.

African American participants discussed the relationship between tradition and the use of $\mathrm{CP}$, as well as beliefs that hitting children will untimely keep them safe, especially with authority figures such as police. Many African American participants also lamented what they perceived as the loss of the "Big Mama" figure that they could rely on as children. They described "Big Mama" as a neighborhood matriarchal figure who was stern and strict and had tacit permission from all neighborhood parents to "whip" any neighborhood children as needed, to "keep them in line."

Lastly, participants were universally firm in their belief that hitting an intimate partner is taboo, but hitting a child is an expected, a normal part of raising a child. When the researcher asked participants what they thought about a law prohibiting children, similar to the Violence Against Women Act, most participants became angry at the prospect of "government interference" in their lives. Likewise, the No Hit policy at the shelter was a source of anger and frustration for most participants for a variety of reasons - they felt frustrated and cooped up, did not know what else to do, spanking was normal to them, and if they could not hit their children in the shelter, they would just do it outside.

\section{Strengths of the Study}

There were several strengths to this study. The qualitative method allowed for indepth answers to interview questions yielding rich data with many subtleties and complexities that could not have been obtained using a quantitative approach. The 
specificity of the population studied also adds to the literature; no studies exists that examine urban homeless parents' beliefs about CP. This study also appears to further support the need for trauma informed care, particularly for vulnerable populations such as homeless youth, adults and their children. As the literature review showed, and the findings of this study reinforced, significant personal histories of trauma and abuse are very common among homeless persons. The results of this study are also consistent with the body of literature that link adverse childhood experiences and toxic stress to youth and adult homelessness (Holloway \& Park, 2012; Keeshin \& Campbell, 2011; Roos, et al, 2013; Steele, et al, 2016; Tsai, Edens \& Rosenheck, 2011). Lastly, these findings further underscore the need for more research, and integration of these research findings into practice, education and policy to continue to develop ways to help traumatized persons recover and learn to stop the cycle of violence within their own family.

\section{Limitations of the Study}

There were several limitations to this study. First, the sample size was small; an increased sample size may have provided an even deeper understanding of the research questions. Another limitation was the relative homogeneity of the study participants in terms of demographics and histories of adverse childhood experiences. Finally, a potential limitation of this study involves potential researcher bias. Although every effort was made to minimize bias (see Chapter IV), it is possible that the researcher affected participant responses during face-to-face interviews, or researcher preconceptions affected the interpretation of data. 


\section{Implications for Research}

The results of this study form a foundation on which to build future studies. Because of the documented negative psychosocial effects of $\mathrm{CP}$, many of which the participants in this study experienced and discussed during their interviews, it is important to continue to conduct more research to learn effective ways to eliminate the use of $\mathrm{CP}$ and teach parents alternative methods of child discipline. Two broad areas are recommended for further research: (1) expanding the target population to include a larger, more diverse parent demographic; and (2) studying what types of educational modalities would be effective in reducing positive attitudes about CP.

This study's participants were similar in terms of race, age, socioeconomic status, cultural and religious beliefs, and all were homeless. As such, the findings of this research may not be applicable to study populations with different life experiences, cultural norms and beliefs. Further research is needed to explore similar research questions with a larger and more demographically diverse sample, and with study participants who have not suffered severe trauma, homelessness and community violence. In fact, a major finding of this study was the strong history of participant trauma, specifically, childhood experiences of severe beatings and concomitant psychological abuse. This finding supports the efforts to designate $\mathrm{CP}$ as an Adverse Childhood Experience (Afifi et al., 2017), as well as to continue research that demonstrates links between the hitting of children and negative health outcomes in adulthood.

Another major finding of this study was that parents do not define hitting in a way that aligns with the no-hit policy where they live. That is, these study participants did not consider a slap on the hand (tapping, popping) or one swat on the child's behind with an 
open hand (spanking) as hitting. Rather, these participants considered more than one hit anywhere on the body, a slap on the face and the use of an instrument (other than a belt) to be hitting. This comports with the research findings of others (Ipsa \& Halgunseth, 2004; Taylor, Hamvas \& Paris, 2011), and overlaps with both cultural and religious beliefs about the acceptability of and need for hitting children. Other research studies investigating the parental attitudes and beliefs about the use of CP may yield different results among a larger and more diverse sample, for example, among parents who do not cite cultural or religious beliefs as reasons they use CP. Additionally, when conducting this research, it is essential to ensure that the investigator and participant are defining $\mathrm{CP}$ in the same manner.

Future research should continue to focus on evaluating the effectiveness of educating parents about the harmful effects of $\mathrm{CP}$, teaching alternatives to $\mathrm{CP}$ that are based on the child's age and developmental level. Some research that has been done in this area is the Play Nicely multimedia interactive parent education program (Chavis et al., 2013; Scholer, Hudnut-Beumler \& Dietrich, 2010; Scholer, Hamilton, Johnson \& Scott, 2010). This program presents parents with simulated scenarios of child aggression and allows the parent to choose his/her response to the child's behavior. When parents choose the $\mathrm{CP}$ option, they are presented with a brief educational presentation regarding alternatives to CP. Several researchers have conducted randomized controlled trials to determine whether the Play Nicely educational program changes parents' attitudes and beliefs about the use of CP (Chavis et al., 2013; Scholer, Hudnut-Beumler \& Dietrich, 2010; Scholer, et al., 2010). In all three studies mentioned here, parents in the intervention group were less likely than the control group to use $\mathrm{CP}$ after they had been 
presented with education about alternatives to CP (Chavis et al., 2013; Scholer, HudnutBeumler et al., 2010; Scholer, et al., 2010). Other interventional research has been conducted to determine if education could change parents' beliefs about CP (Reich, Penner, Duncan, \& Auger, 2012). In this study, the intervention was educational baby books. These baby books teach parents of infants and toddlers alternatives to $\mathrm{CP}$. The findings of this research study found that mothers who read the baby books used CP less than the mothers in the control group. It would be useful to continue to conduct studies to determine if similar results are obtained using these educational interventions, studying varying parent groups, grandparents, child care workers, and ministers.

Study participants who most strongly endorsed CP shared their beliefs that their children belong to them therefore, it should be the right of parents to discipline their children in the way they believe is appropriate. These participants were most strongly opposed to any No-Hit rules and stated that they used CP outside the shelter, and used it appropriately, citing passages from the Bible to support their position. When devising educational strategies, it is essential to understand the religious beliefs that influence the parent or caregiver's decision to use CP. In this regard, the work of Perrin, Miller-Perrin \& Song (2017) is promising. These researchers measured the effectiveness of two interventions on conservative Christian participants' attitudes about spanking. One intervention involved the presentation of research findings regarding the ineffectiveness and potential harm of spanking ("Research"). The second intervention involved a presentation on updated, alternative interpretations of Scripture that are sometimes used to justify the use of CP ("Religion"). One group received the Research Only condition, one group received both the Research and Religion condition, and the third group was the 
Control group. Attitudes Toward Spanking (ATS) scores were measured before and after the intervention. Analysis of the data revealed that favorable attitudes toward spanking decreased compared to the control condition in both intervention conditions, but the attitudes were measured as even less favorable for the Research and Religion condition compared to the Research Only condition. These results are promising as they show that favorable attitudes regarding the use of $\mathrm{CP}$ can change with education. However, this study was conducted on college students attending a Christian university, on participants who are not yet parents. To follow up on this study's findings, this research could be replicated with parents, educators, pediatric health care providers and religious leaders to determine if this educational intervention is successful in changing attitudes about the use of $\mathrm{CP}$ among these groups.

\section{Implications for Education}

This study has identified areas of need for education regarding the use of CP. Each study participant cited family role modeling, cultural influences, religious teachings or all of these as the reason they believe it is appropriate to hit children. These influences drove how the participants define the hitting of children, whether the use of an object was acceptable and if so, what object, as well as who has permission to hit their child. Several participants conceded that CP was ineffective, and that their child or children eventually became desensitized to being hit. This underscores the need to teach parents non-violent, age and developmentally appropriate discipline strategies.

Several types of education are necessary to change beliefs about the acceptability of hitting children, as well as alternatives to $\mathrm{CP}$. To change cultural beliefs about the acceptability of CP, public education would be a start, such as the effort that was carried 
out in Sweden which preceded the legal ban on CP (Durrant \& Ensom, 2012). This would involve a universal, primary prevention approach aimed at changing the social norms regarding the acceptability of CP (Gershoff \& Bitensky, 2007). This endeavor would involve educating the public about the harmful effects of $\mathrm{CP}$, teaching specific alternatives to $\mathrm{CP}$, and highlighting prevention of common "trigger" situations such as prolonged infant crying or toddler tantrums. Similar approaches to public health education have been used successfully in the past, for example, the Ad Council's campaign regarding seatbelt use, the link between smoking and cancer (Gershoff \& Bitensky, 2007), and the Back to Sleep campaign to prevent Sudden Infant Death Syndrome. When the ban of CP went in to effect in Sweden in 1979, public education was carried out via advertisements on the sides on milk cartons (Durant \& Ensom 2012). Perhaps a similar strategy could be implemented in the United States.

On an individual level, the approach needs to be different. As shown in this study, some parents do not define all physical discipline as hitting. One reason that parent education regarding the use of CP may be ineffective is the lack of a universal definition of CP. This underscores the importance of devising educational strategies that are aimed at all forms of physical discipline, including what parents define as tapping, popping, spanking, as well as harsher forms of $\mathrm{CP}$. Considering this, it is essential that before devising any educational strategies regarding alternatives to $\mathrm{CP}$, a clear definition of $\mathrm{CP}$ is provided that aligns with audience beliefs about specific physical disciplinary strategies, and this definition is used when conducting research as well. One definition that is commonly used and is simple, clear and concrete is Straus' definition, used in this 
study. This definition clearly separates $\mathrm{CP}$ from abuse yet illustrates that causing pain to a child is intentional.

Taylor, Hamvas \& Paris (2011) conducted focus groups to study African American parents' perceptions about the use of $\mathrm{CP}$ and found that these parent participants were not likely to stop using CP simply by being taught alternative discipline techniques. These researchers concluded that it will be important to include extended family members as well as trusted leaders in the Black community, such as ministers, in order to speak to the family, community and perceived biblical support for the use of CP.

\section{Implications for Practice}

The findings of this research suggest that the parent participants used $\mathrm{CP}$ because they believed $\mathrm{CP}$ was acceptable and normal, a way to teach and show love, a necessary part of parenting, and because they did not know what else to do. Study participants had been hit themselves as children and this also led to beliefs that $\mathrm{CP}$ was normative; their religious and cultural beliefs influenced their beliefs as well. Some parent participants had unrealistic developmental expectations of their children, which caused them to feel frustrated or stressed, and led to the use of CP. Further, most of the participants had been very traumatized as children, thus affecting their coping mechanisms as adults. Based on these findings, recommendations for nursing (including nurse practitioners), mental health and medical practice are: 1) the use of anticipatory guidance at all well-child visits that addresses normal developmental behavior that may trigger parental frustration and teaches parents alternatives to $\mathrm{CP}$; 2) designation of all pediatric health care facilities, inpatient and outpatient, public or private as No Hit Zones; 3) continuation of work toward the implementation trauma-informed care in all practice settings. 
Chapter II reviewed the evidence demonstrating the harmful effects of CP. Evidence-based, clinical practice guidelines exist regarding primary prevention such as physical and psychosocial growth and development, injury prevention, and vaccine preventable illnesses. Primary prevention should include education at primary care visits to help parents have accurate development expectations for their child, to promote changes in attitudes and beliefs about and teach alternatives to CP. Anticipatory guidance is an integral part of the primary care visit but may be greatly restricted due to time constraints. Parent handouts, and office posters are one suggestion to augment parent education in this area.

The implementation of No-Hit zones in pediatric health care facilities would require program training for all personnel (Gundersen Health System, 2018b). These education materials focus on the prevention of hitting at the early signs of tension building and promoting nonviolent ways to work through conflict. An essential part of this would be to educate all pediatric health care providers about the harmful effects of CP. For example, Hornor et al. (2015) used a pre-and post-survey design before and after an educational intervention on the negative effects of $\mathrm{CP}$ to determine attitudes and beliefs regarding $\mathrm{CP}$ among pediatric health care providers $(\mathrm{n}=882)$. Most $(84.7 \%)$ study participants stated that the way their parents had disciplined them influenced their beliefs about CP. Before the educational intervention, approximately $40 \%$ of participants endorsed the use of CP; after the intervention, $29 \%$ endorsed the use of CP. This underscores the need for both education, and a broader investigation of the attitudes and beliefs regarding the of $\mathrm{CP}$ children among health care providers. 
Lastly, the results of this study underscore the importance of work toward the implementation trauma-informed care in all practice settings. Trauma informed care considers the pervasive nature of trauma and involves the recognition that experiences of trauma have long-lasting effects on individuals, even several generations after the original trauma occurred (Marsac et al., 2016). These effects differ from person to person, depending on the type and degree of trauma that was experienced, and what type of support system is in place to help the individual heal (Wingo et al., 2010). Addressing trauma should expand beyond just behavioral health systems and occur in all health care settings. This can be operationalized by obtaining a social history on children and adolescents, and an ACE score on the adult client.

\section{Implications for Policy}

The results of this study show that participants believed that it was morally wrong to hit an intimate partner, but acceptable, necessary, and even a sign of love to hit a child. Many study participants who endorsed CP cited passages from the Bible to support their position. They also received affirmation and support regarding the use of $\mathrm{CP}$ from family, friends, their cultural and religious group. Some mothers in the study stated that since they carried the child during pregnancy and gave birth to the child, it is her right to decide whether or not the child can be hit as punishment and by whom. All study participants, including fathers, strongly disagreed with any interference with their perceived right to hit their child, stating that they comply with the shelter's No-Hit policy as a condition of their stay, but do not agree with it. Since study participants stated that the use of CP is a parent's right, some explained during their interview that they waited until they were outside the shelter to use $\mathrm{CP}$, so shelter staff would be unaware. 
These participant perspectives have implications for the effectiveness of the shelter's No-Hit policy itself. Many parent participants expressed frustration at not knowing alternatives to CP. These findings suggest that the existence of the No-Hit policy without parental support is not effective. A possible next step would be reinstatement of a recent shelter program that involved parenting classes tied to parental on-site respite time. These parenting classes were well attended, as parents desired the respite time after class, and parents were open to discussing alternative methods of child discipline during these classes.

There is very little in the literature on $\mathrm{CP}$ as a human rights issue, and the literature that exists is published in mainly law journals (Bitensky, 1996; Bitensky, 1998; Bitensky, 1999; Bitensky, 2010; Dwyer, 2010; Freeman, 2010; Futterman, 2003). This is in contrast to the papers published on IPV framed by feminist theory; those papers were published in medical, social work, family therapy, psychology, and nursing journals. This may help to explain, at least partially, why law and public policy differs for adults and children. Public education is necessary to precede the social and policy change that is needed regarding the acceptability of hitting children. This is similar to the history of social change and legal reform surrounding women's rights and the eventual passage of the Violence Against Women Act (VAWA). A review of the literature revealed that much of the literature on IPV that used gender paradigm, feminist theory or human rights theoretical frameworks began in the late 1980s, increased in the 1990s, and VAWA was passed in 1994.

Currently, there are 53 countries across the world that have banned the $\mathrm{CP}$ of children in all settings (Global Initiative to End All Corporal Punishment of Children, 
2018). These countries are members of the United Nations and have both signed and ratified the United Nations' Convention on the Rights of the Child (CRC), which speaks directly to a child's right to protection to all forms of violence in Article 19 of that document. The United States is the only member of the United Nations that has signed but not ratified this treaty (United Nations Treaty Collection, 1989). In the United States, $\mathrm{CP}$ is legal in the home all 50 states, and in schools in 19 states (Gundersen Center for Effective Discipline, 2018a). Reforming state and federal laws regarding the use of CP have not been successful in the past (Douglas, 2009). This endeavor is most likely to be successful if it is carried out in smaller parts. Logistically, it is most realistic for legal reform to first take place at the state level. A ban on CP in schools may be a good place to start. Currently, it is legal for school personnel to hit children at school in 19 states in the United States (Gundersen Center for Effective Discipline, 2018a).

In 1979, Sweden passed the first national legislation banning CP by parents (Durrant \& Ensom, 2012). It is important to note that this legislation is part of the civil, not the criminal code; thus, there is no criminal penalty for using CP. The ban was enacted primarily on the basis of moral principles, before any body of research existed to document the harmful effects of CP. Further, this legislative action was carried out to set a national standard for the humane treatment of children, provide funding for public education regarding CP and its alternatives (Durrant \& Ensom, 2012). This is an example of the approach of banning $\mathrm{CP}$ first and expecting the behaviors to follow; this approach was used with no-smoking laws in the United States (Bitensky, 2006). Lastly, an international human rights approach could be used, with pressure placed on elected officials to ratify the CRC. 


\section{Conclusion}

The goal of this study was to explore the attitudes and beliefs held by homeless parents regarding the use of $\mathrm{CP}$ as a method of child discipline. The eighteen homeless parents who participated in this study all agreed that $\mathrm{CP}$, when defined as tapping, popping or spanking, is appropriate and necessary, and a way to teach, discipline and to show love and caring. Study participants clearly defined the difference between CP and whipping, and not all agreed that it is appropriate to whip a child. Participants' beliefs were strongly influenced by their own childhood experiences of being hit by various adults in their lives, as well as by their immediate family members' beliefs, religious teachings, their sub-culture and the larger, parent culture. The majority indicated considerable opposition to any rules, policies or laws regarding the restriction of the use of CP.

The results of this study also suggest that intergenerational transmission family violence in the form of CP had a significant impact on participants' attitudes and beliefs about hitting children. The participants' words in this study showed how for many, the emotional and mental aftermath of being hit by adults they loved and trusted continues to cause them mental pain even decades later. For some of these same participants, the results of this study strongly suggest that these experiences have also resulted in a desensitization to violence. Lastly, the study results may indicate that for parents living in extreme poverty and homelessness, matters related to survival such as earning a living and having a place to live supersede their desire to learn new ways of parenting. 


\section{APPENDIX A \\ DEMOGRAPHIC QUESTIONNAIRE}

ID\#:

1. What is your gender?
a. female
b. male
c. transgender/other
d. prefer not to identify

2. How long have you been homeless (including doubling up with friends or relatives)? (Please put the answer in years and months below)

3. How old are you in years? (Write age below)

4. What is your marital status?
a. Never married
b. Married
c. Divorced
d. Live together with boyfriend/girlfriend or parent of my child/children

5. What is your race/ethnicity?
a. Asian or Pacific Islander
b. Black/African American
c. Hispanic/Latino
d. American Indian/Native American
e. White/Caucasian
f. Other (write in here)

6. What is the highest degree or level of school you have completed?
a. Some high school, no diploma
b. High school graduate, diploma or the equivalent (for example: GED)
c. Some college credit, no degree
d. Trade/technical/vocational training
e. Associate degree
f. Bachelor's degree
g. Master's degree
h. Doctorate degree 
7. Have you ever served in any branch of the United States military?
a. Yes
b. No

8. If yes, were you deployed for active duty?
a. Yes
b. No

9. If yes, for how long (in months)?

10. What was your total household income last year after taxes? In the space below, write the amount.

11. Who lives with you at the shelter? Include your partner if you are legally married, and all your children under the age of 21 .

12. What languages are spoken in your family? (Mark all that apply)
a. English
b. Spanish
c. Arabic
d. Farsi
e. Other

13. Do you practice any religion?
a. Yes
b. No

If yes, which religion?

14. How strong is your religious faith (Circle answer choice).
a. Very strong 

b. Somewhat strong
c. Not very strong
d. Neither strong nor weak
e. Weak
f. Somewhat weak
g. Very weak

15. How many children do you have under the age of 12 years old that currently live in the shelter with you?

16. Please list the ages and sex [boy or girl] of your child/children below. Use extra space if needed:

Age

1.

2.

3.

4.

5.

6.

7.

8.
Sex (Gender)

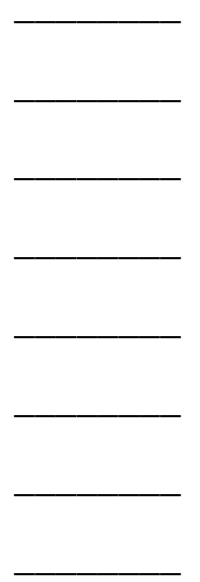




\section{APPENDIX B \\ INTERVIEW QUESTIONS}

1. There's lots of ways that kids are disciplined or punished or corrected when they misbehave. When you think about disciplining kids, what do you think about?

- What are ways that people discipline kids?

- What does the word spanking mean to you?

2. Now I'd like to ask you about your life. I'd like you to think back to when you were a child. Can you tell me about your own experiences with being disciplined (or punished or corrected when you misbehaved) when you were a child, and what that was like for you?

Potential prompts:

- How were you disciplined? Who disciplined you? (Parent, stepparent, grandparent, other family member, teacher, principal, etc.)

- Were you ever spanked (or hit with belt, switch, paddle, ruler or another object)? If so, by who?

- Were you spanked, paddled or otherwise physically punished by school teachers/authorities?

- Did you see other children being disciplined?

- How did you feel about how you were disciplined as a child? When you look back on it now, how do you feel about it?

3. Were you spanked (whupped)? How did you feel about that?

Potential prompts:

- Why do you think people spank kids?

- Should there be an age limit for spanking? (Upper and lower?) Why or why not?

- What do you think works to discipline kids? What doesn't work?

- How do you feel when you see other people spanking their kids?

- What has influenced your own beliefs about child discipline and punishment?

4. Now that you are a parent yourself, can you tell me more about your beliefs and feelings about disciplining kids?

5. What does your family say about spanking kids or teaching them to mind or behave? 
6. How do your religious beliefs guide how you raise your children? What do your religious teachings say about getting your child to mind/behave? What do the people at church say?

7. How do you think violence between two adults in a family compares to hitting or smacking kids in the family?

8. Now let's talk about ways to the kind of help and support homeless parents and kids need to help with child discipline. When you look around the shelter at families, what kind of help do you think they need?

Potential probes:

- Are you happy with how things are going with your own kids? Do you have the information or help you need to discipline your kids?

- How has being homeless or the stresses in your life changed you as a parent? Has it changed how you discipline your kids?

- What makes it easier or harder to discipline your kids the way you want to?

- If you had a magic wand and could do anything in the world to support homeless parents in disciplining their kids, what would you do?

9. What do you think about the no-hit rules at this shelter? Do they work? Why or why not?

10. Should spanking children be a personal decision? Why or why not?

We are almost done! Is there anything I should have asked you that I didn't ask about? Is there anything else that you would like to tell me, or ask me? 


\section{APPENDIX C \\ RECRUITMENT FLYER AND SCRIPT \\ PARTICIPANTS NEEDED FOR RESEARCH STUDY ON PARENTING}

We are looking for volunteers to take part in a study of what parents think about spanking and the no-hit rules here at the shelter

As a participant in this study, you would be asked to fill out a brief questionnaire and answer some questions in an interview

Your participation would involve meeting once for about 30-60 minutes.

To thank you for your time, you will receive a

Target gift card in the amount of 10 dollars

For more information about this study, or to volunteer for this study, please contact:

Ellen Chiocca

School of Nursing at University of Missouri

at

(224-258-4193)

Email: emcmt9@mail.missouri.edu

The study has been reviewed and approved by the University of Missouri School of Nursing

Office of Research Ethics Review Board (Institutional Review Board)

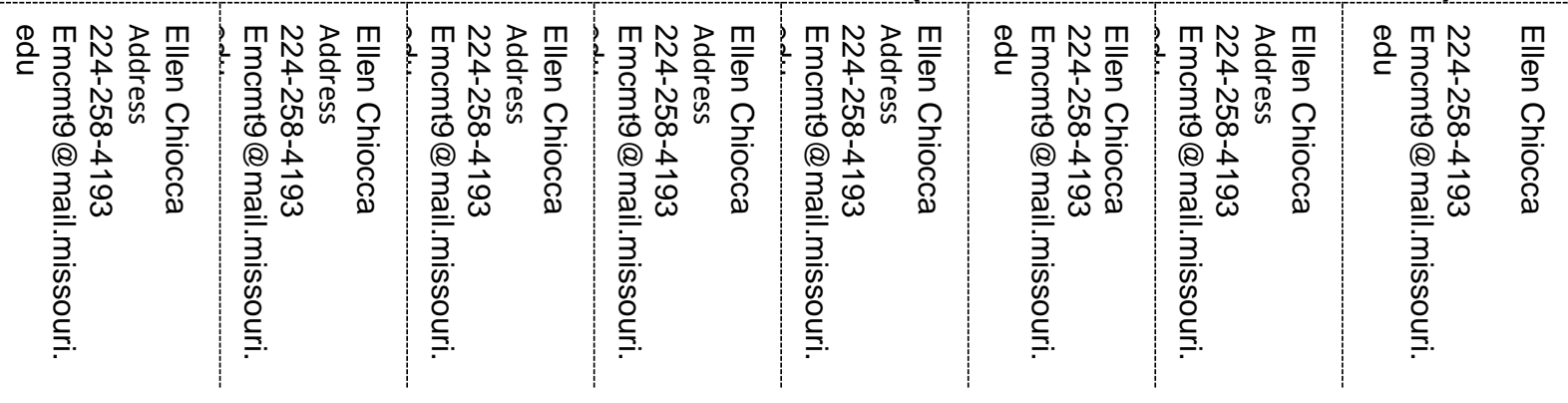




\section{Recruitment Script}

Hello, my name is Ellen Chiocca. I am a graduate student at the University of Missouri in the School of Nursing. I am conducting research on what homeless parents think about spanking kids, and what they think about the no-hit rules at the shelter. I am inviting you to participate because you live here at the shelter.

If you agree, participation in this research includes filling out a survey about how old you are, how many kids you have, who all lives with you, etc. This should take about 5 to 10 minutes. Then, I will interview you for about 30-50 minutes to ask you about your opinions regarding spanking kids, whether you think it works or not, and what you think about the No Hit rules at the shelter. Your total time commitment will be between $30-60$ minutes.

We will be able to conduct the interview at the shelter in a private area, at a time that is convenient for you. All the information collected from you is confidential. That means your name or other identifying features will not be used in any analysis or in any reporting of the research. Your participation in this research is voluntary. You may choose not to participate, to quit at any time during the interview, to not answer certain questions, or to contact me if you change your mind about participating. You may choose how much or how little you will participate without consequences or penalty.

To compensate you for your time, you will receive a Target gift card in the amount of 10 dollars.

If you have any questions or would like to participate in the research, I can be reached at 224-258-4193 or emcmt9@mail.missouri.edu.

Thank you

Ellen Chiocca 


\section{APPENDIX D \\ CONSENT FORM}

\section{Researcher's Name: Ellen Chiocca}

Project Number: 2010371

Project Title: Attitudes and Beliefs about Corporal Punishment among Inner City Homeless Parents: A Qualitative Narrative Study

\section{INTRODUCTION}

This consent may have words that you do not understand. Please ask me (the researcher) to explain any words or anything that you do not clearly understand.

You are being asked to be a part of a study about what homeless parents think about spanking. Please read this form carefully and ask any questions you may have before saying yes to letting me interview you for the study.

\section{WHY IS THIS STUDY BEING DONE?}

The purpose of this research is to help to learn about what homeless parents think about raising kids and if spanking should be a part of raising kids

WHO CAN BE IN THE STUDY? You must be at least 18 years old and have at least one child, age 1 to 12 years.

\section{HOW MANY PEOPLE WILL BE IN THE STUDY?}

About 30 people will take part in this study,

\section{WHAT AM I BEING ASKED TO DO?}

If you agree to be in this study, I will ask you to fill out a paper form with a few questions about you, such as how old are, and how many children you have. Then if you say yes, I will also ask you face-to-face questions. These questions will be about what you think about how kids should be raised, how you were raised, and what you think about the nohit rules at the shelter. I will also ask you what you think about spanking and what you think would help parents to raise their kids. This will take about 30 to 60 minutes to finish. If you say yes, I would also like to audiotape-record the interview.

Special Note: I only want to ask you about what you think about spanking and what you think is the right thing to do when raising kids. I will not directly ask you about whether you spank your own kids. Because I am a nurse, the law in Illinois says that if anything comes up in the interview that tells me that child abuse or neglect happens in the family, the law says that I have to tell the Illinois Department of Child and Family Services (DCFS) as soon as possible. Examples of when I would have to do this is if you tell me that you or your partner hit your child until he or she gets bruised or hurt in any other way; your child(ren) is (are) being touched inappropriately by anyone in the family or close to the family, or is having 
food, medical care or other necessary things kept from him or her on purpose. This report will not be made behind your back, and there is help for you through the shelter and DCFS. HOW LONG WILL I BE IN THE STUDY?

This study will be done in one part on the same day, for about 30 to 60 minutes. I will come to the shelter to talk to you. You can stop being in the study at any time without penalty.

\section{WHAT ARE THE BENEFITS OF BEING IN THE STUDY?}

There are no benefits to you other than learning more about yourself. Parenting is a hard job and I hope to learn more about ways to help parents and kids. Your participation will benefit other parents through what I learn in this study.

\section{WHAT ARE THE RISKS OF BEING IN THE STUDY?}

There is the risk that you may find some of these questions to be sensitive.

WHAT ARE THE COSTS OF BEING IN THE STUDY? There is no cost to you. CONFIDENTIALITY (PRIVACY)

All information from the study will be kept private. Your question and interview answers will be kept in a locked file and you will be identified by a code number, not your name. The code number will be kept in a separate, secure location and only I will have the key. The audio tape of the interview will have no identifying information about you, and I will destroy the tape after I write the interview down, which will be within two to three months after the interview taping. In any writing about this study, I will make sure that it will not be possible to identify you. I will do this by making sure that if you accidentally say anyone's name (including yours) during the interview that I audio tape, I will make sure that I take any and all names out of the interview when I write them down.

COMPENSATION: If you agree to be interviewed for this study, you will receive a Target gift card for 10 dollars after we finish the interview.

Taking part is voluntary: Being in this study is completely voluntary. You may skip any questions that you do not want to answer. If you decide to be in the study, you are free to stop at any time, for any reason.

If you have questions: The name of the researcher conducting this study is Ellen Chiocca. Please ask any questions you have now. If you have questions later, you may contact Ellen Chiocca at emcmt9@mail.missouri.edu or at 1-224- 258-4193. If you have any questions or concerns regarding your rights as a subject in this study, you may contact the University of Missouri Institutional Review Board (IRB) at 573-882-3181.

You will be given a copy of this form to keep for your records. 


\section{APPENDIX E \\ ILLINOIS STATE STATUTE 705 ILCS 405/2-3}

Illinois state law requires that all mandated reporters report suspected child neglect or abuse.

Definition:

"Child abuse is the mistreatment of a child under the age of 18 by:

- A parent or their romantic partner;

- An immediate relative or someone living in their home;

- A caretaker such as a babysitter or daycare worker; or

- Any person responsible for the child's welfare, such as a health care provider, educator, coach or youth program volunteer.

The mistreatment can either result in injury or put the child at serious risk of injury. Child abuse can be physical (i.e. bruises or broken bones), sexual (i.e. fondling or incest), or mental (emotional injury or psychological illness).

Neglect is the failure of a parent or caretaker to meet "minimal parenting" standards for providing adequate supervision, food, clothing, medical care, shelter or other basic needs.” (Smith, Cohen, Lynn \& Peterson, 2015). 


\section{REFERENCES}

Abelow, B. J. (2011). The shaping of New Testament narrative and salvation teachings by painful childhood experience. Archive for the Psychology of Religion, 33 (1), $1-54$.

Afifi, T. O., Brownridge, D. A., Cox, B.J. \& Sareen. J. (2006). Physical punishment, childhood abuse and psychiatric disorders. Child Abuse \& Neglect 30, 10931103. doi: $10.1016 /$ j.chiabu.2006.04.006

Afifi, T., Ford, D., Gershoff, E. T., Merrick, M. T., Grogan-Kaylor, A.,\& Ports, K.A...Peters Bennett, R. (2017). Spanking and adult mental health impairment: The case for the designation of spanking as an adverse childhood experience. Child Abuse and Neglect, 71, 24-31. doi.org/10.1016/j.chiabu.2017.01.014

Anderson, S., and M. Payne. 1994. Corporal punishment in elementary education: Views of Barbadian school children. Child Abuse and Neglect 18, (4) 377-86.

Anney, V. N. (2014). Ensuring the quality of the findings of qualitative research: Looking at trustworthiness criteria. Journal of Emerging Trends in Educational Research and Policy Studies, 5, (2), 272-281.

Annoshian, L. (2005). Violence and aggression in the lives of homeless children: A review. Aggression and Violent Behavior, 10(2), 129-152. doi: 10.1016/j.avb.2003.10.004

Antoine, R. (2008). Commonwealth Caribbean: law and legal systems (2nd ed.). Oxon: Routledge-Cavendish. 
Arnold, E. \& Phil, M. (1982). The use of corporal punishment in child-rearing in the West Indies. Child Abuse and Neglect, 6, 141-145. doi: 10.1016/01452134(82)90006-0

Atieno, O. P (2009). An analysis of the strengths and limitation of qualitative and quantitative research paradigms. Problems of Education in the $21^{\text {st }}$ Century, 13, 13-18.

Bailey, C., Robinson, T. \& Coore-Desai, C. (2014). Corporal punishment in the Caribbean: Attitudes and practices. Social and Economic Studies, 63 (3), 207-233.

Bandura, A. (1977). Social Learning Theory. Englewood Cliffs, NJ: Prentice Hall.

Baptiste, D.A., Hardy, K.V., \& Lewis, L. (1997). Clinical practice with Caribbean immigrant families in the United States: The intersection of emigration, immigration, culture and race (pp. 275-303). In: Rooparine, J. L. \& Brown, J. (Eds.). Caribbean families: Diversity among ethnic groups. Greenwich, CT: Ablex.

Bar, K.J., Wagner, G., Koschke, M., Boettger, S., Schlosser, R. \& Sauer, H. (2007). Increased prefrontal activation during pain perception in major depression. Biological Psychiatry, 62 (11), 1281-1287. doi: 10.1016/j.biopsych.2007.02.011

Bartlett, J. D., Kotake, D., Fauth, R. \& Easterbrooks, M. A. (2017). Intergenerational transmission of child abuse and neglect: Do maltreatment type, perpetrator, and substantiation status matter? Child Abuse \& Neglect, 63, 84-94 doi: 10.1016/j.chiabu.2016.11.021 
Bassuk, E. L. \& Beardslee, W.R. (2014). Depression in homeless mothers: Addressing an unrecognized public health issue. American Journal of Orthopsychiatry, 84 (1), 73-81. doi: 10.1037/h0098949

Baumrind, D. (1996a). A blanket injunction against disciplinary use of spanking is not warranted by the data. Pediatrics, 98(4), 828-831. PMID: 8885981

Baumrind, D. (1996b). The discipline controversy revisited. Family Relations, 45(4), 405-415. doi: $10.2307 / 585170$

Baumrind, D. (1997). Necessary distinctions. Psychological Inquiry, 8(3), 176-182. doi: 10.1207/s15327965pli0803_2

Bell, T. \& Romano, E. (2012). Opinions about child corporal punishment and influencing factors. Journal of Interpersonal Violence, 27, 2208-2229. doi: $10.1177 / 0886260511432154$

Berger, R. (2015). Now I see it, now I don't: Researcher's position and reflexivity in qualitative research. Qualitative Research, 15, 219-234 doi:

$10.1177 / 1468794112468475$

Berlin, L. J., Ispa, J. M., Fine, M. A., Malone, P. S., Brooks-Gunn, J., Brady-Smith, C., ...Bai, Y. (2009). Correlates and consequences of spanking and verbal punishment for low-income White, African American, and Mexican American toddlers. Child Development, 80(5): 1403-1420. doi:10.1111/j.14678624.2009.01341.x. 
Birt, L., Scott, S., Cavers, D., Campbell, C. \& Walter, F. (2016). Member checking: A tool to enhance trustworthiness or merely a nod to validation? Qualitative Health Research, 26 (13) 1802- 1811. doi: 10.1177/1049732316654870

Bitensky, S. H. (1996). We had a dream in Brown v. Board of Education. Michigan State University College of Law, Law Review, 1, 1-16.

Bitensky, S. H. (1998). The child's right to humane discipline under the U.N. Convention on the Rights of the Child: The mandate against all corporal punishment of children. Loyola Poverty Law Journal, 4, 47-53.

Bitensky, S. H. (1999). Spare the rod, embrace human rights: International law's mandate against all corporal punishment of children, Whittier Law Review, 21, 147-161

Bitensky, S. H. (2006). Corporal punishment of children: A human rights violation. Ardsley, NY: Transnational Publishers.

Bitensky, S. H. (2010). The mother of all human rights: The child's right to be free of corporal punishment as hard international law. Ohio Northern University Law Review, 36, 701-720.

Bradley, C. R. (1998). Child rearing in African American families: A study of the disciplinary practices of African American parents. Journal of Multicultural Counseling and Development, 26, 273-281. doi: 10.1002/j.21611912.1998.tb00204.x

Bradley, C. McGowan, J. \& Michelson, D. (2017). How does homelessness affect parenting behaviour? A systematic critical review and thematic synthesis of 
qualitative research. Clinical Child and Family Psychology Review, 1-15. doi: $10.1007 / \mathrm{s} 10567-017-0244-3$

Braun, V. \& Clarke, V. (2006). Using thematic analysis in psychology. Qualitative Research in Psychology, 3 (2), 77-101. doi: 10.1191/1478088706qp063oa

Brod, M., Tesler, L. E., \& Christiansen, T. L. (2009). Qualitative research and content validity: Developing best practices based on science and experience. Quality of Life Research, 18 (9), 1263-1278. doi:10.1007/s11136-009-9540-9

Buckner, J. C. (2008). Understanding the impact of homelessness on children: Challenges and future research directions. American Behavioral Scientist, 51 (6), 721-736. doi: 10.1177/0002764207311984

Buckner, J. C. Bassuk, E. L., Weinreb, L. F., \& Brooks, M. G. (1999). Homelessness and its relation to the mental mealth and behavior of low-income school-age children. Developmental Psychology, 35, (1), 246-257. PMID: 9923479

Burchinal, M., Skinner, D. \& Reznick, J. S. (2010). European American and African American mothers' beliefs about parenting and disciplining infants: A mixedmethod analysis. Parenting Science and Practice, 10, 79-96. doi: $10.1080 / 15295190903212604$

Burke, T \& Sutherland, O. (2014). The meanings Jamaicans associate with corporal punishment. Psychology and Developing Societies 26, 59-89 doi: $10.1177 / 0971333613516229$ 
Caribbean Development Research Services (2009). Corproal punishement and other major educational issues in Barbados. Retrieved from: https://www.unicef.org/easterncaribbean/2009_Final_Barbados_National_Survey _on_Corporal_Punishment_and_Educational_Issues_Report.pdf

Casey, D. \& Murphy, K. (2009). Issues in using methodological triangulation in research. Nurse Researcher, 16 (4) 40-55. doi: 10.7748/nr2009.07.16.4.40.c7160

Centers for Disease Control and Prevention National Center for Injury Prevention and Control, Division of Violence Prevention (2015). The Social-Ecological Model: A Framework for Prevention. Retrieved from: https://www.cdc.gov/violenceprevention/overview/social-ecologicalmodel.html

Centers for Disease Control and Prevention National Center for Injury Prevention and Control, Division of Violence Prevention (2016). Adverse Childhood Experiences (ACEs). Retrieved from:

https://www.cdc.gov/violenceprevention/acestudy/index.html

Chamberlain, C. \& Johnson, G. (2011). Pathways into adult homelessness. Journal of Sociology, 49 (1), 1-18. doi: 10.1177/1440783311422458

Chang, L., Schwartz, D., Dodge, K. A. \& Chang, C. M. (2003). Harsh parenting in relation to child emotion regulation and aggression. Journal of Family Psychology, 17 (4), 598-606. doi: 10.1037/0893-3200.17.4.598

Chavis, A., Hudnut-Beumler, J., Webb, M. W., Neely, J. A., Bickman, L., Dietrich M. S. \& Scholer, S. J. (2013). A brief intervention affects parents' attitudes toward 
using less physical punishment. Child Abuse \& Neglect, 37, 1192-1201, doi 10.1016/j.chiabu.2013.06.003

Child Trends (2015). Attitudes toward spanking. Retrieved from: http://www.childtrends.org/wpcontent/uploads/2012/10/51_Attitudes_Toward_Spanking.pdf

Chiocca, E. M. (2017). American parents' attitudes and beliefs about corporal punishment: An integrative literature review. Journal of Pediatric Health Care, 3, 372-383. doi: 10.1016/j.pedhc.2017.01.002

Combs-Orme, T. \& Cain, D. S. (2008). Predictors of mothers' use of spanking with their infants. Child Abuse and Neglect, 32, 649-657. doi: 10.1016/j.chiabu.2007.08.006

Cope, D. G. (2014). Methods and meanings: Credibility and trustworthiness of qualitative research. Oncology Nursing Forum, 41 (1) 89-91. doi: 10.1188/14.ONF.89-91.

Creswell, J. W. (2015). A concise introduction to mixed methods research. Thousand Oaks, CA: Sage Publications.

Creswell, J. W. (2002). Educational research: Planning, conducting, and evaluating quantitative and qualitative approaches to research. Upper Saddle River, NJ: Merrill/Pearson Education.

Creswell, J. W. \& Creswell, J. D. (2018). Research design: Qualitative, quantitative, and mixed methods approaches ( $5^{\text {th }}$ ed.). Thousand Oaks, CA: Sage Publications.

Creswell, J. W. \& Miller, D. L. (2000). Determining validity in qualitative inquiry. Theory Into Practice, 39 (3), 124-130. doi: 10.1207/s15430421tip3903_2 
Crockford, D.N., Goodyear, B., Edwards, J., Quickfall, J. \& el-Guebaly, N. (2005). Cueinduced brain activity in pathological gamblers, Biological Psychiatry, 58, 787795. doi: 10.1016/j.biopsych.2005.04.037

Crouch, J. L. \& Bell, L. E. (2001). Relationships among parental beliefs in corporal punishment, reported stress, and physical child abuse potential. Child Abuse \& Neglect, 25, 413-419. doi: 10.1016/S0145-2134(00)00256-8

Cuddy, E. \& Reeves, R. V. (2014). Hitting kids: American parenting and physical punishment. Retrieved from: https://www.brookings.edu/research/hitting-kidsamerican-parenting-and-physical-punishment/

David, D. H., Gelberg, L. \& Suchman, N. E. (2012). Implications of homelessness for parenting young children: A preliminary review from a developmental prespective. Infant Mental Health Journal, 33, 1-9. http://doi.org/10.1002/imhj.20333

Davis, P.W., Chandler, J. L., \& LaRossa, R. (2004). "I've tried the switch but he laughs through the tears:" The use and conceptualization of corporal punishment during the Machine Age, 1924-1939. Child Abuse and Neglect, 28, 1291-1310. doi:10.1016/j.chiabu.2004.06.011

Deater-Deckard, K. Dodge, K., Bates, J. \& Petit, G. (1996). Physical discipline among African-American and European American mothers: Links to children's externalizing behaviors. Developmental Psychology, 32, 1065-1072. doi:10.1037/0012-1649.32.6.1065 
Deater-Deckard, K., Lansford, J., Dodge, K.A., Petit, G.S. \& Bates, J.E. (2003). The development of attitudes about physical punishment: An 8-year longitudinal study. Journal of Family Psychology. 17, 351-360. doi: 10.1037/08933200.17.3.351

Denby, R. \& Alford, K. (1996). Understanding African American discipline styles: suggestions for effective social work, Journal of multicultural social work, 4 (3), 81-98. doi:10.1300/J285v04n03_06.

Dietz, T.L. (2000). Disciplining children: characteristics associated with the use of corporal punishment. Child Abuse and Neglect, 24 (12), 1529-1542.doi: $10.1016 / \mathrm{S} 0145-2134(00) 00213-1$

Dobson, J. (2014). The new strong willed child, Reissue edition. Carol Stream, IL: Tyndale House.

Dobson, J. (1992). The new dare to discipline. Wheaton, IL: Living Books/Tyndale House.

Douglas, E. M. (2009). Corporal punishment and the case for policy action. Bridgewater Review, 28(1), 11-14.

Drexler, K., Schweitzer, J.B., Quinn, C. K., Gross, R., Ely, T. D., Muhammad, F., \& Kilts, C.D. (2000). Neural activity related to anger in cocaine-dependent men: a possible link to violence and relapse. American Journal of Addiction, 9, 331-339. doi :10.1080/105504900750047382/ 
Dubowitz, H. (2014). The Safe Environment for Every Kid model: promotion of children's health, development, and safety, and prevention of child neglect. Pediatric annals, 43, e271-7. doi: 10.3928/00904481-20141022-11.

Durrant, J. \& Ensom, R. (2012). Physical punishment of children: Lessons from 20 years of research. Canadian Medical Association Journal, 184, 1373-1377. doi: 10.1503/cmaj.101314

Dwyer, J. G. (2010). Parental entitlement and corporal punishment. Law and Contemporary Problems, 73, 189-210.

Ellison, C. G., Bartkowski, J. P., \& Segal, M.L.(1996a). Conservative Protestantism and the parental use of corporal punishment. Social Forces, 74, 1003-1028. doi: $10.1093 / \mathrm{sf} / 74.3 .1003$

Ellison, C.G., Bartkowski, J.P. \& Segal, M.L. (1996b). Do conservative Protestant parents spank more often? Further evidence from the national survey of families and households. Social Science Quarterly, 77, 663-673. Retrieved from http://www.jstor.org/stable/42863508

Ellison, C. G. \& Bradshaw, M. (2009). Religious beliefs, sociopolitical ideology, and attitudes toward corporal punishment. Journal of Family Issues, 30 (3), 320-340. doi: 10.1177/0192513X08326331

Ellison, C. G., Musick, M.A., \& Holden, G. W. (2011). Does conservative Protestantism moderate the association between corporal punishment and child outcomes? Journal of Marriage and Family, 73, 946 - 961 doi: 10.1111/j.17413737.2011.00854.x 
Ellison, C. G., \& Sherkat, D. E. (1993). Conservative Protestantism and support for corporal punishment. American Sociological Review, 58, 131-144. Retrieved from http://www.jstor.org/stable/2096222

Erkman, F. \& Rohner, R.P. ( 2006). Youths' perception of corporal punishment, parental acceptance, and psychological adjustment in a Turkish metropolis. Cross-Cultural Research, 40 (3), 250-286. doi: 10.1177/1069397106287924

Fantuzzo, J.W., LeBoeuf, W. A., Chen, C. C., Rouse, H. L., \& Culhane, D. P. (2012). The unique and combined effects of homelessness and school mobility on the educational outcomes of young children. Educational Researcher, 41 (9), 393-402 doi: 10.3102/0013189X12468210

Fitzgerald, P.B., Laird, A. R., Maller, J., \& Daskalakis, Z. J. (2008). A meta-analytic study of changes in brain activation in depression. Human Brain Mapping, 29, 683-695. doi: 10.1002/hbm.20426

Fontes, L.A., ( 2002). Child discipline and physical abuse in immigrant Latino families: Reducing violence and misunderstanding. Journal of Counseling and Development, 80 (1), 31-40. doi: 10.1002/j.1556-6678.2002.tb00163.x

Frazier, E.R., Liu, G.C. \& Dauk, K.L. (2014). Creating a safe place for pediatric care: A No Hit Zone. Hospital Pediatrics 4, 247-50. doi: 10.1542/hpeds.2013-0106.

Freeman, M. (2010). Upholding the dignity and best interests of children: International law and the corporal punishment of children. Law and Contemporary Problems, 73, 211-251. 
Frias-Armenta, M. \& McCloskey, L. A. (1998). Determinants of harsh parenting in Mexico. Journal of Abnormal Child Psychology, 26 (2), 129-139 doi: 10.1023/A:102262192

Friedman, D. H. (2000). Parenting in public: Family shelter and public assistance. New York, NY: Columbia University Press.

Friedson, M. (2016). Authoritarian parenting attitudes and social origin: The multigenerational relationship of socioeconomic position to childrearing values. Child Abuse \& Neglect (51), 263-275. doi: 10.1016/j.chiabu.2015.10.001

Futterman, M. (2003). Seeking a standard: Reconciling child abuse and condoned childrearing practices among different cultures. Inter-American Law Review, 34 (3), 491-514. Retrieved from http://www.jstor.org/stable/40176547

Garbarino, J. (1977). The human ecology of child maltreatment: A conceptual model for research. Journal ofMarriage and the Family, 39, 721 - 735.

Gardner Meeks, J.M., Powell, C.A., \& Grantham-McGregor, S.M. (2007). Determinants of aggressive and prosocial behavior among Jamaican schoolboys. Indian Medical Journal, 56 (1), 34-41. doi: 10.1590/S0043-31442007000100007

Gbrich, C. (2013). Qualitative Data Analysis: An Introduction (2nd Ed). London: Sage Publications.

Gershoff, E. T. (2002). Corporal punishment by parents and associated child behaviors and experiences: A meta-analytic and theoretical review. Psychological Bulletin, 128 (4), 539-579. doi: 10.1037//0033-2909.128.4.539 
Gershoff, E. T. (2010). More harm than good: A summary of scientific research on the intended and unintended effects of corporal punishment on children. Law and Contemporary Problems, 73, 33-58. Retrieved from:

http://www.jstor.org.proxy.mul.missouri.edu/stable/25766386

Gershoff, E. T. (2013). Spanking and child development: We know enough now to stop hitting our children. Child Development Perspectives, 7, 133-137. doi:10.1111/cdep.12038

Gershoff, E. T. \& Bitensky, S. H. (2007). The case against corporal punishment of children: converging evidence from social science research and international human rights law and implications for U.S. public policy. Psychology, Public Policy and Law, 13 (4), 231-272. doi: 10.1037/1076-8971.13.4.231

Gershoff, E.T. \& Font, S. A. (2016). Corporal punishment in U.S. public schools: Prevalence, disparities in use, and status in state and federal policy. Society for Research in Child Development Social Policy Report, 30(1), 1-26. Retrieved from: https://www.srcd.org/sites/default/files/documents/spr_30_1.pdf

Gershoff, E.T. \& Grogan-Kaylor, A. (2016). Spanking and child outcomes: Old controversies and new meta-analyses. Journal of Family Psychology, 30, 453-69. doi: 10.1037/fam0000191

Gershoff, E. T., Lansford, J. E., Zelli, A., Grogan-Kaylor, A., Chang, L., Deater-Deckard, K., \& Dodge, K. A. (2010). Parent discipline practices in an international sample: Associations with child behaviors and moderation by perceived normativeness. Child Development, 81 (2), 487-502. doi: 10.1111/j.1467-8624.2009.01409.x 
Gershoff, E. T., Miller, P. C. \& Holden, G.W. (1999). Parenting Influences from the pulpit: Religious affiliation as a determinant of parental corporal punishment. Journal of Family Psychology, 13 (3), 307-320. doi: 10.1037/0893-3200.13.3.307

Geuze. E., Westenberg, H.G., Jochims, A., de Kloet, C.S., Bohs, M., Vermetten, E. \& Schmal, C. (2007). Altered pain processing in veterans with post-traumatic stress disorder. Archives of General Psychiatry, 64, 76-85. doi: 10.1001/archpsyc.64.1.76

Giles-Sims, J. Straus, M. A. \& Sugarman, D. B. (1995). Child, maternal and family characteristics associated with spanking. Family Relations, 44, 170-176. doi: $10.2307 / 584804$

Global Initiative to End All Corporal Punishment of Children (2018). Progress. Retrieved from: https://endcorporalpunishment.org/countdown/

Grady, M.P. (1998). Qualitative and Action Research: A Practitioner Handbook. Bloomington: Phi Delta Kappa Educational Foundation.

Grant, R., Gracy, D., Goldsmith, G., Shapiro, A. \& Redlener, I.E. (2013). Twenty-five years of child and family homelessness: Where are we now? American Journal of Public Health, 103 (suppl 2), e1-e10. doi: 10.2105/AJPH.2013.301618

Green, H. D., Tucker, J.S., Wenzel, S. L., Golinelli, D., Kennedy, D. P., Ryan, G. W., \& Zhou, A. J. (2012). Association of childhood abuse with homeless women's social networks. Child Abuse \& Neglect, 36, 21-31. doi: 10.1016/j.chiabu.2011.07.005 
Greven, P. (1991). Spare the child: The religious roots of physical punishment and the psychological impact of physical abuse. New York: Knopf.

Grasmick, H.G., Bursik, R.J., \& Kimpel, M., (1991). Protestant fundamentalism and attitudes toward corporal punishment of children. Violence and Victims, 6, 283298. PMID: 1822698

Grasmick, H. G., Morgan, C. S., \& Kennedy, M. B. (1992). Support for corporal punishment in the schools: A comparison of the effects of socioeconomic status and religion. Social Science Quarterly, 73(1), 177-187.

Grogan-Kaylor, A. (2004). The effect of corporal punishment on anti-social behavior in children. Social Work Research, 28, 153-162. doi: 10.1093/swr/28.3.153

Grogan-Kaylor, A. (2005). Corporal punishment and the growth trajectory of children's antisocial behavior. Child Maltreatment, 10, 283-292. doi:

$10.1177 / 1077559505277803$

Grogan-Kaylor, A., \& Otis, M. D. (2007). The predictors of parental use of corporal punishment. Family Relations, 56, 80-91. doi: 10.1111/j.1741-3729.2007.00441.x

Gundersen Center for Effective Discipline (2018). Punishment vs. abuse. Retrieved from: http://www.gundersenhealth.org/ncptc/center-for-effective-discipline/disciplineand-the-law/punishment-vs-abuse/

Gundersen Center for Effective Discipline (2018a). Discipline at school. Retrieved from: http://www.gundersenhealth.org/ncptc/center-for-effective-discipline/disciplineat-school/ 
Gundersen Health System (2018b). No Hit Zones. Retrieved from:

http://www.thisisanohitzone.org/thisisanohitzone/implementation-tools/

Gunnoe, M.L. \& Mariner, C. L. (1997). Toward a developmental-contextual model of the effects of parental spanking on children's aggression. Archives of Pediatric and Adolescent Medicine, 151, 768-775.

Haber, M.G. \& Toro, P. A. (2004). Homelessness among families, children, and adolescents: An ecological-developmental perspective. Clinical Child and Family Psychology Review, 7, 123-164 doi: 10.1023/B:CCFP.0000045124.09503.

Hatch, J.A. (2002). Doing qualitative research in educational settings. Albany, NY: SUNY Press.

Hineline, P. N., \& Rosales-Ruiz, J. (2012). Behavior in relation to aversive events: Punishment and negative reinforcement. In G. J. Madden, W. V. Dube, T. Hackenberg, G. W. V. Dube, T. Hackenberg, G. Hanley, \& K. A. Lattal (Eds.), APA handbook of behavior analysis (pp. 483-512). Washington, DC: American Psychological Association.

Holden, G. W., Brown, A. S., Baldwin, A. S., \& Croft Caderao, K. (2014). Research findings can change attitudes about corporal punishment. Child Abuse and Neglect, 38(5), 902-908. doi:10.1016/j.chiabu.2013.10.013

Holloway, H. L. \& Park, J. (2012). Adverse Childhood Experiences (ACEs), service use, and service helpfulness among people experiencing homelessness. Families in Society: The Journal of Contemporary Social Services, 93(2), 85-93. doi: $10.1606 / 1044-3894.4192$ 
Hopper, E.K. Bassuk, E. L. \& Olivet, J. (2009). Shelter from the storm: Traumainformed care in homelessness services settings. The Open Health Services and Policy Journal, 2, 131-151.

Hornor, G., Bretl, D., Chapman, E., Chiocca, E., Donnell, C., Doughty, K., Houser, S., Marshall, B., Morris, K., \& Garcia Quinones, S. (2015). Corporal punishment: Evaluation of an intervention by PNPs. Journal of Pediatric Health Care, 29 (6), 526-535. DOI: 10.1016/j.pedhc.2015.04.016

Hou, C., Liu, J., Wang, K., Li, L., Liang, M., He, Z...Jiang, T. (2007). Brain responses to symptom provocation and trauma-related short-term memory recall in coal mining accident survivors with acute severe PTSD. Brain Research, 1144, 165174. doi: 10.1016/j.brainres.2007.01.089

Houghton, C., Casey, D., Shaw, D., \& Murphy, K. (2013). Rigor in qualitative case-study research. Nurse Researcher, 20 (4), 12-17.

Hsieh, H. \& Shannon, S. E. (2005). Three approaches to qualitative content analysis. Qualitative Health Research, 15 (9), 1277-1288. doi: 0.1177/1049732305276687

Huang, C.Y., Costeines, J., Ayala, C., \& Kaufman, J.S. (2014). Parenting stress, social support, and depression for ethnic minority adolescent mothers: Impact on child development. Journal of Child and Family Studies, 23, 255-262. doi: $10.1007 / \mathrm{s} 10826-013-9807-1$

Hunter, W. M., Jain, D., Sadowski, L. S. \& Sanhueza, A. I. (2000). Risk factors for severe child discipline practices in rural India. Journal of Pediatric Psychology, 25 (6), 435-447. PMID: 10980048 
Holden, G. W., Williamson, P.A. \& Holland, G.W. (2014). Eavesdropping on the family: a pilot investigation of corporal punishment in the home. Journal of Family Psychology, 28, 401-406. doi: 10.1037/a0036370.

Huang, C.Y., Costeines, J., Ayala, C. \& Kaufman, J. S. (2014). Parenting stress, social support, and depression for ethnic minority adolescent mothers: Impact on child development. Journal of Child and Family Studies, 23 (2), 255-262. doi: $10.1007 / \mathrm{s} 10826-013-9807-1$

Ispa, J.M. \& Halgunseth, L.C. (2004). Talking about corporal punishment: Nine lowincome African American mothers' perspectives. Early Childhood Research Quarterly, 19, 463-484. doi:10.1016/j.ecresq.2004.07.002

Jacob, S. A., \& Furgerson, S. P. (2012). Writing interview protocols and conducting interviews: Tips for students new to the field of qualitative research. The Qualitative Report, 17, 1-10.

Jaffee, S. R., Caspi, A., Moffitt, T., E., Polo-Thomas, M., Price, T. S., \& Taylor, A. (2004). The limits of child effects: Evidence for genetically mediated child effects on corporal punishment but not on physical maltreatment. Developmental Psychology, 40, 1047-1058. doi: 10.1037/0012-1649.40.6.1047

Javo, C., Ronning, J. A., Heyerdahl, S., \& Rudmin, F. W. (2004). Parenting correlates of child behavior problems in a multiethnic community sample of preschool children in northern Norway. European Child \& Adolescent Psychiatry, 13, 8-18. doi: 10.1007/s00787-004-0349-3 
Kakar, S. (2012). The inner world: A psychoanalytic study of childhood and society in India (4 ${ }^{\text {th }}$ Ed.) Delhi: Oxford University Press.

Kelch-Oliver, K., \& Oyeshiku Smith, C. (2015). Using an evidence-based parenting intervention with African American parents. The Family Journal: Counseling and Therapy for Couples and Families, 23, 26-32. doi: 10.1177/1066480714555697

Keeshin, B.R. \& Campbell, K. (2011). Screening homeless youth for histories of abuse: Prevalence, enduring effects, and interest in treatment. Child Abuse and Neglect, 35, 401-407. doi:10.1016/j.chiabu.2011.01.015

Kolhatkar, G. \& Berkowitz, C. (2014). Cultural considerations and child maltreatment: in search of universal principles. Pediatric Clinics of North America, 61, 1007-1022. doi: 10.1016/j.pcl.2014.06.005.

Knox, M. (2010). On hitting children: A review of corporal punishment in the United States. Journal of Pediatric Health Care, 24 (2), 103-107. doi:

10.1016/j.pedhc.2009.03.001

Lansford, J. E. (2010). The special problem of cultural differences in effects of corporal punishment. Law and Contemporary Problems, 73, 89-106. Retrieved from: https://scholarship.law.duke.edu/lcp/vol73/iss2/5

Lansford, J. E., Alampay, L. P., Al-Hassan, S., Bacchini, D., Bombi, A. S., Bornstein, M. H., ... Zelli, A. (2010). Corporal punishment of children in nine countries as a function of child gender and parent gender. International Journal of Pediatrics, 
Retrieved from: https://www.ncbi.nlm.nih.gov/pmc/articles/PMC2952896/ doi:10.1155/2010/672780.

Lansford, J.E. \& Dodge, K.A. (2008). Cultural norms for adult corporal punishment of children and societal rates of endorsement and use of violence. Parenting, Science and Practice, 8 (3), 257-270. doi: 10.1080/15295190802204843

Larzelere, R. E. (1996). A review of the outcomes of parental use of nonabusive or customary physical punishment. Pediatrics, 98, 824-831, 858. PMID: 8885980

Larzelere, R. E. (2000). Child outcomes of nonabusive and customary physical punishment by parents: An updated literature review. Clinical Child and Family Psychology Review, 3 (4), 199-221. doi: 0.1023/A:1026473020315

Larzelere, R. E., \& Kuhn, B. R. (2005). Comparing child outcomes of physical punishment and alternative disciplinary tactics: A meta-analysis. Clinical Child and Family Psychology Review, 8(1), 1-37. doi: 10.1007/s10567-005-2340-z

Lau, T. F., Kim, J. H., Tsui, H., Cheung, A., Lau, M., \& Yu, A. (2005). The relationship between physical maltreatment and substance use among adolescents: A survey of 788 adolescents in Hong Kong. Journal of Adolescent Health, 37, 110-119. doi: $10.1177 / 1359105310384297$

LeCuyer, E. A., Christensen, J. J. Kearney, M. H. \& Kitzman, H. J. (2011). African American mothers' self-described discipline strategies with young children. Issues in Comprehensive Pediatric Nursing, 34, 144-162, doi:

$0.3109 / 01460862.2011 .596457$ 
Lincoln, Y.S. \& Guba, E.G. (1985). Naturalistic Inquiry. Newbury Park, CA: Sage Publications.

Lindsey, E. W. (1998). The impact of homelessness and shelter life on family relationships. Family Relations, 47(3), 243-252. doi: 10.2307/584973

MacKenzie, M.J., Nicklas, E., Waldfogel,J. \& Brooks-Gunn, J. (2012). Corporal punishment and child behavioural and cognitive outcomes through 5 years of age: Evidence from a contemporary urban birth cohort study. Infant and Child Development, 21, 3-33. doi: 10.1002/icd.758

Mahoney, A., Pargament, K. I., Tarakeshwar, N. \& Swank, A.B. (2000). Religion in the home in the 1980s and 1990s: A meta-analytic review and conceptual analysis of links between religion, marriage and parenting. Journal of Family Psychology, 15, 559-596. doi: 10.1037/1941-1022.S.1.63

Malterud, K. (2001). Qualitative research: Standards, challenges, and guidelines. The Lancet, 358, 483-488. doi:10.1016/S0140-6736(01)05627-6

Marsac, M. L., Kassam-Adams, N., Hildenbrand, A. K., Nicholls, E., Winston, F. K., Leff, S. S., \& Fein, J. (2016). Implementing a trauma-informed approach in pediatric healthcare networks. Pediatrics, 170, (1), 70-77. doi.org/10.1001/jamapediatrics.2015.2206

Maslow, A.H. (1943) A theory of human motivation, Psychological Review 50(4), 370396. 
Mathurin, M.N., Gielen, U.P., \& Lancaster, J. (2006). Corporal punishment and personality traits in the children of St. Croix, U.S. Virgin Islands. Cross-Cultural Research, 40 (3), 306-324. doi: 10.1177/1069397105284678

McLoyd, V. C. \& Smith, J. (2002). Physical discipline and behavior problems in African American, European American and Hispanic children: Emotional support as a moderator. Journal of Marriage and the Family, 64, 40-53. doi: 10.1111/j.17413737.2002 .00040

Mersky, J. P., Berger, L. M., Reynolds, A. J. \& Gromoske, A. N. (2009). Risk factors for child and adolescent maltreatment: A longitudinal investigation of a cohort of inner-city youth. Child Maltreatment, 14, (1): 73-88. doi: $10.1177 / 1077559508318399$

Messer, J., Goodman, R., Rowe, R., Meltzer, H., \& Maughan, B. (2006). Preadolescent conduct problems in girls and boys. Journal of the American Academy of Child and Adolescent Psychiatry, 45 (2), 184-191. doi:

10.1097/01.chi.0000186403.13088.d8

Miller-Perrin, C. \& Perrin, R. (2017). Changing attitudes about spanking among conservative Christians using interventions that focus on empirical research evidence and progressive biblical interpretations. Child Abuse and Neglect, 71, 69-79. doi: 10.1016/j.chiabu.2017.03.015

Monnat, S. M. \& Chandler, R. F. (2015). Long term physical health consequences of Adverse Childhood Experiences. The Sociological Quarterly, 56 (4), 723-752. doi: $10.1111 /$ tsq. 12107 
Murdock, G. P., \& White, D. R. (1969). Standard cross-cultural sample. Ethnology, 8, 329-369.

National Alliance to End Homelessness (2016). Children and families. Retrieved from: https://endhomelessness.org/homelessness-in-america/who-experienceshomelessness/children-and-families/

National Association of Children's Hospitals and Related Institutions [NACHRI] (2006). Defining the children's hospital role in child maltreatment. Retrieved from: http://bsfi.barnlakarforeningen.se/wpcontent/uploads/sites/13/2016/03/nachri.full_.guidelines05.pdf

National Coalition for the Homeless (2014). Homelessness in America. Retrieved from: http://nationalhomeless.org/about-homelessness/

Nelson, D. A., Hart, C. H., Yang, C., Olsen, J. A, \& Jin, S. (2006). Aversive parenting in China: Associations with child physical and relational aggression. Child Development, 77 (3), 554-572. doi: 10.1111/j.1467-8624.2006.00890.x

Nilsson, M. (2005). Global initiative handbook: Hitting people is wrong-and children are people too. Sweden: Save the Children.

Nooe, R.M. \& Patterson, D. A. (2010). The Ecology of homelessness. Journal of Human Behavior in the Social Environment, 20, 105-152 doi:

$10.1080 / 10911350903269757$ 
Owen, S.S. \& Wagner, K. (2006). Explaining school corporal punishment: Evangelical Protestantism and social capital in a path model. Social Justice Research, 19 (4), 471-499. doi:10. 1007/s11211-006-0024-6

Pagani, L. S., Tremblay, R. E., Nagin, D., Zoccolillo, M., Vitaro, F., \& McDuff, P. (2004). Risk factor models for adolescent verbal and physical aggression toward mothers. International Journal of Behavioral Development, 28, 528-537. doi: $10.1080 / 01650250444000243$

Park, J. M., Ostler, T. \& Fertig, A. (2015). Physical and psychological aggression towards a child among homeless, doubled-up, and other low-income families. Journal of Social Service Research, 41, (3), 413-423. doi: $10.1080 / 01488376.2015 .1018660$

Polit, D.F., \& Beck, C.T. (2017). Nursing research: Generating and assessing evidence for nursing practice (10th Ed.). Philadelphia, PA: Lippincott Williams and Wilkins.

Rao, N., McHale, J.P., \& Pearson, E. (2003). Links between socialization goals and child-rearing practices in Chinese and Indian mothers. Infant and Child Development, 12, 475-492 doi: 10.1002/icd.341

Raust, A., Slama, F., Mathieu, F., Roy, L., Chenu, A., Koncke, D... Belliver, F. (2007). Prefrontal cortex dysfunction in patients with suicidal behavior. Psychological Medicine, 37, 411-419. doi: 10.1017/S0033291706009111 
Reavis, J.A., Looman, J., Franco, K. A. \& Rojas, B. (2013). Adverse Childhood Experiences and adult criminality: How long must we live before we possess our own lives? The Permanente Journal, 17 (2), 44-48. doi: 10.7812/TPP/12-072

Reich, S. M., Penner, E. K., Duncan, G. J., \& Auger, A. (2012). Using baby books to change new mothers' attitudes about corporal punishment. Child Abuse and Neglect, 36(2), 108-117. doi: 10.1016/j.chiabu.2011.09.017

Renteln, A.D. (2010). Corporal punishment and the cultural defense. Law and Contemporary problems, 73, 253-279. Retrieved from: https://scholarship.law.duke.edu/lcp/vol73/iss2/10

Rodriguez-JenKins, J. \& Marcenko, M. O. (2014). Parenting stress among child welfare involved families: Differences by child placement. Children and Youth Services Review, 46, 19-27. doi:10.1016/j.childyouth.2014.07.024.

Roos, L.E., Mota, N., Afifi, T. O., Katz, L. Y., Distasio, J. \& Sareen J. (2013). Relationship between Adverse Childhood Experiences and homelessness and the impact of Axis I and II disorders. American Journal of Public Health, 103 (S2), S275- S281. doi: 10.2105/AJPH.2013.301323

Saldana, J. (2016). The coding manual for qualitative researchers (3rd Ed). Thousand Oaks, CA: Sage Publications.

Scholer, S. J., Hamilton, E. C., Johnson, M. C., \& Scott, T. A. (2010). A brief intervention may affect parents' attitudes toward using less physical punishment. Family \& Community Health, 33, 106-116. doi: 10.1097/FCH.0b013e3181d592ef 
Scholer S.J., Hudnut-Beulmer, J. \& Dietrich, M.S. (2011). A brief primary care intervention affects parents' plans to discipline. Pediatrics, 125, e242-e249. doi: 10.1542/peds.2009-0874

Schwartz, J.P., Hage, S.M., Bush, I., \& Burns, L. K. (2006). Unhealthy parenting and potential mediators as contributing factors to future intimate violence: A review of the literature. Trauma Violence Abuse, 7, 206-221. doi: $10.1177 / 1524838006288932$

Shelton, K. H., Taylor, P.J., Bonner, A., \& van den Bree, M. (2009). Risk factors for homelessness: Evidence from a population-based study. Psychiatric Services, 60 (4), 465-472. doi: 10.1176/ps.2009.60.4.465

Shenton, A. K. (2004). Strategies for ensuring trustworthiness in qualitative research projects. Education for Information 22, 63-75. doi: 10.3233/EFI-2004-22201

Shinn, M., Gibbons-Benton, J. \& Brown, S. R. (2015). Poverty, homelessness, and family break-up. Child Welfare, 94 (1), 105-122. PMID: 29326481

Sim, T. N., \& Ong, L. P. (2005). Parent physical punishment and child aggression in Singapore Chinese preschool sample. Journal of Marriage and the Family, 67, 85-99. doi: 10.1111/j.0022-2445.2005.00007.x

Simons, D. \& Wurtele, S. (2010). Relationships between parents' use of corporal punishment and their children's endorsement of spanking and hitting other children. Child Abuse \& Neglect, 34, 639-646. doi: 10.1016/j.chiabu.2010.01.012. 
Slap (2018). In Merriam-Webster online. Retrieved from https://www.merriamwebster.com/dictionary/slap

Smith, S. L., Cohen, A. H., Lynn, M. \& Peterson, C.R. (2015). Manual for mandated reporters, Illinois Department of Children and Family Services' Children's' Justice Task Force. Retrieved from https://www.illinois.gov/dcfs/safekids/reporting/Documents/cfs_105021_mandated_reporter_manual.pdf

Smith, D. E. \& Mosby, G. (2003). Jamaican child-rearing practices: The role of corporal punishment. Adolescence, 38 (150), 369-381. PMID: 14560888

Solis, J. M., Shadur, J. M., Burns, A. R., \& Hussong, A. M. (2012). Understanding the diverse needs of children whose parents abuse substances. Current Drug Abuse Reviews, 5(2), 135-147. PMID: 22455509

Springer, K. W., Sheridan, J., Kuo, D., \& Carnes, M. (2003). The long-term health outcomes of childhood abuse: An overview and a call to action. Journal of General Internal Medicine, 18(10), 864-870. doi.org/10.1046/j.15251497.2003.20918.x

State of Illinois (2015). Illinois General Assembly Illinois Compiled Statutes (705 ILCS 405/2-3) (from Ch. 37, par. 802-3), Sec. 2-3. Neglected or abused minor. 99-143, eff. 7-27-15. Retrieved from: http://www.ilga.gov/legislation/ilcs/fulltext.asp?DocName=070504050K2-3 
Steele, H., Bate, J., Steele, M., Dube, S. H., Danskin, K., Knafo, H.,... Murphy, A. (2016). Adverse childhood experiences, poverty, and parenting stress. Canadian Journal of Behavioural Science, 48, (1), 32-38. doi: 10.1037/cbs0000034

Stein, J.A., Burden Leslie, M. \& Nyamathi, A (2002). Relative contributions of parent substance use and childhood maltreatment to chronic homelessness, depression, and substance abuse problems among homeless women: mediating roles of selfesteem and abuse in adulthood. Child Abuse \& Neglect 26, 1011-1027. doi: $10.1016 / \mathrm{S} 0145-2134(02) 00382-4$

Straus, M. (2010). Prevalence, societal causes, and trends in corporal punishment by parents in world perspective. Law and Contemporary Problems, 73 (3), 1-30. Available at: https://scholarship.law.duke.edu/lcp/vol73/iss2/2

Straus, M. (2001). Beating the devil out of them (2nd Ed.). New Jersey: Transaction.

Straus, M. (1991). Discipline and deviance: Physical punishment of children and violence and other crime in adulthood. Social Problems, 38 (2), 133-154. doi: $10.2307 / 800524$

Stuckey, H. L. (2015). The second step in data analysis: Coding qualitative research data. Journal of Social Health and Diabetes, 3, 7-10. doi: 10.4103/2321-0656.140875

Swat (2018). In Merriam-Webster online. Retrieved from https://www.merriamwebster.com/dictionary/swat 
Swick, K., J. (2008). The dynamics of violence and homelessness among young families. Early Childhood Education Journal, 36 (1), 81-85. doi: 10.1007/s10643-0070220-5

Swick, K., \& Williams, R. (2006). An analysis of Bronfenbrenner's bio-ecological perspective for early childhood educators': Implications for working with families experiencing stress. Early Childhood Education Journal, 33(5), 371-378. doi: 10.1007/s10643-006-0078-y

Taylor, C. A., Hamvas, L. \& Paris, R. (2011). Perceived instrumentality and normativeness of corporal punishment use among black mothers. Family Relations, 60, 60-72. doi:10.1111/j.1741-3729.2010.00633.x.

Taylor, C.A., Hamvas, L., Rice, J., Newman, D.L. \& DeJong, W. (2011). Perceived social norms, expectations, and attitudes toward corporal punishment among an urban community sample of parents. Journal of Urban Health, 88, 254-269. doi:10.1007/s11524-011-9548-7.

Taylor, C.A., Manganello, J. A., Lee, S. J. \& Rice, J. C. (2010). Mothers' spanking of 3Year-old children and subsequent risk of children's aggressive behavior. Pediatrics, 125, e1057-e1065. doi:10.1542/peds.2009-2678.

Taylor, C. A., Al-Hiyari, R., Lee, S.J., Priebe, A., Guerrero, L.W., \& Bales, A. (2016). Beliefs and ideologies linked with approval of corporal punishment a content analysis of online comments. Health Education Research, 31, 563-575. doi: 10.1093/her/cyw029 
Thompson, R., Kaczor, K., Lorenz, D.J., Bennett, B.L., Meyers, G. \& Pierce, M.C. (2017). Is the use of physical discipline associated with aggressive behaviors in young children? Academic Pediatrics, 17. 34-44. doi: 10.1016/j.acap.2016.02.014

Tomoda, A., Suzuki, H., Rabi, K., Yi-Shin, S., Polcari, A \& Teicher, M. H. (2009). Reduced prefrontal cortical gray matter volume in young adults exposed to harsh corporal punishment. Neuroimage, 47 T66-T71. doi:

10.1016/j.neuroimage.2009.03.005

Tsai, J., Edens, E.L. \& Rosenheck, R. A. (2011). A typology of childhood problems among chronically homeless adults and its association with housing and clinical outcomes. Journal of Health Care for the Poor and Underserved, 22 (3), 853-870. doi: $10.1353 / \mathrm{hpu} .2011 .0081$

United Nations Committee on the Rights of the Child (2006). Convention on the rights of the child. Retrieved from:

http://www.ohchr.org/EN/ProfessionalInterest/Pages/CRC.aspx

United States Department of Health \& Human Services, Administration for Children and Families, Administration on Children, Youth and Families, Children's Bureau. (2017). Child Maltreatment 2015. Retrieved from:

http://www.acf.hhs.gov/programs/cb/research-data-technology/statistics-research/childmaltreatment.

United States Department of Health and Human Services, National Institutes of Health Office of Extramural Research. (2018). Frequently asked questions: Certificates of confidentiality. Retrieved from: https://humansubjects.nih.gov/coc/faqs 
United States Department of Housing and Urban Development Office of Community Planning and Development. (2016). The 2016 Annual Homeless Assessment Report (AHAR) to Congress: Part 1: Point-in-time estimates of homelessness. Retrieved from: https://www.hudexchange.info/resources/documents/2016AHAR-Part-1.pdf

Vaismoradi, M., Jones, J., Turunen, H. \& Snelgrove, S. (2016). Theme development in qualitative content analysis and thematic analysis. Journal of Nursing Education and Practice, 6 (5), 100-110. doi: 10.5430/jnep.v6n5p100

Veltman, D.J., de Ruiter, M.B., Rombouts, S.A., Lazeron, R. H., Barkhof, F...Phaf, R. H. (2005). Neurophysiological correlates of increased verbal working memory in high-dissociative participants: a functional MRI study. Psychological Medicine, 35 (2), 175-185. doi: 10.1017/S0033291704002971

Vieth, V. I. (2014). From sticks to flowers: Guidelines for child protection professionals working with parents using scripture to justify corporal punishment," William Mitchell Law Review, 40 (3), 907-942. Retrieved from: http://open.mitchellhamline.edu/wmlr/vol40/iss3/3

Vitale, S.A. \& Prashad, T. (2017). Cultural awareness: Coining and cupping. International Archives of Nursing and Health Care, 3 (3), 1-3. doi: $10.23937 / 2469-5823 / 1510080$

Vitolo, Y.L.C., Fleitlich-Bilyk, B., Goodman, R. \& Bordin, I.A.S. (2005). Parental beliefs and child-rearing attitudes and mental health problems among schoolchildren. Revista Saude Publica, 39 (5), 1-8. doi: 10.1590/S0034-89102005000500004 
Wang, Q. \& Chang, L. (2015). Parenting and child socialization in contemporary China. (pp. 53-68). In: Bond, M. H. (Ed.). Oxford Handbook of Chinese Psychology (Oxford Library of Psychology) Reprint Edition. New York: Oxford University Press.

Wingo, A. P., Wrenn, G., Pelletier, T., Gutman, A. R., Bradley, B., \& Ressler, K. J. (2010). Moderating effects of resilience on depression in individuals with a history of childhood abuse or trauma exposure. Journal of Affective Disorders, 126, (3), 411-414. doi: 10.1016/j.jad.2010.04.009

Xu, X., Tung, Y., \& Dunaway, R.G. (2000). Cultural, human, and social capital as determinants of corporal punishment: Toward an integrated theoretical model. Journal of Interpersonal Violence, 15, 603-630. doi:

$10.1177 / 088626000015006004$

Yin, R. K. (2016). Qualitative research from start to finish ( $2^{\text {nd }}$ Ed.). New York: Guilford Publications.

Wang, C. C. \& Geale, S. K. (2015). The power of story: Narrative inquiry as a methodology in nursing research. International Journal of Nursing Sciences, 2, 195-198. doi: 10.1016/j.ijnss.2015.04.014

United Nations Treaty Collection (1989). Convention on the Rights of the Child. Retrieved from: https://treaties.un.org/doc/publication/mtdsg/volume\%20i/chapter\%20iv/iv11.en.pdf 
United States Department of Health and Human Services (2018). Poverty guidelines.

Retrieved from: https://aspe.hhs.gov/poverty-guidelines

Wiehe, V. R. (1990). Religious influence on parental attitudes toward the use of corporal punishment. Journal of Family Violence, 5, 173-186. doi: 10.1007/BF00978518 


\section{VITA}

Ellen Chiocca was born and raised in Chicago. She earned a Bachelor of Science in Nursing from Saint Xavier University in Chicago, Illinois. For six years, she worked as a registered nurse in neonatal and pediatric intensive care at which point she returned to school to pursue a graduate degree in nursing, earning a Master of Science in Nursing from Loyola University Chicago in 1991. She then taught the nursing of children at Loyola, while continuing her clinical practice, and pursuing a post-master's certificate, becoming a board-certified primary care pediatric nurse practitioner in 1999. Ms.

Chiocca has taught the nursing of children for 25 years, while maintaining her clinical practice in both inpatient and primary care pediatrics. She has published over 25 articles and one textbook and is a board member of the Academy on Violence and Abuse and the U.S. Alliance to End the Hitting of Children. 